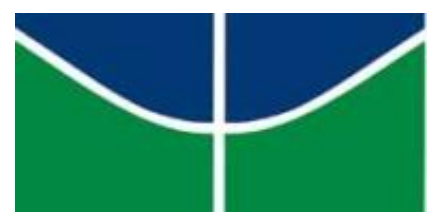

Universidade de Brasília

Faculdade UnB Planaltina

Programa de Pós-Graduação em Meio Ambiente e Desenvolvimento Rural

Darlan Quinta de Brito

AVALIAÇÃO ECOTOXICOLÓGICA DAS CINZAS DE QUEIMADAS

DO CERRADO EM AMBIENTES AQUÁTICOS

DISSERTAÇÃO DE MESTRADO

Planaltina-DF

Outubro, 2014. 


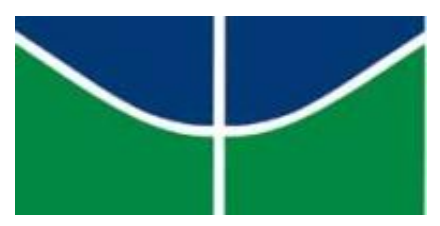

Universidade de Brasília

Faculdade UnB Planaltina

Programa de Pós-Graduação em Meio Ambiente e Desenvolvimento Rural

Darlan Quinta de Brito

\section{AVALIAÇÃO ECOTOXICOLÓGICA DAS CINZAS DE QUEIMADAS DO CERRADO EM AMBIENTES AQUÁTICOS}

Dissertação de mestrado apresentada ao Programa de Pós-Graduação em Meio Ambiente e Desenvolvimento Rural, como requisito parcial para obtenção do título de Mestre em Meio Ambiente e Desenvolvimento Rural, da Universidade de Brasília.

Orientador: Prof. Dr. Carlos José Sousa Passos

Co-orientador: Prof. Dr. Eduardo Cyrino Oliveira Filho

Planaltina-DF

Outubro, 2014. 
Ficha catalogrätica elaborada pela Biblioteca Central da Universidade de Brasilia. Acervo 1020075

B862a Aval iaça ecotoxicológica das cinzas de que imadas

do Cerrado em ambientes aquáticos / Darlan Quinta

de Brito. - 2014.

vii, $120 \mathrm{f} .:$ il. ; $30 \mathrm{~cm}$.

Dissertaçāo (mestrado) - Universidade de Brasilia, Faculdade UnB Planal t ina, Programa de Pōs-Graduaçāo

em Meio Ambiente e Desenvolvimento Rural, 2014.

Inclui bibliografia.

Or ientaçāo: Car los Josē Sousa Passos :

Coor ientaço: Eduardo oyrino de ol iveira Filho.

1. Cerrados. 2. Queimada. 3. Toxicologia ambiental.

4. Ecologia aquática. I. Passos, Carlos Josē Sousa.

II. Ol iveira Filho, Eduardo Oyrino de. III. Titulo. 


\section{UNIVERSIDADE DE BRASÍLIA \\ FACULDADE UNB PLANALTINA \\ PROGRAMA DE PÓS-GRADUAÇÃO EM MEIO AMBIENTE E DESENVOLVIMENTO RURAL}

Termo de Aprovação

“Avaliação Ecotoxicológica das Cinzas de Queimadas do Cerrado em Ambientes Aquáticos"

Darlan Quinta de Brito

Banca Examinadora

Orientador: Prof. Dr. Carlos José Sousa Passos

Presidente (UnB/FUP)

Orientador: Prof. Dr. Ludgero Cardoso Galli Vieira Membro Titular (UnB/FUP)

Orientador: Prof. Dr. Cesar Koppe Grisolia

Membro Interno não vinculado ao Programa (UnB/IB-GEM) 
“A ciência exercita a capacidade, não o saber. $O$ valor de praticar com rigor, por algum tempo, uma ciência rigorosa não está propriamente em seus resultados: pois eles sempre serão uma gota ínfima, ante o mar das coisas dignas de saber. Mas isso produz um aumento de energia, de capacidade dedutiva, de tenacidade; aprende-se a alcançar um fim de modo pertinente. Neste sentido é valioso, em vista de tudo o que se fará depois, ter sido homem de ciência."

(NIETZSCHE, 1878 - 1886, in Humano, demasiado humano) 


\section{AGRADECIMENTOS}

Ao Programa de Pós Graduação em Meio Ambiente e Desenvolvimento Sustentável (PPG-MADER) pelo suporte durante estes dois anos de estudo.

Ao professor Eduardo Cyrino, o meu profundo agradecimento pelo apoio, estímulo e dedicação incansável na esfera técnico-científica e institucional, tendo contribuído para o bom andamento e finalização desta dissertação.

Ao professor Carlos Passos, agradeço pela oportunidade concedida, pelos ensinamentos, paciência, apoio e sugestões no texto final.

Ao $\mathrm{CNPq}$ pelo apoio financeiro, permitindo, efetivamente, a realização desta dissertação.

À APA-Águas Emendadas e à EMBRAPA Cerrados por ter possibilitado a realização deste trabalho por meio de sua infra-estrutura.

Ao Aristides e Jorivê, sempre solícitos no auxílio dos trâmites burocráticos. Aos colegas da turma de mestrado, especialmente aos amigos de Monitoramento Ambiental (Carla, Daphne e Leandro) pelo apoio e aprendizados mútuos.

Ao Luiz Gontijo por ter colaborado com esta dissertação na condução dos experimentos de solubilização das cinzas. À Zélia, Nathan, Dênis e Fernanda pelo apoio durante as coletas de campo e conversas agradáveis.

Ao Sr. Jatobá pelo auxílio de campo, repleto de doses de bom humor e companheirismo.

Aos colegas do Laboratório de Química Analítica de Plantas (Vilderete, Antônio Alves, Fernando, Francisco Bastos, Fernanda, Delvico, Luciano e Aline) pelo apoio, convivência e amizades inabaláveis, fator determinante na conclusão desta dissertação. Aos grandes amigos de Aveiro pela competente atuação na área de Ecotoxicologia, inesgotável paciência e amizades inestimáveis. À minha família, pelos ensinamentos, amor incondicional e apoio constantes.

Ao ser supremo de Luz que tem me dado forças para superar todas as dificuldades.

E por fim, a todos, e foram muitos, que de diversas formas me apoiaram constantemente para a realização desta dissertação, o meu mais sincero reconhecimento. 


\section{RESUMO}

No cenário mundial das mudanças climáticas, vários estudos preveem o aumento das queimadas em diferentes partes do mundo. Grandes extensões de áreas nativas e de pasto são queimadas no Bioma Cerrado anualmente, e o mau uso da prática de queimadas durante os períodos de estiagem tem acarretado sérios danos à biodiversidade dos ecossistemas e à saúde da população. Com o advento das chuvas após o período de seca no bioma Cerrado, grande quantidade de cinzas da biomassa são lixiviadas e entram nos sistemas aquáticos, podendo ocasionar efeitos adversos. Diante disso, o presente trabalho propôs-se a avaliar os atributos químicos das cinzas e do solo de três áreas distintas queimadas em setembro de 2010. Avaliou-se, também, o potencial de toxicidade das cinzas provenientes de áreas do bioma Cerrado e de uma área de pasto por meio de testes ecotoxicológicos com Ceriodaphnia dubia, o peixe Danio rerio e o molusco Biomphalaria glabrata. Um vasto grupo de metais (Al, B, $\mathrm{Ca}, \mathrm{Cd}, \mathrm{Cr}, \mathrm{Cu}, \mathrm{Fe}, \mathrm{K}, \mathrm{Mg}, \mathrm{Mn}, \mathrm{Mo}, \mathrm{Ni}, \mathrm{P}, \mathrm{Pb}, \mathrm{S}, \mathrm{Si}, \mathrm{Sr}, \mathrm{V}$, Ti e $\mathrm{Zn}$ ) foram determinados e quantificados no solo, nas cinzas e na solubilização das cinzas. A comparação química das três áreas apresentou pouca diferença qualitativa, sendo que a quantidade dos elementos químicos foi o aspecto de maior relevância. A composição química das cinzas apresentou valores superiores à composição química do solo, no entanto apenas uma pequena parcela dos compostos são solubilizados. Apesar disso, a presença das cinzas na água elevou os sólidos solúveis totais (STD) e a condutividade elétrica (CE), devido à presença dos sais dissolvidos. Os íons aumentaram o pH e diminuíram o OD na água, alterando, portanto, a qualidade da água. Os testes conduzidos no laboratório indicaram que ambientes lênticos podem ser mais sensíveis aos efeitos das cinzas das queimadas em comparação aos ambientes lóticos. Com relação aos efeitos ecotoxicológicos, constataram-se diferenças de toxicidade das cinzas para os organismos estudados. Todas as cinzas apresentaram um índice elevado de toxicidade no ensaio de $C$. dubia (CL50-48hs: 6.33\% (4.83-8.28) cinza de Pasto). Com relação aos ensaios com o $D$. rerio e com $B$. glabrata, não foi constatada toxicidade para as cinzas de Pasto e Torre. As cinzas da Lagoa Bonita (área de transição cerrado sentido restrito para vereda) apresentaram toxicidade para D. rerio $\left(\mathrm{CL}_{50}-24 \mathrm{hs}: 31.50 \%\right.$; $\left.\mathrm{CL}_{50}-48 \mathrm{hs}: 25.0 \%\right)$ e $B$. glabrata ( $\mathrm{CL}_{50}$-24hs: $50.0 \%$ (37.7- 66.4); $\mathrm{CL}_{50}-48 \mathrm{hs:} 35.4 \%$ ). Estes resultados demonstram que as queimadas influenciam a toxicidade às águas superficiais, tornando este ambiente tóxico para a sobrevida de comunidades aquáticas zooplanctônicas, independentemente da fitofisionomia e da paisagem, e enfatizam portanto a necessidade de estudos mais aprofundados para melhor compreender-se a complexidade dos efeitos ecológicos do fogo em comunidades aquáticas.

Palavras-chave: Cerrados, queimadas, ecossistemas aquáticos, cinzas, atributos químicos e ensaios ecotoxicológicos. 


\section{ABSTRACT}

In the global scenario of climate change, several studies predict an increase of fires in different parts of the world. Large extensions of native areas and pasture are burned in Brazil, especially in the Cerrado biome (Brazilian Savanna). The inadequate practices of burning during drought periods have caused intense fires, which bring several damages to biodiversity and ecosystem balance. With the occurrence of rains after the dry season, different chemical compounds from the ashes come into the aquatic systems and cause adverse effects to these ecosystems. Thus, this study aimed to evaluate chemical properties of the ash and soil from three distinct areas burned in September 2010. It also evaluated potential toxicity of ash by ecotoxicological essays with Ceriodaphnia dubia, Danio rerio and Biomphalaria glabrata. A large group of metals (Al, B, Ca, Cd, Cr, Cu, Fe, K, Mg, Mn, Mo, Ni, P, Pb, S, Si, Sr, V, Ti and $\mathrm{Zn}$ ) were quantified in soil, in the ashes and in the ash solubilization. The chemical composition of the ash showed higher values in relation to the ash soil samples. However, only a small quantity of these compounds was solubilized. Nevertheless, the ash in the water increased the total soluble solids (STD) and electrical conductivity (EC) due to the presence of ions. The solubilized ions increased the $\mathrm{pH}$ and decreased the OD concentrations in the water, altering the quality of water. The results showed that the lentic aquatic systems are more sensible to the effects of ashes in comparison to the lotic systems in short period. Regarding the ecotoxicological effects, we found differences in toxicity of ashes for the organisms studied. All ashes showed high toxicity during the $C$. dubia test ( $\mathrm{CL}_{50}-48$ hours): $6.33 \%$ (4.83- 8.28) for pasture ashes), whereas in relation to D. rerio and B. glabrata, toxicity was not observed when they were exposed to ashes from pasture area and native area (Torre). Lagoa Bonita ashes showed toxicity for B. glabrata (CL50-24hs: 50.0\% (37.7- 66.4); LC50 48hs: $35.4 \%$ ) and for D. rerio ( $\mathrm{LC}_{50}-24 \mathrm{hs}: 31.50 \%$; $\left.\mathrm{LC}_{50}-48 \mathrm{hs}: 25.0 \%\right)$. These results strongly suggest that the fires influence the toxicity in surface waters, making the environment toxic for the survival of aquatic zooplankton communities regardless of the vegetation type, and therefore emphasize the need of further studies to allow a better understanding of the complexity of the ecological effects of fire on aquatic communities.

Key words: Cerrado, Fires, aquatic ecosystems, ash chemistry and ecotoxicological biossays. 


\section{LISTA DE ABREVIATURAS E SIGLAS}
ABNT: $\quad$ Associação Brasileira de Normas Técnicas
CE: $\quad$ Condutividade elétrica
CE50: $\quad$ Concentração Efetiva média
CETESB: Companhia de Tecnologia e Saneamento Ambiental de São Paulo
CI: $\quad$ Cromatografia iônica
CL50: $\quad$ Concentração Letal média
Environmental Protection Agency (Agência de Proteção Ambiental dos
EPA: $\quad$ Estados Unidos)
ESECAE: Estação Ecológica de Águas Emendadas
EMBRAPA: Empresa Brasileira de Pesquisa Agropecuária
g.L $\mathbf{L}^{-\mathbf{1}}: \quad$ Gramas por litro

HAPs: Hidrocarbonetos aromáticos policíclicos

IBAMA: Instituto Brasileiro do Meio Ambiente e dos Recursos Naturais Renováveis

IBGE: Instituto Brasileiro de Geografia e Estatística

(Inductively Coupled Plasma - Atomic Emission Spectrometry)

ICP-AES: Espectrometria de Emissão Atômica por Plasma Acoplado Indutivamente

INPE: $\quad$ Instituto Nacional de Pesquisas Espaciais

ISO: $\quad$ International Standard Organization

L: $\quad$ Litro

m: $\quad$ Metros

mg: $\quad$ Miligrama

ml: $\quad$ Mililitros

mm: Milímetros

MMA: $\quad$ Ministério do Meio Ambiente

MO: $\quad$ Matéria orgânica

NBR: $\quad$ Norma Brasileira

OD: $\quad$ Oxigênio Dissolvido

Organization for Economic Cooperation and Development (Organização

OECD: para a Cooperação e Desenvolvimento Econômico)

PAHs: $\quad$ Polycyclic Aromatic Hydrocarbons

PCA: $\quad$ Análise das Componentes Principais 
pH: Potencial hidrogeniônico

PREVFOGO: Sistema Nacional de Prevenção e Combate a Incêndios Florestais

SEMARH-DF: Secretaria de Meio Ambiente e Recursos Hídricos do Distrito Federal STD: Sólidos Totais Disponíveis

TA: Testes agudos

TC: $\quad$ Testes crônicos

v/v: $\quad$ Volume/volume

$\mu \mathrm{m}: \quad$ Micrômetros 


\section{LISTA DE FIGURAS E TABELAS}

\section{INTRODUÇÃO}

FIGURA 1 - Esquema representativo do experimento integrativo no presente estudo.

Os conteúdos dos dois capítulos da dissertação estão em cinza.

FIGURA 2 - Distribuição do bioma Cerrado original no Brasil e mapa do bioma Cerrado contendo a distribuição espacial das áreas com vegetação (verde), desmatamento acumulado até 2008 (marrom) 20

FIGURA 3 - Diferentes formaç̃es vegetais e fitofisionomias no bioma Cerrado 22

FIGURA 4 - Fêmea em idade fértil de Ceriodaphnia dubia (Aumento de 40x). 32

FIGURA 5 - Aspecto geral de Danio rerio adulto 33

FIGURA 6 - Caramujos da espécie Biomphalaria glabrata. A. Caramujos em meio de cultura do Laboratório de Ecotoxicologia da Embrapa Cerrados. B. Caramujo em detalhe 34

FIGURA 7 - Imagem de satélite com os quatro pontos amostrados de áreas queimadas (Google earth, 2008). 35

FIGURA 8 - Imagem de satélite com a apresentação mais detalhada da área definida como Torre. A - Imagem da vegetação queimada na área definida como Torre. B - Imagem de um dos pontos de coleta de amostras de cinzas e de solo na área (Google earth, 2008). 36

FIGURA 9 - Imagem de satélite com a apresentação mais detalhada da área definida como Pasto. A - Imagem da vegetação queimada na área definida como Pasto e B - pontos de coleta de amostras de cinzas e solo na área definida como Pasto (Google earth, 2008). 
FIGURA 10 - Imagem de satélite com a apresentação mais detalhada da área definida como Lagoa Bonita. A- Paisagem da área queimada de Lagoa Bonita e B - Procedimento de coleta de amostras de cinzas (Google earth, 2008).. 38

FIGURA 11 - Imagem de satélite com a apresentação mais detalhada da área definida como Águas Emendadas. A - Área da vegetação queimada. B Amostragem um dos pontos de coleta de cinzas e de solo (Google earth, 2008).

FIGURA 12 - A área de coleta da vegetação queimada próxima à Lagoa Bonita (E. E. de Águas Emendadas, DF). A- Área de coleta das cinzas; B - Peneiração; C - Agitação e D- Condução de ensaios de exposição aguda com o microcrustáceo Ceriodaphnia. dubia. 40

FIGURA 13 - Bioensaios com C. dubia. A- Concentrações recém preparadas; B- As mesmas concentrações após $30 \mathrm{~min}$; C- Concentrações após a filtração $(0,45 \mu \mathrm{m}) ; \quad$ Condução do teste com cinzas não filtradas. .43

FIGURA 14 - Testes de exposição do D. rerio. A- Peixe D. rerio em aquário no laboratório para ambientação; B- Condução do teste com cinzas nãofiltradas com aeração. C- Detalhe do teste após algumas horas de exposição. D- Decantação das cinzas no término do teste 44

FIGURA 15 - Teste de exposição das cinzas de Lagoa Bonita ao molusco B. glabrata. 


\section{CAPÍTULO 1}

FIGURA 1 - Caracterização química das cinzas de queimadas provenientes das quatro áreas estudadas. Elementos presentes em maior quantidade. Valores expressos em ppm. 54

FIGURA 2 - Caracterização química das cinzas de queimadas provenientes das áreas estudadas. Elementos presentes em menor quantidade. Valores expressos em ppm. 55

FIGURA 3 - Alterações do pH e do Oxigênio Dissolvido (OD) na água com cinzas durante $96 \mathrm{hs}$ em agitação contínua.

FIGURA 4 - Comportamento dos parâmetros sólidos totais dissolvidos e condutividade elétrica durante $96 \mathrm{hs}$ de agitação das cinzas em água mole sintética.

FIGURA 5 - Variação do pH. do Oxigênio Dissolvido (OD). da Condutividade elétrica e dos Sólidos Totais Dissolvidos (STD) da água com cinzas da área da Lagoa Bonita nas condições com agitação contínua e sem agitação ao longo de 15 dias 64

FIGURA 6 - Variação do pH. do Oxigênio Dissolvido (OD). da Condutividade elétrica e dos Sólidos Totais Dissolvidos (STD) nas amostras de água controle e diluições com cinzas da área da Lagoa Bonita durante 15 dias sem agitação.. 65

FIGURA 7 - Projeção espacial da ordenação dos vetores das variáveis químicas nas duas componentes principais.

Tabela 2 - Taxa de solubilização obtida pela razão entre a quantidade de metais disponíveis na solução pela quantidade elementos encontrados nas cinzas e Cargas das componentes principais indicando as percentagens de explicação da variabilidade das variáveis químicas nas áreas amostradas. 
Tabela 3 - Solubilização de cátions e ânions das cinzas da área da Lagoa Bonita em água mole sintética após 4, 10, 15 e 30 dias de agitação (mg.L $\left.\mathrm{L}^{-1}\right)$. Média e (Desvio Padrão).

Tabela 4 - Solubilização de cátions e ânions das cinzas das três áreas em água mole sintética após 4 dias de agitação $\left(\mathrm{mg} \cdot \mathrm{L}^{-1}\right)$. 60

\section{CAPÍTULO 2}

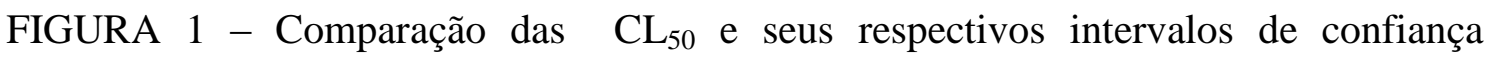
$(\mathrm{IC}=95 \%)$ da exposição das amostras filtradas e não filtradas de cinzas ao microcrustáceo C. dubia. 86

Tabela 1 - Comparação dos resultados dos ensaios realizados com as amostras filtradas para o microcrustáceo C. dubia. 84

Tabela 2 - Comparação entre os resultados dos ensaios realizados com as amostras filtradas (F) e não-filtradas (NF) de cinzas para o microcrustáceo C. dubia. . 85

Tabela 3 - Comparação dos resultados dos ensaios de exposição das amostras de cinzas de Lagoa Bonita ao D. rerio com aeração e sem aeração. 87

Tabela $4-\mathrm{CL}_{50}(\%)$ das amostras de cinzas ao molusco $B$. glabrata e ao peixe $D$ rerio. 


\section{Sumário}

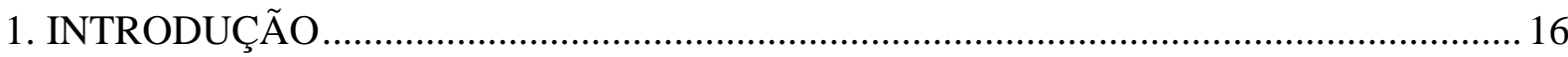

1.2. OBJETIVOS E ESTRUTURA DA DISSERTAÇÃO................................................ 18

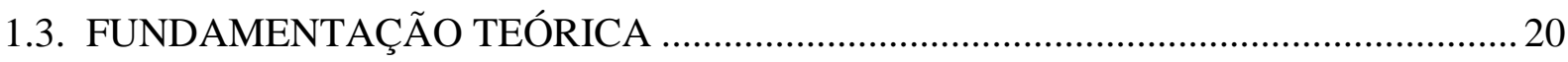

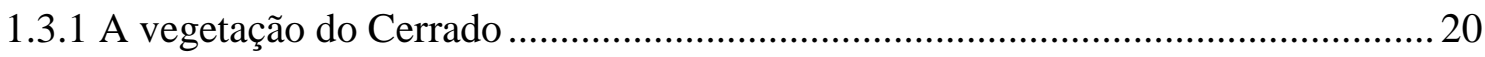

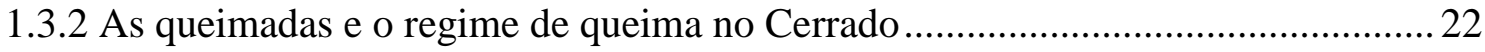

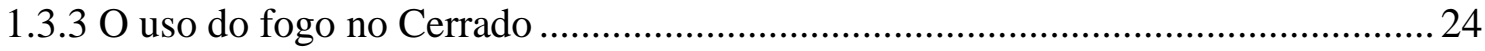

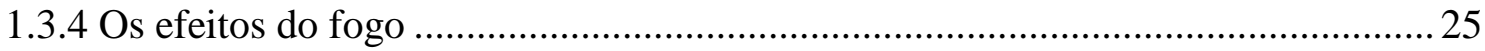



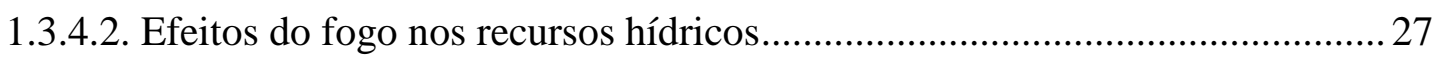

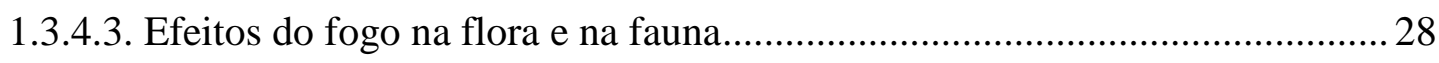

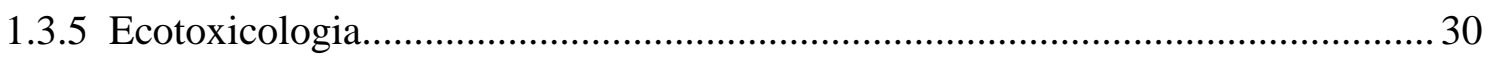

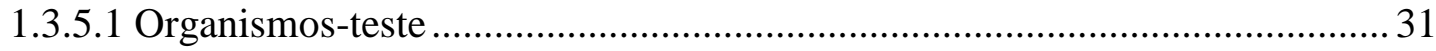

1.3.5.2 Ceriodaphnia dubia (Cladocera, Crustacea) ................................................ 31

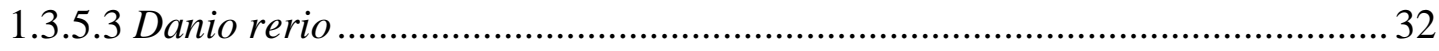

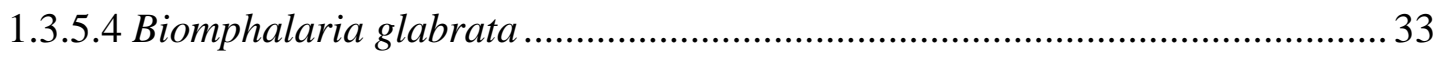

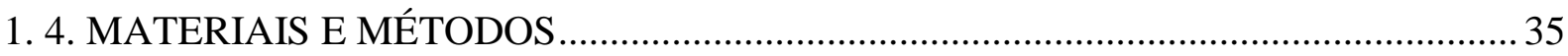

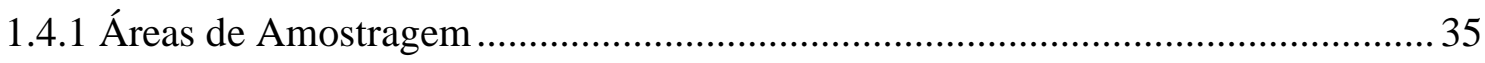

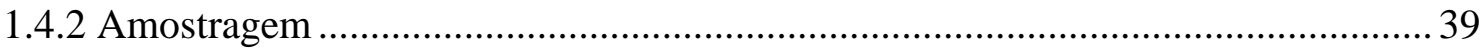

1.4.2.1 Procedimentos de coleta de amostras …....................................................... 39

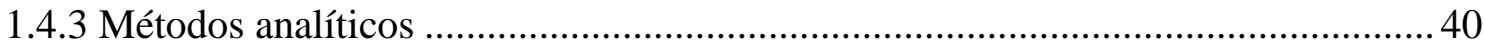

1.4.3.1 Parâmetros físico-químicos ........................................................................... 40

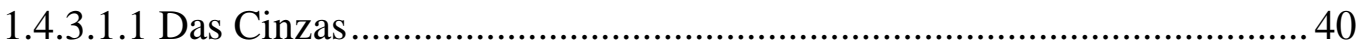

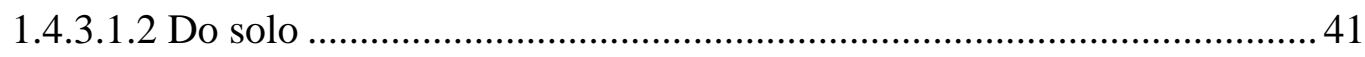

1.4.4.1.3 Das alterações na água ............................................................. 41

1.4.4 Avaliação de parâmetros ecotoxicológicos ......................................................... 42

1.4.4.1 Ensaio de mortalidade do Ceriodaphnia dubia (Cladocera, Crustacea) . 42

1.4.4.2 Ensaio de mortalidade do Peixe Danio rerio ......................................... 44

1.4.4.3 Ensaio de mortalidade do Molusco gastrópode Biomphalaria glabrata. 44

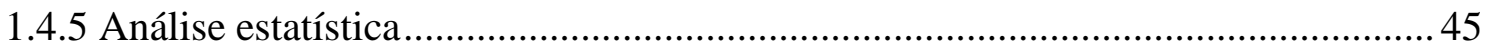

1.4.5.1 Análise Multivariada - Análise das Componentes Principais (PCA) ................ 45 
CAPÍTULO I - Efeitos das cinzas de Queimadas do Cerrado nas características físico-

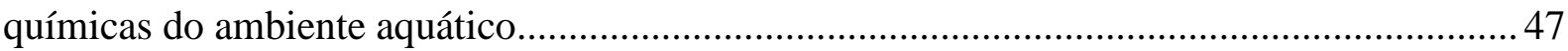

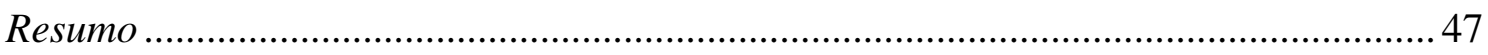

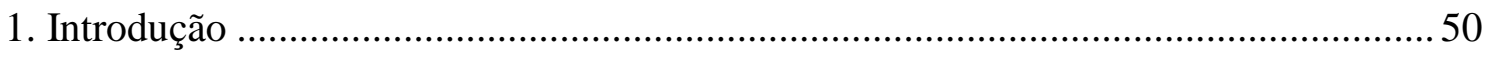

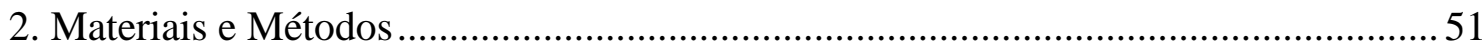

2.1 Área de Estudo e coleta das amostras ......................................................... 51

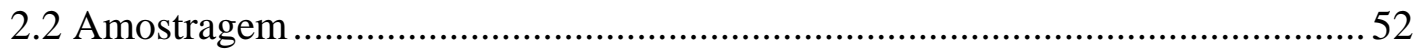

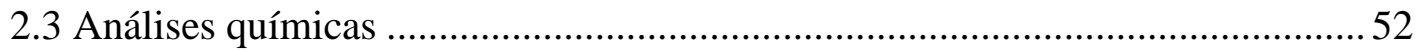

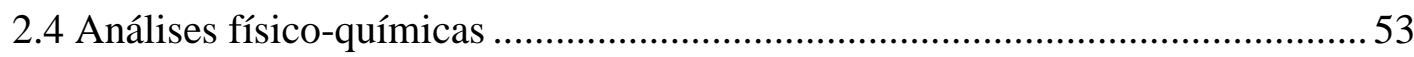

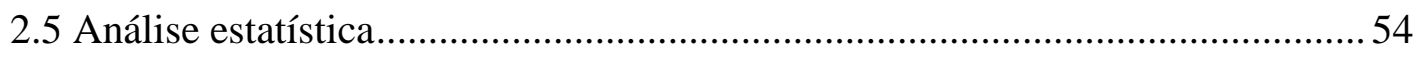

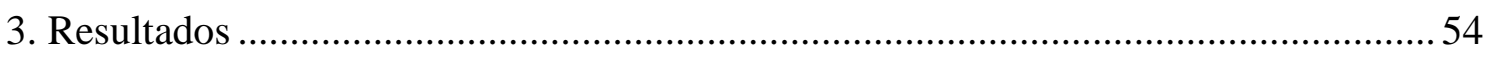

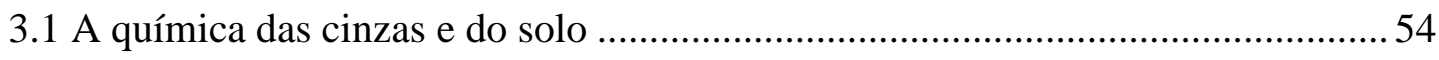

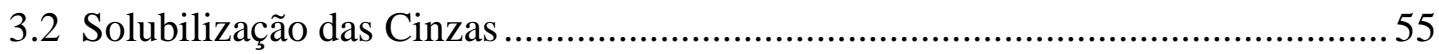

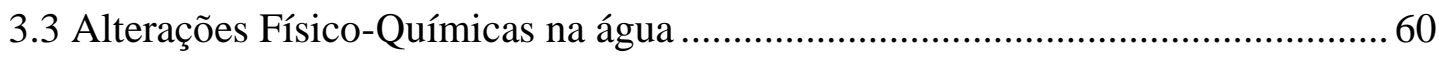

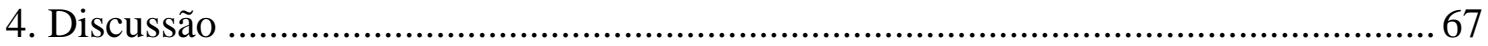

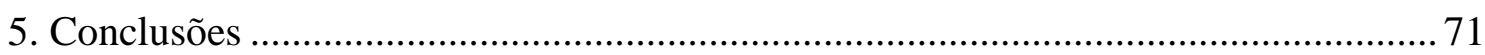

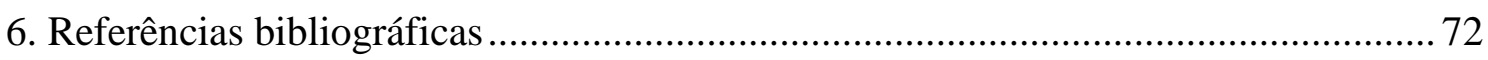

CAPÍTULO II - Avaliação da ecotoxicidade aquática das cinzas de queimadas do

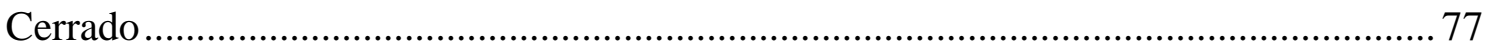

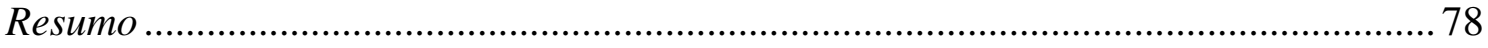

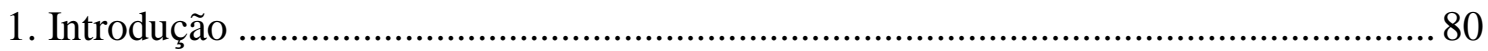

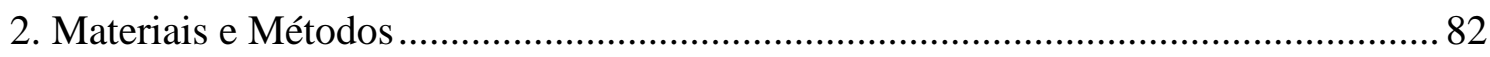

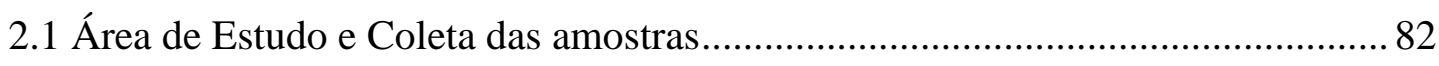

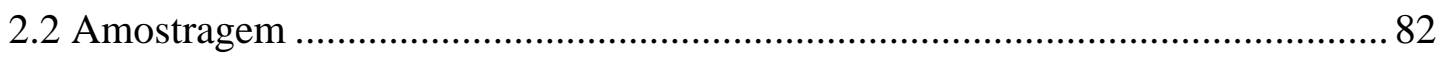

2.3 Ensaio de Toxicidade Aguda com Ceriodaphnia dubia .................................... 82

2.4 Ensaio de Toxicidade Aguda com peixe Danio rerio ........................................ 83

2.5 Ensaio de Toxicidade Aguda com Biomphalaria glabrata ….............................. 83

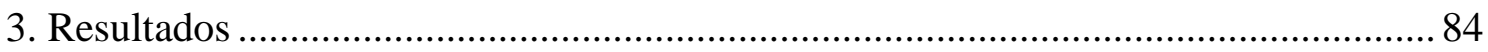

3.1 Ensaio de mortalidade com Ceriodaphnia dúbia .............................................. 84

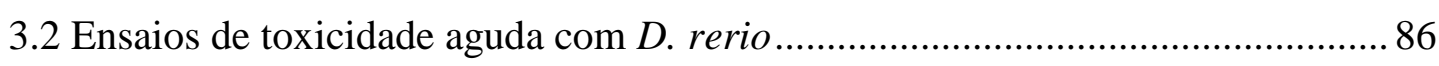

3.3 Ensaios de toxicidade aguda com o caramujo B. glabrata ................................. 87

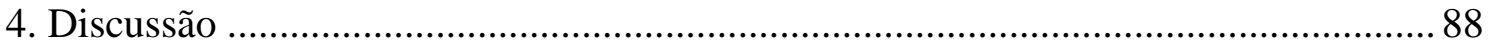

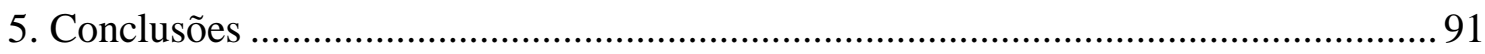




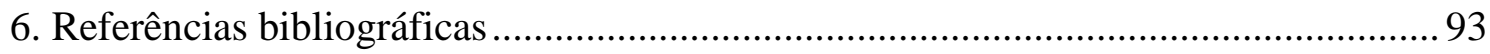

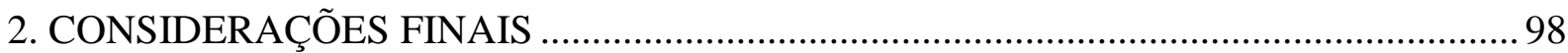



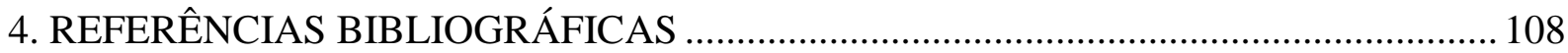




\section{INTRODUÇÃO}

Em 2007, o Painel Intergovernamental de Mudanças Climáticas (IPCC em inglês) publicou uma série de relatórios que endossavam o grau de certeza sobre o papel das ações humanas nas causas do aquecimento global (IPCC, 2007). De acordo com diversos documentos publicados, as queimadas e os incêndios florestais destacam-se como os principais elementos da matriz de emissões de gases do efeito estufa (GEEs) nos países em desenvolvimento. Todavia, as principais fontes de emissões de GEEs no Brasil têm-se alterado profundamente nos últimos dez anos, devido às ações de combate ao desmatamento e ao uso de novas tecnologias na agropecuária, culminando em uma não correlação direta entre desmatamento e crescimento agropecuário (LAPOLA, 2014).

O padrão brasileiro de emissão de GEEs tem-se modificado bastante nos últimos anos. O desmatamento, que correspondia a $57 \%$ das emissões totais do país em 2005, passou a corresponder a $22 \%$ em 2010. O setor agropecuário passou a assumir a liderança, com $37 \%$ das emissões nacionais em 2010, oriundas principalmente da digestão de ruminantes, da decomposição de dejetos animais e do uso de fertilizantes (LAPOLA, 2014).

Apesar dessas alterações, a prática das queimadas tem sido uma das principais causas de incêndios florestais no país e a contribuição do Brasil na emissão mundial de GEEs continua relativamente elevada ${ }^{1}$.

Parcela considerável das emissões de GEEs no país provém do uso do fogo no meio rural como forma de manejo e de incêndios, quando provocados pelo mau uso dessa prática (NOBRE, 2002; SILVA et al., 2004; MMA, 2010).

O uso do fogo como forma de manejo no meio rural do Brasil é permitido na forma de queima controlada e regulamentada pelo Decreto $\mathrm{n}^{\circ} 2.661$ de 8 de julho de 1998 (BRASIL, 1998). Consoante à legislação ambiental, as queimadas autorizadas seguem técnicas e constituem um crime ambiental quando as técnicas de controle não são consideradas, estando o infrator sujeito às sanções penais cabíveis (SILVA FILHO et al. 2009).

\footnotetext{
${ }^{1} \mathrm{O}$ Brasil está entre os cinco maiores emissores mundiais de gases de efeito estufa, sendo que $61 \%$ das suas emissões são resultantes de mudanças de uso do solo e desmatamento, de acordo com a Segunda Comunicação Nacional do Brasil à Convenção-Quadro das Nações Unidas sobre Mudança do Clima (Coordenação-Geral de Mudanças Globais do Clima - Ministério da Ciência e Tecnologia, 2010).
} 
No entanto, o uso indiscriminado do fogo pelo decorre, sobretudo, da fraca atuação de órgãos públicos, da vulnerabilidade socioeconômica e dos aspectos culturais das populações (SAMPAIO et al., 2008; IBAMA, 2011).

O uso do fogo tem sido uma característica na expansão da agropecuária no Brasil (KLINK e MACHADO, 2005). Em propriedades rurais, as queimadas são comumente utilizadas pelos agricultores para a limpeza do terreno (NEPSTAD et al., 1999). No bioma Cerrado, as queimadas coincidem com o período de estiagem e, portanto, se a prática não seguir os procedimentos técnicos adequados, o fogo ocasiona sérios riscos ambientais e danos à saúde da população humana (KAUFMAN et al., 1998; ARBEX et al. 2000; ROSEIRO e TAKAYANAGUI, 2004).

O Cerrado é um ecossistema que possui uma relação forte com o fogo, pois o fogo exerce importante papel ecológico estrutura da vegetação das savanas na por meio da seleção de espécies ao longo de milhares de anos (COUTINHO, 1990; BOND et al., 2005). O fogo altera a cobertura vegetal, muda o albedo e a umidade do solo em escala local e afeta o clima, regimes de temperatura e a ciclagem de vários elementos em escala regional (LAL, 2008).

As queimadas podem ocasionar sérios efeitos ambientais tanto aos ecossistemas terrestres quanto aos ecossistemas aquáticos (SPENCER et al., 2003). Esses efeitos podem ser imediatos ou de longa duração (e.g., meses e anos) após as queimadas, dependendo do tipo da vegetação, do relevo, da geologia, das condições meteorológicas, da intensidade, assim como da duração e da severidade do fogo (EMMERICH, 1998; SPENCER et al., 2003, SHAKESBY e DOERR, 2006).

O fogo altera a cobertura vegetal e a camada superior do solo, passando a ter um impacto no movimento da água entre os vários compartimentos do ciclo hidrológico (SPENCER et al., 2003). Com a queima da vegetação, tem-se a diminuição da taxa de evapotranspiração e os excedentes hídricos superficiais tendem a aumentar com a ocorrência das chuvas. Na medida em que o fogo altera a qualidade da água, ele pode afetar a comunidade aquática, tais como o fitoplâncton, os macro e microinvertebrados, além dos peixes.

Nesse contexto, o uso do fogo para o manejo, o combate às queimadas descontroladas e a necessidade de compreensão dos efeitos do fogo incentivam estudos sobre os efeitos de queimadas em diferentes compartimentos ambientais. Embora haja várias linhas de pesquisa 
relacionadas aos efeitos do fogo nos compartimentos terrestres e atmosféricos (PIVELLO e COUTINHO, 1992; MIRANDA et al., 2002; PEREIRA et al., 2007), poucos trabalhos têm sido direcionados à obtenção de informações dos efeitos das queimadas sobre os recursos hídricos (SHAKESBY e DOERR, 2006; EARL e BLINN, 2003) e sobre as espécies aquáticas em regiões tropicais, sobretudo quanto à toxicidade das cinzas em áreas queimadas.

Portanto, para o entendimento do funcionamento dos ecossistemas após as queimadas, são necessários estudos em diferentes compartimentos ambientais. Com o período chuvoso nas áreas queimadas, uma grande quantidade de nutrientes e de material particulado presente nas cinzas é transportada para os rios, acarretando alterações nas propriedades físico-químicas desses ambientes (LARANJEIRA e LEITÃO, 2008). De acordo com Shakesby e Doerr (2006), o pH dos rios pode ser afetado pela deposição das cinzas nos cursos de água após o fogo, e após um ano do fogo, o aumento dos valores de $\mathrm{pH}$ dos solos pode contribuir para o aumento do $\mathrm{pH}$ da água dos rios. A condutividade elétrica (CE) e o $\mathrm{pH}$ nos rios aumentam após as cinzas de áreas queimadas alcançarem a água, e o oxigênio dissolvido (OD) diminui. Contudo, após quatro meses, os valores destes parâmetros voltaram às condições originais de pré-queima em rios norte-americanos (EARL e BLINN, 2003).

Após esta breve introdução da temática, torna-se perceptível a necessidade de estudos que apontem alterações sobre os parâmetros físico-químicos da água e sobre as respostas da biota aquática, a fim de gerar informações e subsídios para ações de manejo que visam minimizar os efeitos de queimadas no ambiente aquático e contribuir às ações de manejo e preservação das bacias hidrográficas em áreas queimadas na região.

\subsection{OBJETIVOS E ESTRUTURA DA DISSERTAÇÃO}

O objetivo geral do presente trabalho é avaliar os efeitos limnológicos e ecotoxicológicos de cinzas provenientes de queimadas de áreas nativas de Cerrado e de uma área de pasto.

Visando ao alcance do objetivo geral, definiram-se os seguintes objetivos específicos:

i. Caracterizar a composição química das cinzas de áreas de queimadas no Cerrado nativo e de cinzas de uma área de pasto;

ii. Identificar os efeitos de cinzas provenientes de áreas de queimadas no Cerrado sobre parâmetros físico-químicos de qualidade da água; 
iii. Avaliar a toxicidade aguda de cinzas provenientes de áreas de queimadas no Cerrado sobre organismos aquáticos;

iv. Comparar a toxicidade de cinzas obtidas em áreas queimadas de Cerrado nativo com a toxicidade de cinzas de área de pasto;

Nesse contexto, uma avaliação integrada das cinzas contemplando as análises físicoquímicas e biológicas foi realizada, de acordo com a figura 1.

Figura 1 - Esquema representativo do experimento integrativo no presente estudo. Os conteúdos dos dois capítulos da dissertação estão em cinza.

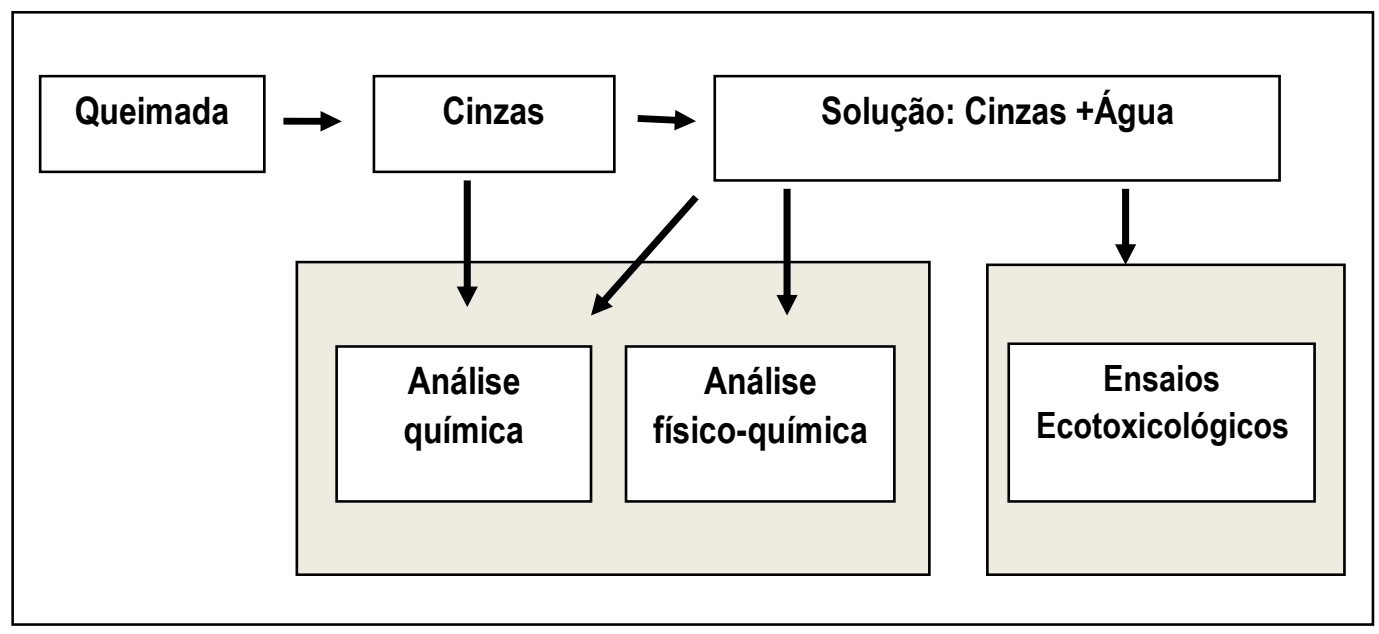

A dissertação está organizada em dois capítulos escritos na forma de artigos científicos. O capítulo 1 propõe-se a avaliar a química das cinzas e os efeitos físico-químicos das cinzas na água, de forma a atender aos objetivos i e ii; por sua vez, o capítulo 2 traz uma avaliação dos efeitos ecotoxicológicos de cinzas de diferentes áreas de vegetação do Cerrado sobre organismos aquáticos (objetivos iii e iv).

Além dos dois capítulos, a dissertação possui uma introdução que apresenta o estado da arte sobre os efeitos ambientais das queimadas a partir da revisão da literatura, e a conclusão geral que integra os principais resultados dos dois capítulos de forma a ter uma visão geral sobre os efeitos das queimadas do Cerrado em ecossistemas aquáticos. 


\subsection{FUNDAMENTAÇÃO TEÓRICA}

\subsubsection{A vegetação do Cerrado}

O Cerrado é o segundo maior bioma brasileiro e possui uma alta biodiversidade e é extremamente rico em recursos hídricos (MENDONÇA et al.,1998; KLINK e MACHADO, 2005). O bioma destaca-se em extensão geográfica, ocupando significativa porção da América do Sul. Ocupava originalmente cerca de $20 \%$ do território nacional (OLIVEIRA-FILHO e RATTER, 2002) e sua distribuição ocorre principalmente na região do Planalto Central (FELFILI e SILVA JÚNIOR, 2005) (Figura 2).

Recentes estudos mostraram que a flora vascular do Cerrado compõe-se por mais de 11.000 espécies (MENDONÇA et al., 2008) e apresenta o segundo maior número de endemismos em espécies de plantas com sementes (FORZZA et al., 2010). No entanto, no decorrer dos últimos 40 anos, mais da metade dos 2 milhões de $\mathrm{km}^{2}$ originais foram convetidos em pastagens plantadas, culturas anuais e outros tipos de uso, os quais trouxeram grandes danos ambientais e têm ocasionado alterações nas frequências de queimadas e possíveis mudanças climáticas regionais (KLINK e MACHADO, 2005; ALHO e MARTINS, 1995; SANO et al., 2010) (Figura 2).

Figura 2 - Distribuição do bioma Cerrado original no Brasil e mapa do bioma Cerrado contendo a distribuição espacial das áreas com vegetação (verde), desmatamento acumulado até 2008 (marrom). Fonte (MMA, 2007).
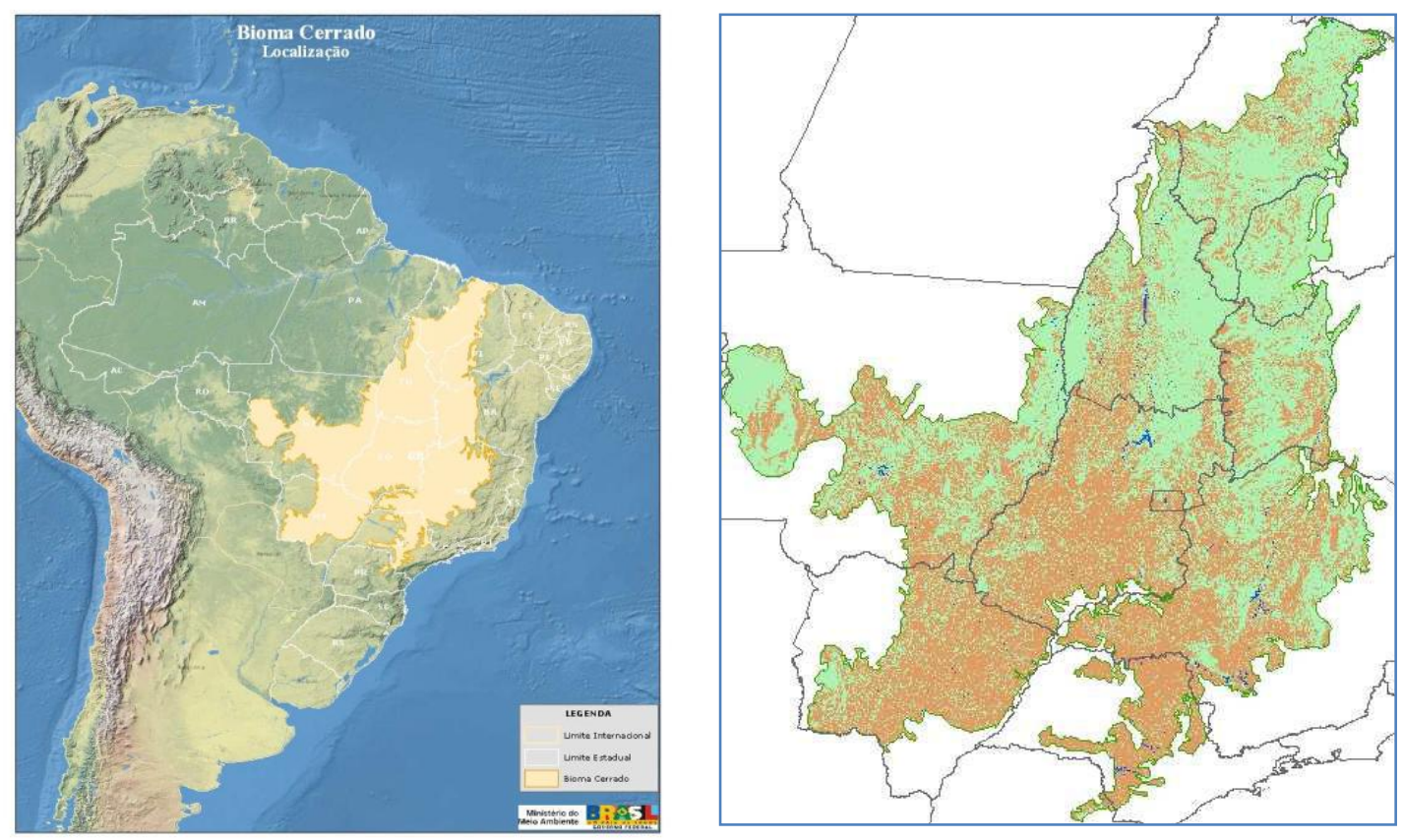
Apesar do bioma Cerrado ser o principal responsável pela produção hídrica de algumas das mais importantes bacias hidrográficas do país, ele é um dos ambientes mais ameaçados do mundo. Em decorrência do cenário de degradação e de alto endemismo, o bioma é considerado um dos hotspots mundiais (MYERS et al., 2000) e, portanto, tem despertado a atenção para a preservação de sua biodiversidade e conservação dos seus recursos naturais (PROBIO, 1999; OLIVEIRA-FILHO e RATTER, 2002; MITTERMEIER et al., 2005).

O Cerrado possui duas estações bem definidas: seca e chuvosa e é classificado como savana tropical úmida (RIBEIRO e WALTER, 2008). Possui uma vegetação rasteira, formada principalmente por gramíneas, que coexiste com espécies lenhosas e arbustos esparsos (MENDONÇA et al., 1998; KLINK e MOREIRA,2002). Durante a estação seca, grande parte da biomassa aérea do estrato herbáceo morre, favorecendo a ocorrência de incêndios, tanto por via natural quanto antrópica (MIRANDA e SATO, 2005).

O bioma Cerrado apresenta um conjunto variado de habitats e fitofisionomias, segundo a ocorrência de determinado estrato, que inclui: (a) o cerradão (formações florestais com dossel mais ou menos fechado); (b) o cerrado stricto sensu (fisionomia densa de árvores e arbustos com até $12 \mathrm{~m}$ de altura e um estrato herbáceo-graminoso); (c) o campo cerrado (com fisionomia aberta do estrato arbóreo-arbustivo); (d) o campo sujo (formado por áreas de gramíneas com arbustos bem dispersos) e (e) o campo limpo (formação dominada por gramíneas) (GOODLAND, 1972; COUTINHO, 1990) (Figura 3).

Os diferentes tipos vegetacionais do Cerrado correspondem ao gradiente de biomassa e da capacidade de fixação de carbono alocado na biomassa da parte aérea e subterrânea (DURIGAN, 2004). A proporção biomassa subterrânea/biomassa aérea (parte aérea viva da vegetação) pode variar de 2,6 no cerrado aberto a 7,7 no campo sujo, considerando que os tecidos subterrâneos correspondem a cerca de $65 \%$ e $76 \%$ da biomassa total do ecossistema (CASTRO e KAUFFMAN, 1998).

Pelo fato de possuir uma vegetação rasteira abundante, o Cerrado é um bioma em que o fogo alastra-se facilmente. Nesse sentido, esse bioma necessita de uma atenção especial das autoridades competentes no que tange à prevenção das queimadas (KLINK e MACHADO, 2005). 
Figura 3 - Diferentes formações vegetais e fitofisionomias no bioma Cerrado (RIBEIRO e WALTER, 2001).

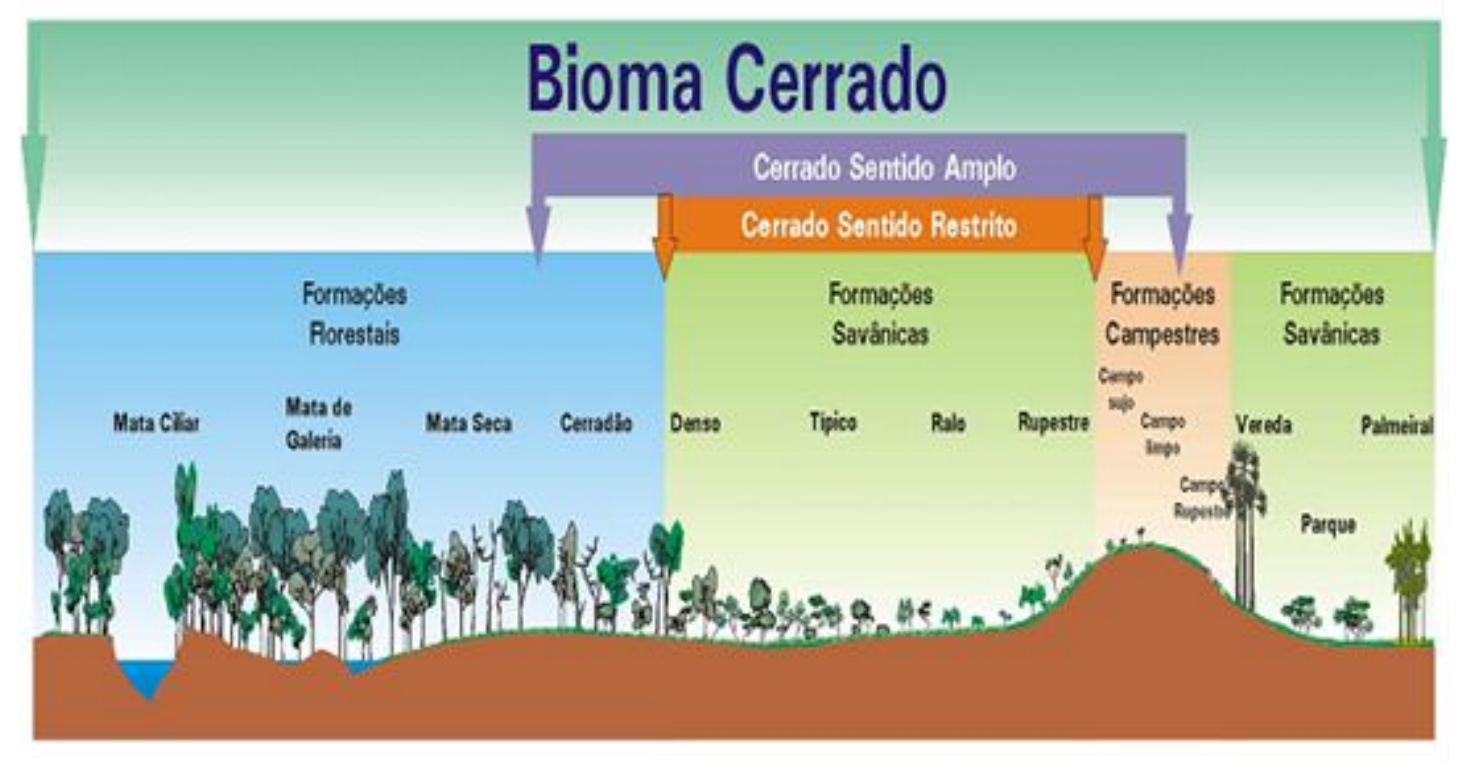

A ocupação do bioma Cerrado tanto para urbanização como para atividades agrícolas vem sendo amplamente discutida, sobretudo com relação à redução de sua biodiversidade e à redução de suas nascentes (KLINK e MACHADO, 2005; AQUINO et al., 2008). Embora haja técnicas modernas e menos destrutivas para o manejo do solo, as queimadas ainda ocorrem principalmente para a limpeza de pastagens e abertura de novas áreas agrícolas (COUTINHO, 1990; MISTRY, 1998), contribuindo para a redução da mata em áreas de nascentes e, potencialmente, para o desequilíbrio dos corpos hídricos com o aporte de grande quantidade de cinzas advindas das queimadas.

\subsubsection{As queimadas e o regime de queima no Cerrado}

As queimadas naturais acontecem, sobretudo, no período de chuvas, pois são provocadas pelos raios (geralmente ocorrem em setembro, sendo esse o mês que marca o início da estação chuvosa na região dos cerrados). Sendo assim, elas não causam um efeito devastador como os incêndios provocados pelas ações antrópicas. As queimadas causadas pelo ser humano geralmente são acidentais, mas podem ser intencionais. Elas se encontram inseridas no processo produtivo brasileiro, principalmente na limpeza de pastagens e a abertura de áreas agrícolas na região (COUTINHO, 1990; IBAMA, 2011). Em curto prazo, é a maneira mais econômica que os produtores têm de solucionar questões relacionadas ao plantio e à renovação das pastagens (NEPSTAD et al., 1999; IBAMA, 2011). 
Em comparação às queimadas naturais, as queimadas não-naturais costumam ser antecipadas para julho ou agosto, pois é o período em que a maior parte dos agricultores queimam os restos da colheita e preparam suas terras para novos plantios ou quando os pecuaristas queimam o pasto nativo para facilitar a rebrota das gramíneas secas e fornecer, portanto, folhas frescas ao gado no período de estiagem.

A ocorrência de queimadas na área central do Cerrado inicia-se geralmente no mês de maio, coincidindo com o período de estiagem (maio a setembro). Observa-se, historicamente, o crescimento do número de queimadas nos meses de junho e julho em relação aos meses anteriores, atingindo-se o número máximo de focos de áreas queimadas no mês de agosto. Nos meses de setembro e outubro, verifica-se uma queda acentuada do número de queimadas, devido ao início das chuvas. Desse modo, o período de maior risco (condições atmosféricas favoráveis à propagação do fogo) corresponde ao mês de agosto e o início do mês de setembro (COUTINHO, 1990; IBAMA 2011).

O uso do fogo tem ocorrido de maneira cada vez mais descontrolada (INPE, 2012). Além dos efeitos oriundos das mudanças climáticas (KLINK e MACHADO, 2005), o aumento expressivo dos focos de queimadas de um ano ao outro deve-se, sobretudo, à dinâmica do setor agropecuário, segundo especialistas ${ }^{2}$. Em momento econômico favorável à expansão dos rebanhos e das práticas agrícolas, há consideravelmente o aumento do uso de fogo pelos produtores rurais para a abertura da pastagem e limpeza da terra para o cultivo.

As queimadas são eventos que constituem grande preocupação da comunidade acadêmica e de órgãos ambientais, dada a sua significativa contribuição para o aquecimento global (IBAMA, 2011) e pelo seu reconhecimento como um dos principais fatores responsáveis pelas perturbações nos ecossistemas do Bioma Cerrado (KLINK e MACHADO, 2005).

No Brasil, o agronegócio avança nas florestas da região Norte e em áreas remanescentes de Cerrado. Em 2012, o maior índice de queimadas foi verificado nos municípios do Mato Grosso, justamente no Estado onde o agronegócio mais avançou. Em 2010, Mato Grosso registrou 46.077 focos de calor (INPE, 2012).

\footnotetext{
${ }^{2}$ No Brasil, as imagens são geradas pelo Instituto Nacional de Pesquisas Espaciais (INPE), que repassam ao PREVFOGO informações para quantificação dos focos quentes em todo país. De janeiro até o início de setembro de 2012, foram registrados mais de 104 mil focos de incêndio do Centro-Oeste à Amazônia.
} 
O Instituto Nacional de Pesquisas Espaciais registra através do satélite NOAA-15 os focos de calor mensais em todos os estados do país. Os focos de calor é utilizado na interpretação do registro de calor captado na superfície do solo por sensores espaciais, que captam e registram qualquer temperatura acima de $47^{\circ} \mathrm{C}$ e a interpretam como sendo um foco de calor (INPE, 2010).

O Distrito Federal é uma região relativamente pequena, se comparada ao tamanho dos estados brasileiros. No entanto, tem-se registrado um grande número de queimadas anualmente, sendo que em 2010 mais de 120 dias de estiagem carbonizaram 35 mil hectares de vegetação preservada e quase 3 mil ocorrências de focos de incêndios foram registradas de janeiro a setembro (INPE, 2012).

\subsubsection{O uso do fogo no Cerrado}

O fogo é um dos fatores determinantes do tipo de vegetação savânica, sendo considerado como fator de diversidade fisionômica (SATO, 2003). Estudos antropológicos realizados por Guidon e Delibrias demonstraram que grupos primitivos faziam uso do fogo no Brasil Central há cerca de 32.000 anos (LOMBARDI, 2003).

Outros estudos revelam que o uso do fogo era muito difundido entre os grupos indígenas que habitavam a região dos Cerrados (PIVELLO, 2006). A tribo indígena Kayapó, por exemplo, faz uso do fogo, como prática de manejo em áreas do Cerrado, para o controle de espécies vegetais daninhas e para o estímulo da produção de espécies frutíferas (LAGARES, 2006). Por meio do fogo, os índios se beneficiam de diferentes modos, tais como: o estímulo da floração/frutificação de espécies, a atração da fauna herbívora, a fuga de animais peçonhentos, além do uso em rituais religiosos (PIVELLO, 2006). Desse modo, eles praticam a queima em pequenas áreas ou em áreas maiores em um sistema de mosaico, interpolando áreas queimadas com áreas não-queimadas, que servem de refúgio às espécies da fauna e da flora mais sensíveis ao fogo.

Por outro lado, as alterações na região, a partir da década de 1960, com o uso das práticas agropecuárias convencionais, não possibilitou a adoção do sistema de queima em mosaico e tem ocasionado o aumento da frequência e da extensão de áreas queimadas com efeitos adversos nos ecossistemas (KLINK e MACHADO, 2005; PIVELLO, 2006; ALHO e MARTINS, 1995; SANO et al., 2010). 
Nesse sentido, os incêndios na região dos Cerrados na antiguidade não tinham grandes proporções e frequências como os atuais. A negligência de ações básicas de controle têm acarretado grandes perdas ambientais e econômicas (COUTINHO, 1990; IBAMA, 2011).

Portanto, o uso adequado do fogo ocasiona uma série de benefícios ao equilíbrio do bioma Cerrado. Nas savanas, o fogo é um instrumento de manejo natural muito importante, que desencadeia vários processos ecológicos e tem sido uma estratégia de manejo eficiente para a manutenção de pastagens naturais, de parques nacionais e reservas biológicas destinados à proteção dos ecossistemas do Cerrado (SOARES, 2000; PIVELLO, 2006; MISTRY e BIZERRIL, 2011).

\subsubsection{Os efeitos do fogo}

O fogo é importante agente na estruturação das comunidades de Cerrado (MISTRY, 1998; MOREIRA, 2000). A vegetação do cerrado apresenta características adaptativas à passagem do fogo e mostra-se muito resiliente ao fogo com frequência em intervalos de cinco anos, por outro lado regimes bianuais de fogo tendem a modificar a fisionomia para formações mais abertas (MIRANDA et al., 2002).

As queimadas acidentais ocorrem, às vezes, mais de uma vez por ano, inviabilizando a recuperação da vegetação nativa. No contexto local, as queimadas são nocivas à conservação da biodiversidade, alteram o ciclo biogeoquímico de nutrientes e reduzem a penetração de água no subsolo (MEIRELLES, 1990; BUSTAMANTE e OLIVEIRA, 2008).

Em uma perspectiva regional, causam poluição atmosférica com prejuízos à saúde humana e alterações ambientais em ecossistemas inteiros (ARBEX et al., 2000; IBAMA, 2008; MALEKNIA et al., 2009). Um estudo sobre a transferência de macronutrientes para a atmosfera de uma vegetação de campo cerrado no estado de São Paulo constatou que, em média, 95\% do nitrogênio e entre $42 \%$ e 59\% do fósforo, potássio, cálcio, magnésio e enxofre contidos na biomassa aérea são liberados para a atmosfera (PIVELLO e COUTINHO, 1992).

No âmbito global, as queimadas são associadas a alterações da composição química da atmosfera e do clima da biosfera (LAGARES, 2006; IBAMA, 2008). Simulações realizadas nas savanas da América do Sul, África e Austrália mostraram que o uso do solo pode alterar o clima das savanas tropicais, principalmente na diminuição da precipitação e no aumento da temperatura, com consequências ecológicas e econômicas (HOFFMANN e JACKSON, 2000). 
A queima é um processo de combustão de biomassa onde se tem liberação de água $\left(\mathrm{H}_{2} \mathrm{O}\right)$ e dióxido de carbono $\left(\mathrm{CO}_{2}\right)$. Outros elementos como o monóxido de carbono $(\mathrm{CO})$, o óxido nitroso $\left(\mathrm{N}_{2} \mathrm{O}\right)$, os hidrocarbonetos e partículas de aerossóis são gerados durante as queimadas (SPENCER et al., 2003). Quando uma vegetação é queimada, os elementos incorporados na biomassa são volatilizados, tais como nitrogênio $(\mathrm{N})$, fósforo $(\mathrm{P})$, potássio $(\mathrm{K})$, cálcio $(\mathrm{Ca})$, magnésio $(\mathrm{Mg})$, cobre $(\mathrm{Cu})$, ferro $(\mathrm{Fe})$, manganês $(\mathrm{Mn})$ e zinco $(\mathrm{Zn})$ e/ou são mineralizados formando cinzas, como o $\mathrm{Ca}, \mathrm{Mg}$ e $\mathrm{K}$ (SPENCER et al., 2003).

As cinzas também podem ser constituídas por metais pesados e hidrocarbonetos aromáticos policíclicos (HAPs) (FERREIRA et al., 2004). Os HPAs são formados em processos de combustão incompleta, a altas temperaturas e, portanto, são emitidos por quaquer tipo de combustão. Quando a matéria orgânica é queimada, formam-se vários tipos de HPAs, cuja concentração e complexidade das misturas dependem das fontes emissoras, além da pressão e temperatura (YUNKER et al., 2002).

Esses compostos podem contaminar o ar (MALEKNIA et al., 2009), o solo e a água (SPENCER e HAUER, 1991; EARL e BLINN, 2003; SPENCER et al., 2003) e exercem um impacto não compreendido totalmente nas cadeias alimentares.

A fuligem liberada nas queimadas permanece em suspensão no ar e tem sido apontada como fonte geradora de HPAs (ANDRADE, 2004; VASCONCELLOS et al., 2007) e responsável pelo aumento de incidência de casos de problemas respiratórios em uma região com incidência de queimadas em plantações de cana-de-açúcar (ARBEX et al., 2000).

\subsubsection{Os efeitos do fogo no solo}

Apesar da vegetação de Cerrado apresentar certa resiliência às queimadas, os ciclos biogeoquímicos são alterados devido à mineralização dos nutrientes contidos na biomassa queimada (BUSTAMANTE e OLIVEIRA, 2008).

Os efeitos do fogo nos solos podem ser analisados a partir do estudo dos aspectos físicos, químicos e biológicos do solo. Dentre as mudanças que ocorrem no aspecto físico, pode-se citar a variação de temperatura e umidade, as alterações na estrutura e na porosidade do solo (MEIRELLES, 1990). No meio químico, ocorrem alterações do pH do solo, a volatilização dos elementos químicos presentes na biomassa, a mineralização da matéria orgânica (MO), dentre outras transformações (LARANJEIRA e LEITÃO, 2008). 
A perda da MO causada pelo fogo expõe o solo às intempéries, provocando modificações em suas propriedades físicas (porosidade e penetrabilidade de água), tornando-o mais susceptível aos processos erosivos (MEIRELLES, 1990). Dessa forma, há a redução da taxa de infiltração e o aumento do escorrimento superficial, o que potencializa os riscos de erosão. Os processos erosivos acabam proporcionando perdas consideráveis de nutrientes, principalmente devido à remoção de grande parte das cinzas (EARL e BLINN, 2003). Em áreas vegetais de topografia acidentada, os processos de carreamento (run-off) de cinzas são muito mais evidentes, ocasionando efeitos mais agravantes.

Além das alterações físicas, pode também ocorrer algumas alterações químicas no solo na passagem do fogo (MEIRELLES, 1990). Quando a MO é queimada, as substâncias nela contidas são liberadas em forma de óxidos que são depositados como cinzas na superfície do solo. Estas cinzas, geralmente ricas em óxidos solúveis de bases, transformam-se em carbonatos capazes de neutralizar a acidez do solo (LARANJEIRA e LEITÃO, 2008; MARCOLAN et al., 2009). O fogo acelera a mineralização da MO do solo, viabilizando processos que em condições naturais demandariam longos períodos. O grande problema nesse processo de "decomposição" consiste na rápida liberação de nutrientes em um curto período (FREITAS e SANT'ANNA, 2004). De fato, a quantidade liberada de nutrientes é bastante superior à capacidade de assimilação pelas plantas, ocasionando perdas de nutrientes por erosão, lixiviação e percolação.

Pivello e Coutinho (1992) mostraram que, em um ecossistema de vegetação herbáceoarbustiva de campo cerrado no estado de São Paulo, é necessário e adequado intervalo de três anos entre queimadas sucessivas para que haja a ciclagem da matéria sem efeito negativo no balanço nutricional desse ecossistema.

\subsubsection{Efeitos do fogo nos recursos hídricos}

O Cerrado possui um solo com altas concentrações de alumínio e ferro (ALVIM e ARAÚJO, 1952; ARENS, 1958; GOODLAND, 1971). Quando ocorre uma queimada, cinzas e materiais particulados podem ser transportados através das chuvas para rios e/ou águas subterrâneas, e causar impactos em comunidades aquáticas (MINSHALL et al., 2001; SCRIMGEOUR et al., 2001).

Poucos estudos têm investigado os impactos decorrentes das queimadas sobre os recursos hídricos tanto na Europa quanto nos trópicos. Estudos realizados em zonas 
temperadas permitiram a obtenção de informações que não podem ser extrapoláveis para ecossistemas tropicais, em função da composição da vegetação e da suscetibilidade das espécies aquáticas. Alguns desses estudos mostraram que a liberação potencial de cinzas para o ambiente pode afetar a biodiversidade nos ecossistemas de florestas (ARONSSON e EKELUND, 2004) e causar impactos em comunidades de rios, tais como algas, macroinvertebrados e peixes (ROBINSON et al., 1994; MINSHALL et al., 2001; SCRIMGEOUR et al., 2001).

A região do Cerrado é a principal responsável pela produção hídrica de algumas das mais importantes bacias hidrográficas do país (KLINK, 1996; SILVA e BATES, 2002) e a área do Distrito Federal (DF) encontra-se inserida nas regiões hidrográficas do São Francisco (sub-bacia hidrográfica do rio Preto), do Tocantins-Araguaia (drenada pelo rio Maranhão), e do Paraná (drenada pelas bacias hidrográficas dos rios São Bartolomeu, Descoberto, Corumbá, São Marcos e Lago Paranoá).

Devido a sua localização geográfica, o DF possui uma rede de drenagem formada por rios de cabeceiras (rios rasos) e, por isso, são bastantes vulneráveis à contaminação.

\subsubsection{Efeitos do fogo na flora e na fauna}

As áreas com diferentes regimes de fogo tem mostrado que os distúrbios naturais e/ou antropogênicos podem causar diferentes efeitos sobre a estrutura de comunidades vegetais (MCGINLEY e TILMAN,1993; MIRANDA et al., 2002).

Em termos florísticos e fitossociológicos, os impactos do fogo sobre a vegetação influenciam na dormência das sementes, floração, polinização, densidade e crescimento de mortalidade das plantas (PEREIRA et al., 2007).

$\mathrm{O}$ intensivo uso do fogo tende a favorecer plantas herbáceas devido à subsequente redução no recrutamento de árvores nas savanas (MISTRY, 1998; MOREIRA, 2000) e o aumento na frequência das queimadas reduz a densidade e tamanho de plantas lenhosas significamente (HOFFMANN, 1999). Essas alterações na estrutura das comunidades podem ocasionar perdas nos estoques de carbono e nitrogênio na biomassa e no transporte de nutrientes para a atmosfera (BUSTAMANTE e OLIVEIRA, 2008; PIVELLO e COUTINHO, 1992). Ressalta-se ainda que o fogo intenso tem representado uma grande ameaça à integridade biológica de ecossistemas, cuja fragmentação em ritmo acelerado tem propiciado a formação de paisagens dominadas por plantas exóticas (IBAMA, 2008). 
Os combustíveis leves (e.g., gramíneas) desencadeiam incêndios bastante rápidos e com baixa produção de calor, e os combustíveis mais pesados (e.g., troncos de árvores lenhosas) produzem queimas lentas, contudo extremamente quentes. Deste modo, a paisagem com domínio horizontal de combustíveis propicia o avanço do incêndio, ao passo que uma paisagem vegetacional descontínua o desacelera (SEMARH - DF, 2004).

Os efeitos do fogo sobre a microbiota do solo são bastante complexos, haja vista a heterogeneidade espacial do solo, das condições ambientais e da intensidade e severidade da queima. De fato, os efeitos da passagem do fogo sobre esses microorganismos devem-se basicamente às alterações químicas ocasionadas pelo fogo. Os incêndios podem reduzir consideravelmente o número de microorganismos próximos à superfície do solo (ARAÚJO e RIBEIRO, 2005), contudo o aumento da temperatura média do solo e a diminuição de sua acidez favorecem a atividade biológica de certos microorganismos, resultando no aumento de abundância e sucessão ecológica desses organismos (SOARES e BATISTA, 2007). Observase também que as mudanças na dinâmica populacional da microbiota do solo podem levar às alterações das propriedades físicas e químicas do recurso edáfico.

Assim como as queimadas esporádicas em áreas restritas funcionam como mantenedoras da diversidade da flora no Cerrado, os efeitos do fogo atuam para a diversidade da maioria dos animais ao permitir o aumento da produção de alimento aos mamíferos silvestres (PRADA, 2001).

Diferentes segmentos da fauna respondem de forma distinta às queimadas. De fato, a intensidade e o tipo de danos dependem das características e da época dos incêndios. Ressaltase ainda que alguns animais possuem capacidade de pressentir o fogo e fugirem, no entanto os grandes incêndios podem impedir a fuga de animais de grande porte devido à presença de camadas espessas de fumaça e as extensas frentes de fogo (SOARES; BATISTA, 2007). Animais terrestres com mobilidade limitada parecem ser os mais vulneráveis ao fogo. Há poucos registros de mortalidade em répteis e anfíbios, apesar da mobilidade desses animais ser limitada (KOPROSKI, 2005).

Certamente, os grupos que utilizam a vegetação como abrigo e nidificação tendem a sentir mais os efeitos com as queimadas intensas e frequentes. Sendo assim, podem ser destacados dois fatores importantes para o equilíbrio e manutenção da fauna após uma queimada: o tamanho da área queimada e a distância da fonte de colonizadores (MARINHOFILHO et al., 1994).

Estudos mostraram que áreas com ausência de queimadas apresentaram maior riqueza e/ou abundância de espécies de anfíbios quando comparadas a áreas que haviam sido 
queimadas (CANO e LEYNAUD, 2010; MATTHEWS et al., 2010). No entanto, um realizado em uma área de Cerrado com uma assembleia de anuros não constatou influência negativa das queimadas, considerando que as características ecológicas das espécies estudadas favoreceram a persistência desses animais nas áreas queimadas (MORAIS et al., 2011).

\subsubsection{Ecotoxicologia}

Com a publicação do livro de Rachel Carson "Silent Spring” (início da década de 1960), nota-se, pela primeira vez, uma grande repercussão em vários setores da comunidade mundial no que tange aos riscos e perigos da poluição química, do uso não limitado de pesticidas e da ocorrência de inúmeros desastres ecológicos. Assistia-se, naquele momento, a uma progressiva conscientização da comunidade mundial sobre a necessidade de um controle e gestão adequada dos recursos naturais.

Nesse contexto, o termo Ecotoxicologia é dito pela primeira vez por Truhaut, em 1969, como uma extensão da toxicologia. Truhaut definiu a Ecotoxicologia como sendo uma ciência que descreve os efeitos tóxicos de diversos agentes em organismos vivos. Essa ampla definição incluía o estudo dos efeitos tóxicos em diferentes níveis: o nível celular, da espécie, da população, da comunidade e do ecossistema (TRUHAUT, 1977).

O princípio fundamental dos testes de toxicidade baseia-se na resposta dos organismos vivos à presença de agentes tóxicos, sendo essa resposta dependente da dose (nível de exposição) ao agente tóxico. A partir desse princípio, os testes de toxicidade são projetados para descrever uma relação concentração-resposta (HOFFMAN et al., 2003).

Embora no ambiente aquático as substâncias nocivas estejam sujeitas a diversos processos bióticos e abióticos que não são simulados em condições de laboratório, estudos mostram que os testes ecotoxicológicos são imprescindíveis para predizer os possíveis efeitos tóxicos dos contaminantes no ambiente (COSTA et al., 2008). Além do mais, os bioensaios são importantes instrumentos para avaliar o potencial de risco ambiental dos contaminantes, uma vez que apenas as análises químicas não permitem essa avaliação.

Os testes ecotoxicológicos tornam-se um complemento na caracterização da substância que se pretende avaliar. Os componentes químicos isolados não determinam a toxicidade, considerando que a associação com vários outros componentes do ambiente natural pode gerar substâncias tóxicas ou não aos organismos. 
De fato, os testes ecotoxicológicos determinam a capacidade que um contaminante (seja ele natural ou artificial) tem para produzir efeitos nos seres vivos, tendo como referência um controle (não exposto ao contaminante). Os agentes tóxicos afetam diferentemente os processos metabólicos e, consequentemente, várias respostas podem ser originadas (ZAGATTO, 2006).

\subsubsection{Organismos-teste}

Para uma avaliação ecotoxicológica mais abrangente, devem ser usados organismos de elevada relevância ecológica e de níveis tróficos diferentes. Além disso, os organismos usados em ensaios ecotoxicológicos devem ser facilmente cultivados em laboratório, devem ser sensíveis a uma variedade de poluentes, e devem ser de fácil obtenção a partir de fontes comerciais ou no meio ambiente (BUIKEMA JR et al., 1982; EPA, 2002).

A seguir, apresentam-se alguns exemplos de organismos-testes geralmente usados em ensaios ecotoxicológicos, tais como o microcrustáceo Ceriodaphnia dubia, o peixe Danio rerio e o molusco Biomphalaria glabrata.

\subsubsection{Ceriodaphnia dubia (Cladocera, Crustacea)}

Os ensaios de toxicidade envolvendo os microcrustáceos planctônicos são largamente utilizados no monitoramento da qualidade das águas e na avaliação da toxicidade de efluentes (OLIVEIRA-FILHO et al., 2009a; ROSA, 2008), pois esses organismos figuram-se como elo importante nas cadeias alimentares aquáticas e são facilmente cultivados em condições laboratoriais (ABNT, 2005). Segundo Ruppert et al. (2005), os microcrustáceos são representantes ecologicamente importantes das comunidades bentônicas e planctônicas de lagos e rios.

Vulgarmente conhecida como pulga d'água, a Ceriodaphnia dubia Richard, 1894 (da ordem Cladocera, família Daphniidae) é um microcrustáceo zooplanctônico, de 0,8 mm a 0,9 mm de comprimento. Na cadeia alimentar aquática, atua como consumidor primário ao se alimentar de material orgânico particulado e de microalgas por filtração, e serve de alimento para uma diversidade de vertebrados (ABNT, 2005).

Nesse contexto, os cladóceros são ideais para os testes de toxicidade aguda e crônica de produtos químicos e efluentes em condições $e x$-situ, por serem organismos muito sensíveis 
a alterações ambientais, facilmente cultivados em laboratório, de ciclo de vida curto e com homogeneidade das gerações (reprodução por partenogênese) (EPS, 2007).

A figura 4 mostra a fotografia de $C$. dubia adulta observada em microscópio óptico com o aumento de 40 vezes.

Figura 4 - Fêmea em idade fértil de Ceriodaphnia dubia (Aumento de 40x).

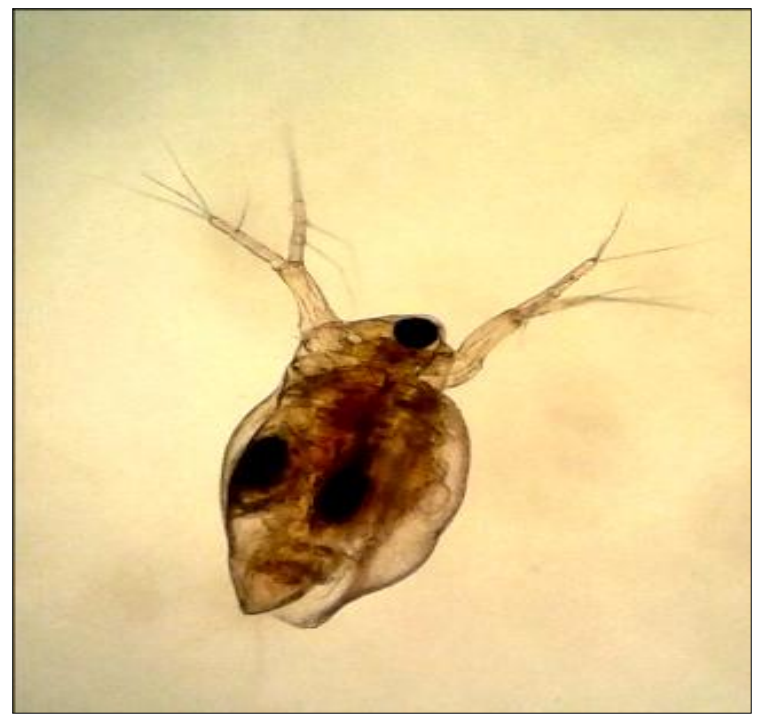

\subsubsection{Danio rerio}

O peixe zebra, Danio rerio (Hamilton Buchanam, 1822), é um pequeno peixe tropical muito conhecido na aquariofilia. As características que o tornaram popular na aquariofilia são justamente as mesmas que o conduziram a uma das espécies mais utilizadas em ensaios ecotoxicológicos (Figura 5).

D. rerio é uma espécie bentopelágica de água doce (temperatura: $18-24^{\circ} \mathrm{C} ; \mathrm{pH}$ : 6-8), pertencente à família dos CYPRINIDAE e à ordem dos CYPRINIFORMES, com distribuição pela Ásia (WESTERFIELD, 2000).

Figura 5 adulto. Fonte:

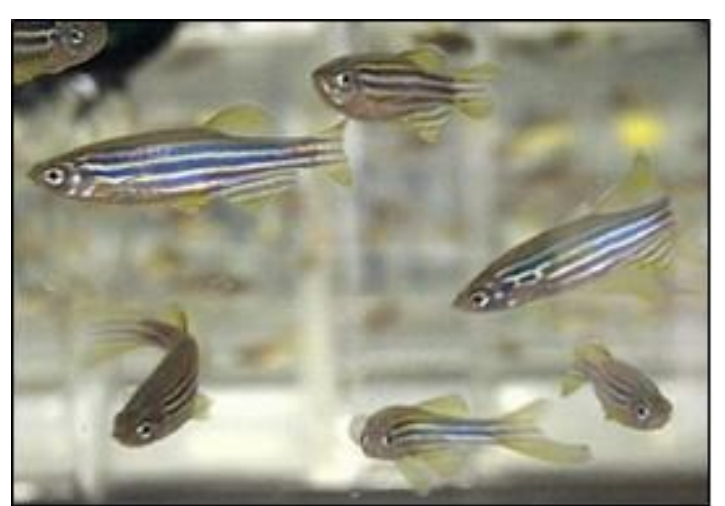

Aspecto geral de Danio rerio Aplysia (2012). 
Esta espécie mede cerca de 3 a $5 \mathrm{~cm}$ em idade adulta. É uma espécie de fácil obtenção e manutenção e, sob condições adequadas, obtém-se um grande número de desovas. Uma fêmea de $D$. rerio é capaz de desovar aproximadamente 50 a 200 ovos por dia (WESTERFIELD, 2000).

Devido às suas características, o $D$. rerio tem sido utilizado como modelo em inúmeros estudos no campo da genética molecular, da biologia dos vertebrados, bem como na neurobiologia (KIMMEL et al., 1995; LELE et al, 1996; WESTERFIELD, 2000) e na ecotoxicologia (HILL, et al. 2005).

O seu desenvolvimento embrionário encontra-se descrito em vários estudos (KIMMEL et al., 1995) e tem sido uma base para a interpretação dos efeitos provocados por metais pesados, medicamentos e poluentes ambientais. Os testes com embriões de D. rerio têm sido recomendados como modelo em ecotoxicologia e toxicologia geral (EPA, 1996; NAGEL, 2002; ABNT, 2004; OECD 236, 2013).

\subsubsection{Biomphalaria glabrata}

Os caramujos do gênero Biomphalaria são largamente estudados no Brasil, em decorrência de três das suas espécies serem hospedeiras intermediárias do Schistosoma mansoni, trematódeo causador da esquistossomose mansônica. Entre as 10 espécies e uma subespécie de Biomphalaria identificadas no Brasil (LIMA, 1995), as mais estudadas no Brasil são: Biomphalaria tenagophila, Biomphalaria glabrata e Biomphalaria straminea (SOUZA e LIMA, 1990).

B. glabrata (Say, 1818) é o maior molusco da família Planorbidae com distribuição geográfica em aproximadamente dezesseis estados brasileiros, além do Distrito Federal (Figura 6). Pertencente à família Planorbidae, esses caramujos podem ser encontrados em uma grande variedade de corpos d'água doce (lênticos ou lóticos), sendo localizados preferencialmente em águas rasas. Possuem como substrato o leito lodoso ou rochoso, assim 
como a vegetação enraizada ou flutuante próxima das margens dos corpos aquáticos (PARAENSE, 1972). Nos habitats favoráveis à colonização dessa espécie, observam-se algumas características comuns, tais como: a riqueza de microflora e de matéria orgânica, baixa turbidez, boa luminosidade, o $\mathrm{pH}$ entre 6 e 8 , o baixo teor de cloreto de sódio $(\mathrm{NaCl})$ e temperatura média entre 20 e $25^{\circ} \mathrm{C}$ (PARAENSE, 1972).

Figura 6 - Caramujos da espécie Biomphalaria glabrata. A. Caramujos em meio de cultura do Laboratório de Ecotoxicologia da Embrapa Cerrados. B. Caramujo em detalhe (Fonte: The Genome Institute-USA).
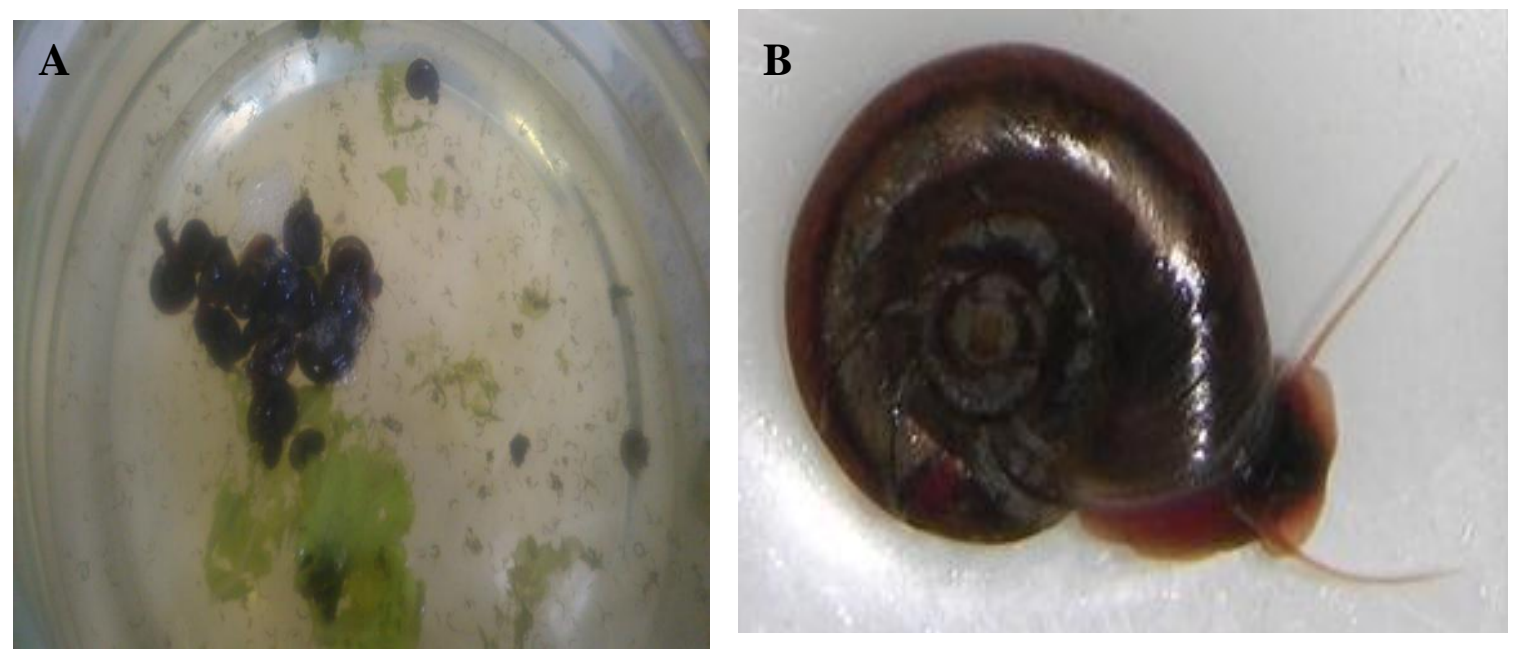

B. glabrata são moluscos pulmonados aquáticos típicos, com concha com até $40 \mathrm{~mm}$ de diâmetro e $11 \mathrm{~mm}$ de largura, seis a sete giros arredondados, crescendo lentamente em diâmetro. O planorbídeo raspa com a rádula e ingere materiais de variados tipos, entre os quais: o limo que se forma nas superfícies submersas e que possui algas, bactérias e outros microrganismos; o lodo rico em matéria orgânica e sais minerais; folhas e outros órgãos de plantas aquáticas; além de fragmentos de organismos animais e vegetais em decomposição e excrementos de outros animais (PARAENSE, 1972; OLIVEIRA-FILHO et al., 1999).

Os planorbídeos são capazes de se reproduzir por autofecundação através de muitas gerações. A desova, geralmente noturna, é colocada sobre o lado inferior de folhas flutuantes ou qualquer suporte sólido submerso. A massa de ovos enrijece lentamente em contato com a água, apresentando em menos de trinta minutos o aspecto de um disco transparente, firme e flexível (PARAENSE, 1972). A divisão do ovo começa cerca de 2 horas após a postura 
(KAWANO et al.,1992) e a eclosão ocorre entre sete e dez dias (OLIVEIRA-FILHO et al., 1999).

Devido a todas as características conhecidas sobre a ecologia do organismo, de sua abrangência e importância nos ecossistemas aquáticos, além da fácil manutenção e cultivo em laboratório, justifica-se o uso da espécie B. glabrata no presente estudo.

\section{4. MATERIAIS E MÉTODOS}

\subsection{1 Áreas de Amostragem}

As quatro principais áreas queimadas amostradas foram todas selecionadas no Distrito Federal no segundo semestre do ano de 2010, e identificadas como: 1- Torre de TV; 2 Pasto Embrapa; 3 - Lagoa Bonita e 4 - Águas Emendadas (Figura 7).

Figura 7 - Imagem de satélite com os quatro pontos amostrados de áreas queimadas (Google earth, 2008).

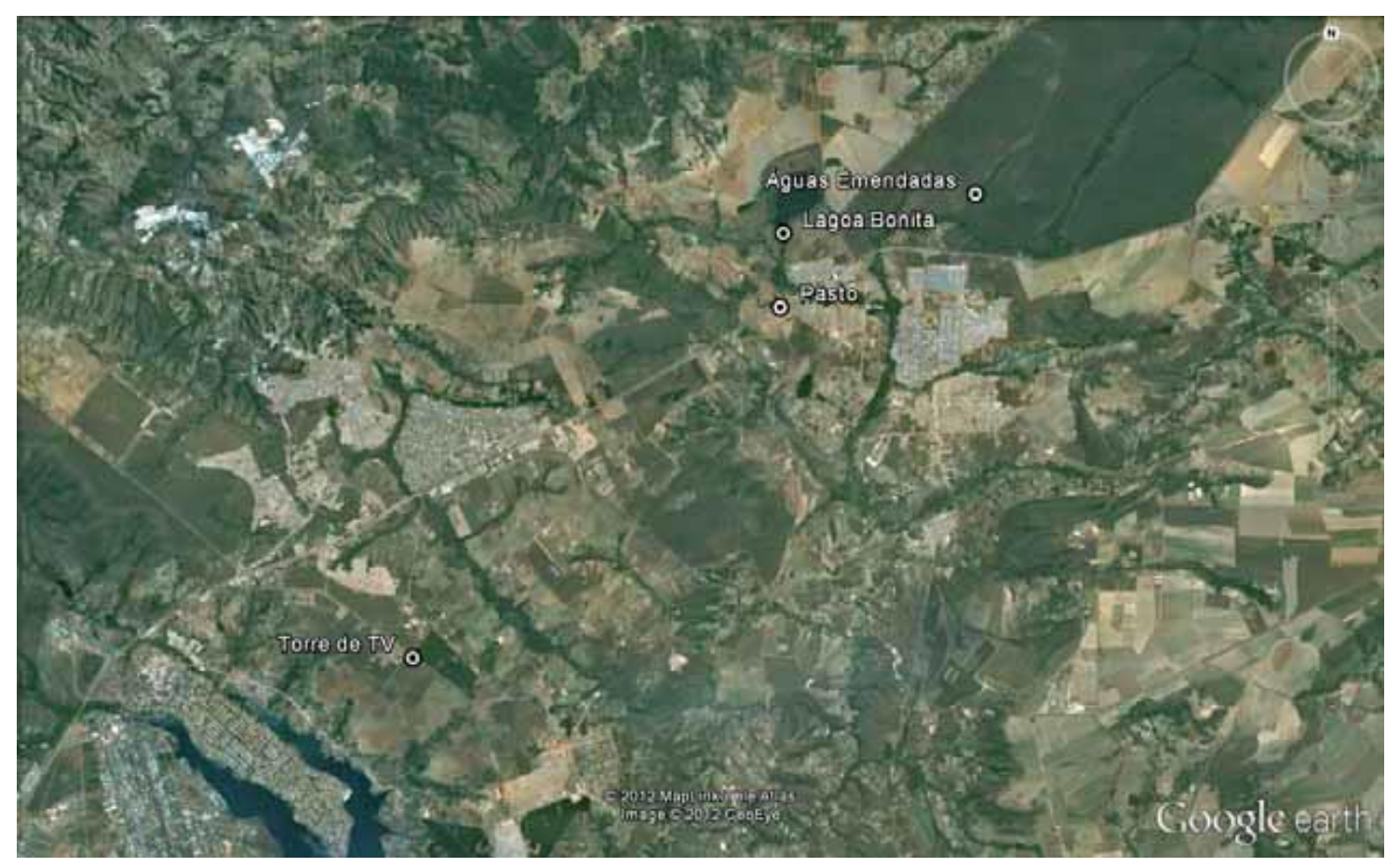

Nesse contexto, a primeira área selecionada foi nomeada como Torre, por estar localizada próxima à nova Torre de TV Digital do Distrito Federal. Trata-se de uma área com vegetação nativa, identificada como área de Cerrado Típico. As coordenadas geográficas $S$ $15^{\circ} 42^{\prime} 44,0^{\prime \prime}$ e $W 047^{\circ} 48^{\prime} 29,8^{\prime \prime}$ delimitaram essa região para amostragem de cinzas (Figura 8). 
As figuras $8 \mathrm{~A}$ e $8 \mathrm{~B}$ apresentam com maior detalhamento o local queimado e um dos pontos de coleta das amostras de cinzas e solo utilizadas nos ensaios laboratoriais.

Figura 8 - Imagem de satélite com a apresentação mais detalhada da área definida como Torre. A - Imagem da vegetação queimada na área definida como Torre. B Imagem de um dos pontos de coleta de amostras de cinzas e de solo na área (Google earth, 2008).
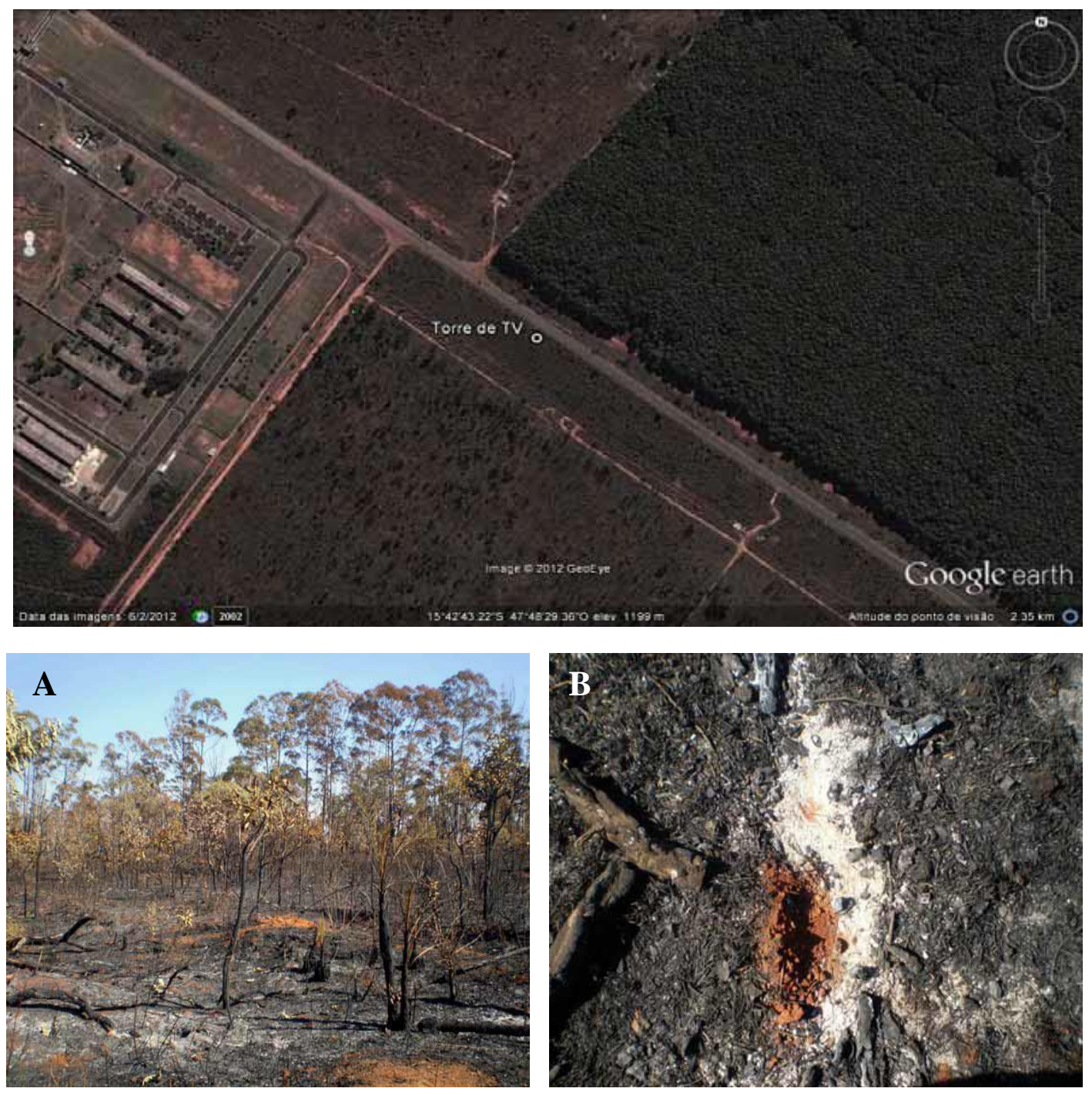

A segunda área selecionada localiza-se próximo à Embrapa Cerrados, e foi identificada como uma área de pastagem, mais especificamente como área coberta pela gramínea Brachiaria sp.

As coordenadas geográficas $S$ 15³6 $40,8^{\prime \prime}$ e $W 047^{\circ} 41^{\prime} 52,1^{\prime \prime}$ delimitaram essa região para amostragem de cinzas, podendo ser melhor visualizada na figura 9 e foi denominada 
como Pasto. As figuras 9A e 9B mostram a área queimada e um dos pontos de coleta de amostras, respectivamente.

Figura 9 - Imagem de satélite com a apresentação mais detalhada da área definida como Pasto. A - Imagem da vegetação queimada na área definida como Pasto e B pontos de coleta de amostras de cinzas e solo na área definida como Pasto (Google earth, 2008).
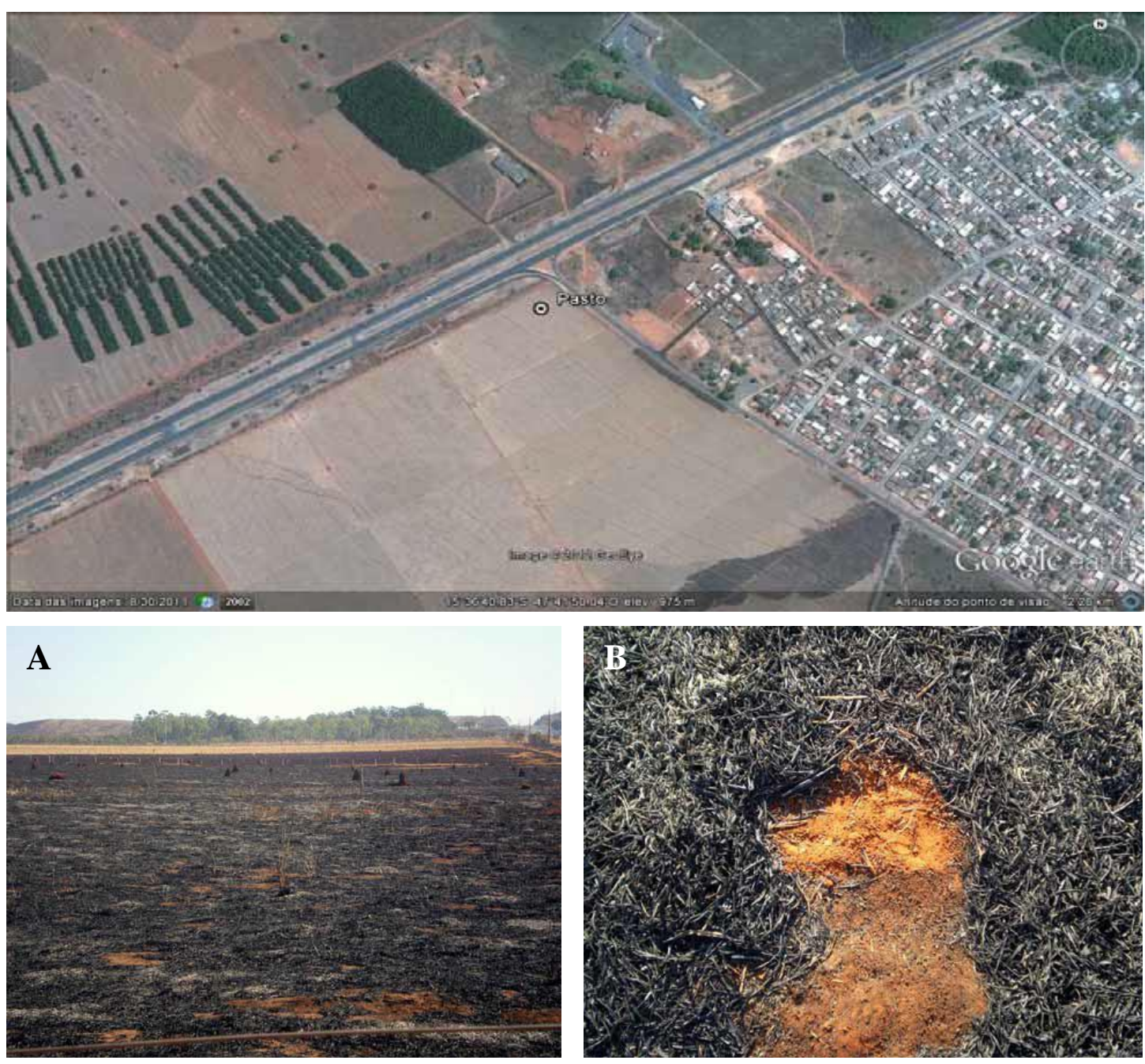

A terceira e quarta área selecionadas para amostragem de cinzas, localizam-se no interior da Estação Ecológica de Águas Emendadas. A primeira foi identificada como uma área de transição de vereda para campo savana, e denominada de Lagoa Bonita, coordenadas geográficas $S 15^{\circ} 35^{\prime} 29,9^{\prime \prime}$ e $W 047^{\circ} 41^{\prime} 48,8^{\prime \prime}$, por se localizar na saída da Lagoa Bonita em direção ao Ribeirão Mestre D'armas (Figura 10); e a segunda foi identificada como uma área de transição de mata para Cerrado típico/Vereda, mais no interior da Estação, denominada de 
Águas Emendadas e localizada sob as coordenadas geográficas S15³4'42,1" e W047³8'18,9" (Figura 11).

Figura 10 - Imagem de satélite com a apresentação mais detalhada da área definida como Lagoa Bonita. A- Paisagem da área queimada de Lagoa Bonita e B - Procedimento de coleta de amostras de cinzas (Google earth, 2008).
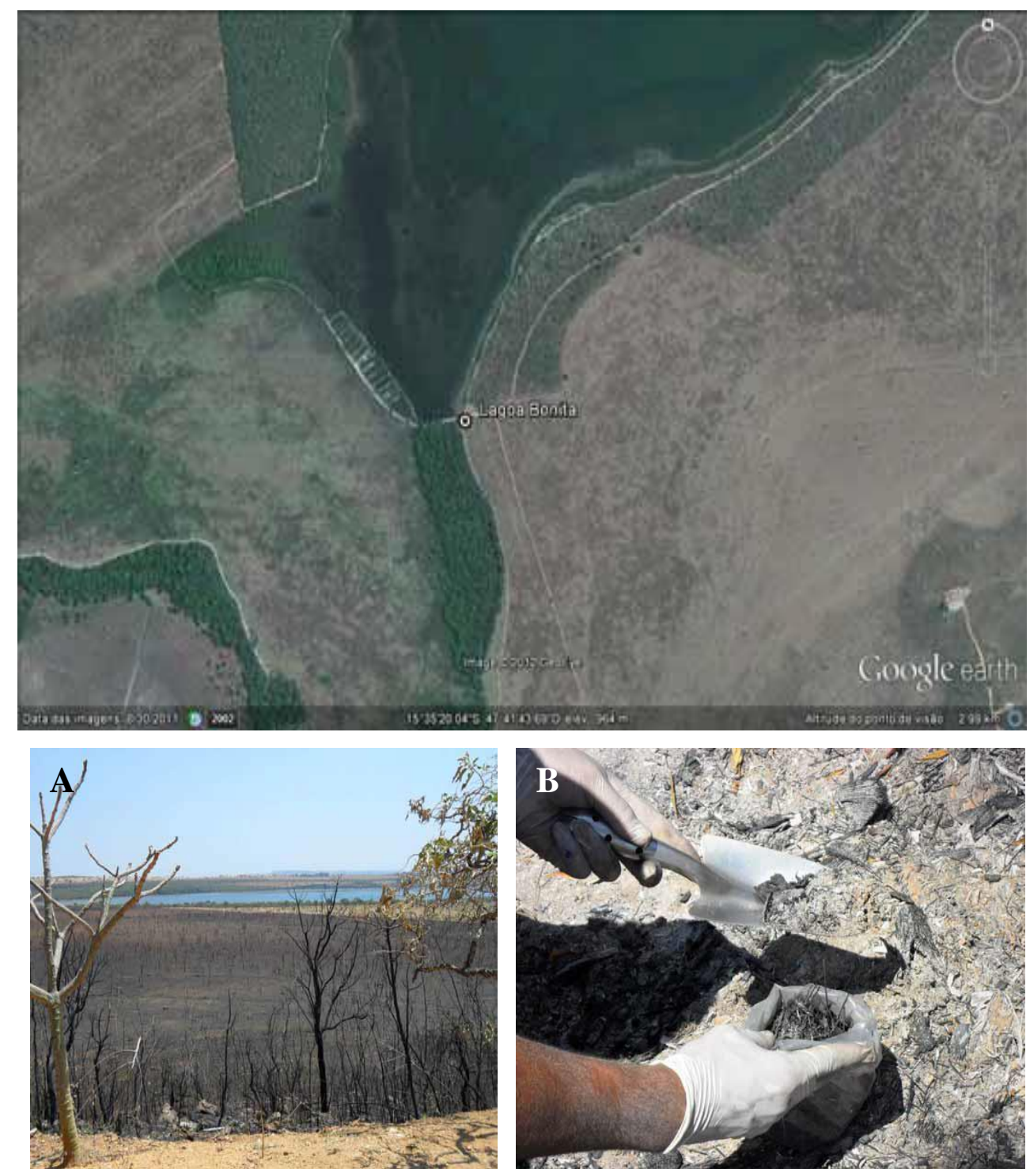

As figuras 10A, 10B, 11A e 11B mostram os locais queimados e um dos pontos de coleta de amostras, respectivamente nas áreas Lagoa Bonita e Águas Emendadas.

Figura 11 - Imagem de satélite com a apresentação mais detalhada da área definida como Águas Emendadas. A - Área da vegetação queimada. B - 
Amostragem um dos pontos de coleta de cinzas e de solo (Google earth, 2008).
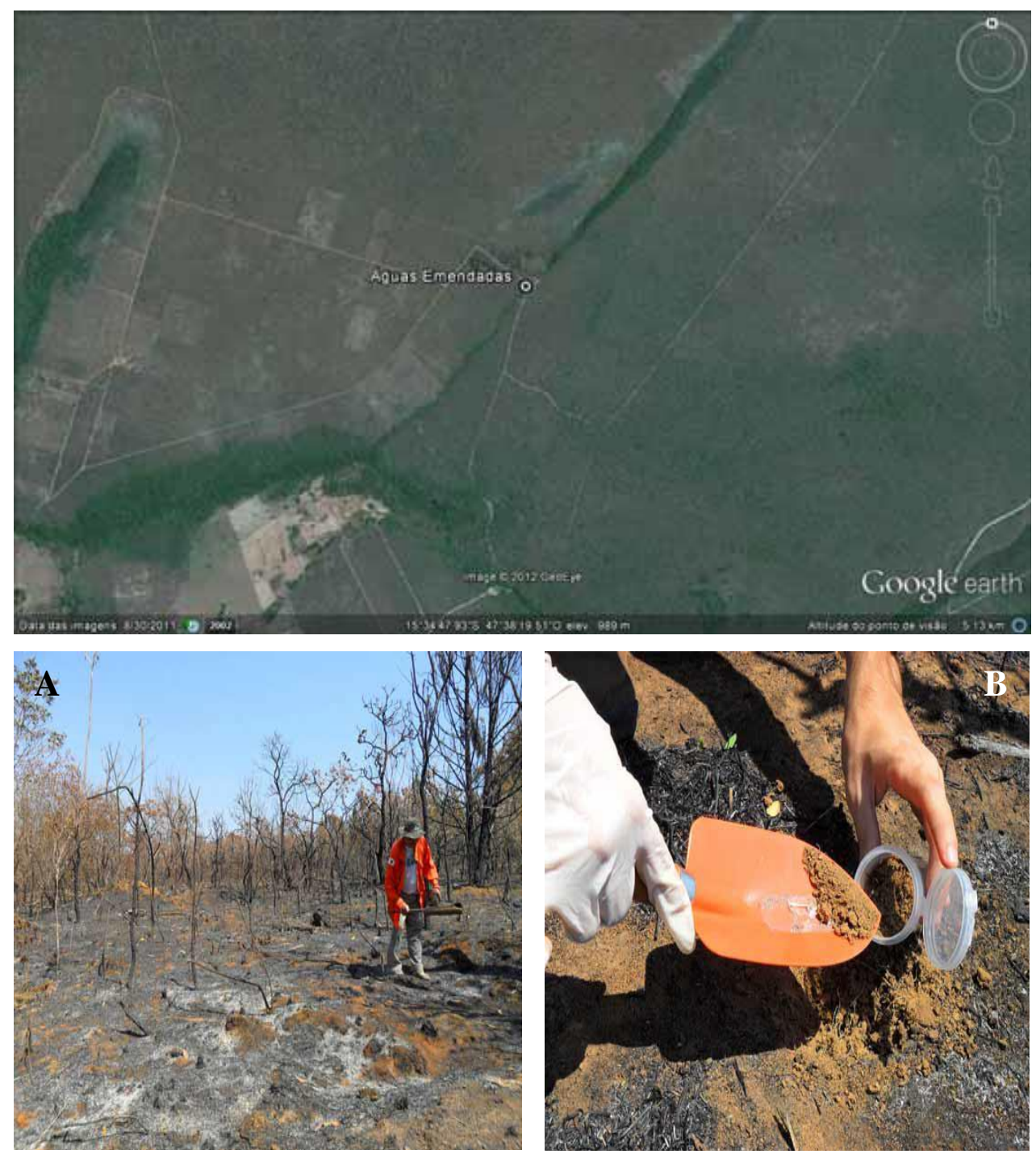

\subsubsection{Amostragem}

\subsubsection{Procedimentos de coleta de amostras}

Para investigar as propriedades de matéria vegetal representativa do Bioma Cerrado, foram selecionadas diferentes áreas para coleta de cinzas após ter sido evidenciada a queimada.

As cinzas foram coletadas imediatamente após a ocorrência das queimadas no período de estiagem, de forma a contemplar uma maior diversidade espacial da área. Como as cinzas não se encontram distribuídas de modo homogêneo na área, foram selecionados os locais onde havia maior depósito delas. As cinzas obtidas foram transportadas para o laboratório e 
peneiradas em malha com dimensão de $1 \mathrm{~mm}$, visando a obtenção da cinza propriamente dita e a eliminação de resíduos de carvão (Figura 12). Nos mesmos locais em que foram coletadas as cinzas, foram colhidas também amostras de solo nos primeiros $10 \mathrm{~mm}$ de superfície.

Figura 12 - A área de coleta da vegetação queimada próxima à Lagoa Bonita (E. E. de Águas Emendadas, DF). A- Área de coleta das cinzas; B - Peneiração; C - Agitação e D- Condução de ensaios de exposição aguda com o microcrustáceo Ceriodaphnia. dubia.
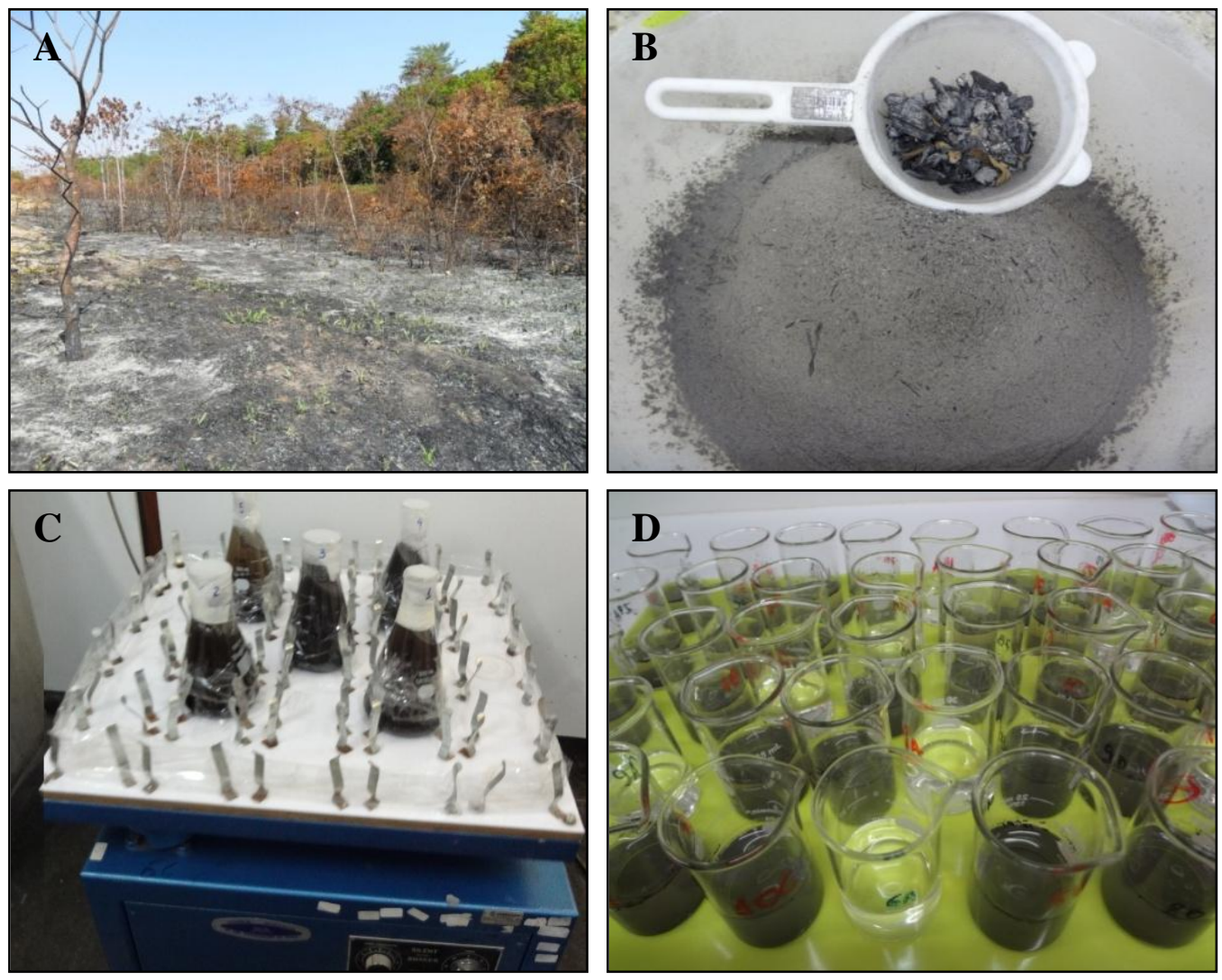

\subsubsection{Métodos analíticos}

\subsubsection{Parâmetros físico-químicos}

\subsection{Das Cinzas}

A composição química das cinzas coletadas foi definida por meio de extração ácida e determinação dos teores de metais e metais alcalinos terrosos por espectrometria de emissão atômica (ICP-AES). Foram utilizados padrões na faixa de 0,5 a $40 \mathrm{mg} \cdot \mathrm{L}^{-1}$ para os 19 elementos analisados, feitos a partir de soluções certificadas Merck (1000 mg/L). Os limites de detecção para cada elemento foi de $0,001 \mathrm{mg} \cdot \mathrm{L}^{-1}$. 
Para avaliar a solubilização dos elementos químicos na água, foram realizadas as mesmas análises na água após a mistura com as cinzas. Essas análises foram realizadas no Laboratório de Química de Plantas e no Laboratório de Química de Água da Embrapa Cerrados. Além disso, também foi avaliada a solubilização de elementos químicos nas cinzas após 24 horas de agitação em água ultrapura. Essas análises foram realizadas em ICP-EAS.

Para melhor avaliar o potencial de solubilização em função do tempo de agitação, foi escolhida amostra de cinzas de Lagoa Bonita e a mesma foi mantida em agitação por 30 dias, com leituras aos 4, 10, 15 e 30 dias. Nesse caso, as cinzas foram diluídas em água mole sintética, produzida em laboratório de acordo com ABNT (2005). Em cada um desses dias, foi retirada uma alíquota de $30 \mathrm{ml}$ para análise em cromatografia iônica (CI).

Com o uso de um cromatógrafo (modelo 761 Compact IC marca Metrohm), foram quantificados os ânions (fluoreto, cloreto, nitrito, brometo, fosfato, sulfato) e cátions (lítio, sódio, potássio, cálcio e magnésio). Para a análise das soluções na CI foram utilizados padrões na faixa de 0,02 a $50 \mathrm{mg} . \mathrm{L}^{-1}$ feitos a partir de soluções certificadas Merck (1000 mg. $\left.\mathrm{L}^{-1}\right)$. As faixas utilizadas dos limites de detecção para cada ânion foi de $0,001 \mathrm{mg} \cdot \mathrm{L}^{-1}$. Essas análises foram realizadas no Laboratório de Química de Água da Embrapa Cerrados.

\subsection{Do solo}

A análise química do solo das áreas coletadas foi realizada por meio de extração ácida em água régia ( $\mathrm{HCl}: \mathrm{HNO}_{3}$ 3:1) e posterior leitura no ICP-AES, visando obter a comparação entre a química das cinzas e do solo. Essas análises foram realizadas no Laboratório de Química de Solos da Embrapa Cerrados.

\subsection{Das alterações na água}

Foi realizado estudo das interações entre as cinzas e a água, no que se refere às alterações físico-químicas da água. As cinzas foram coletadas nas áreas selecionadas e diluídas em duas amostras, em béqueres de $2000 \mathrm{~mL}$ com concentração de 100g.L $\mathrm{L}^{-1}$, usando água mole de dureza, em torno de $40 \mathrm{mg} . \mathrm{L}^{-1} \mathrm{em} \mathrm{CaCO}_{3}$, sintetizada em laboratório conforme ABNT (2004).

A primeira amostra (A1) foi mantida em agitação constante e a segunda amostra (A2) sem agitação, ambas mantidas em estufa incubadora a $20^{\circ} \mathrm{C}$ e ausência de iluminação, com o 
objetivo de simular as diferenças existentes entre ambientes lóticos e lênticos, respectivamente.

Os parâmetros temperatura, oxigênio dissolvido (OD), pH, condutividade e sólidos totais dissolvidos (STD) foram aferidos na água mole sintética antes da adição das cinzas nos dois casos. Após o início dos ensaios, os mesmos parâmetros foram registrados a cada 24 horas. Para a leitura do OD, foi utilizado um oxímetro de bancada Orion 3-Star Thermo. Para análises de temperatura, $\mathrm{pH}$, condutividade e STD utilizou-se o medidor multiparâmetro SensION 156, da marca Hach. Essas análises foram realizadas no Laboratório de Química de Água da Embrapa Cerrados.

\subsubsection{Avaliação de parâmetros ecotoxicológicos}

O ensaio de toxicidade aguda (TA) pode ser definido como aquele que avalia os efeitos, em geral severos e rápidos, sofridos pelos organismos expostos, em um curto período de tempo, geralmente de um a quatro dias.

Nos ensaios de toxicidade aguda usualmente os critérios de avaliação são a mortalidade e a imobilidade do organismo-teste. Esses critérios são utilizados porque são facilmente determinados e possuem significado biológico e ecológico para o ambiente.

Nesse trabalho, foram realizados ensaios com três espécies de organismos aquáticos, sendo a Ceriodaphnia dubia pertencente ao zooplâncton, o peixe Danio rerio, ao nécton; e o Biompharia glabrata, aos bentos

\subsubsection{Ensaio de mortalidade do Ceriodaphnia dubia (Cladocera, Crustacea)}

Para determinar o potencial tóxico das cinzas para organismos do zooplâncton, foram realizados ensaios para avaliar os efeitos das cinzas coletadas sobre o microcrustáceo Ceriodaphnia dubia, de acordo com a norma NBR 13373 (ABNT, 2005).

Os ensaios consistiram na exposição de 10 jovens de 0 a 24 horas de idade durante 48 horas e a avaliação da mortalidade dos indivíduos. Os organismos foram expostos individualmente a $10 \mathrm{~mL}$ de solução de cinzas em béqueres de $25 \mathrm{~mL}$, previamente lavados com água mole (Figura 13). As amostras foram testadas brutas (100\%) e com um gradiente de diluições preparadas com água de cultivo. $\mathrm{O}$ pH e o OD das soluções foram medidos no início 
e no término dos ensaios. Os ensaios foram considerados válidos quando não foi observado mortalidade de até $10 \%$ de efeito no grupo controle.

Figura 13 - Bioensaios com C. dubia. A- Concentrações recém preparadas; B- As mesmas concentrações após $30 \mathrm{~min}$; CConcentrações após a filtração $(0,45 \mu \mathrm{m})$; Condução do teste com cinzas não-filtradas.
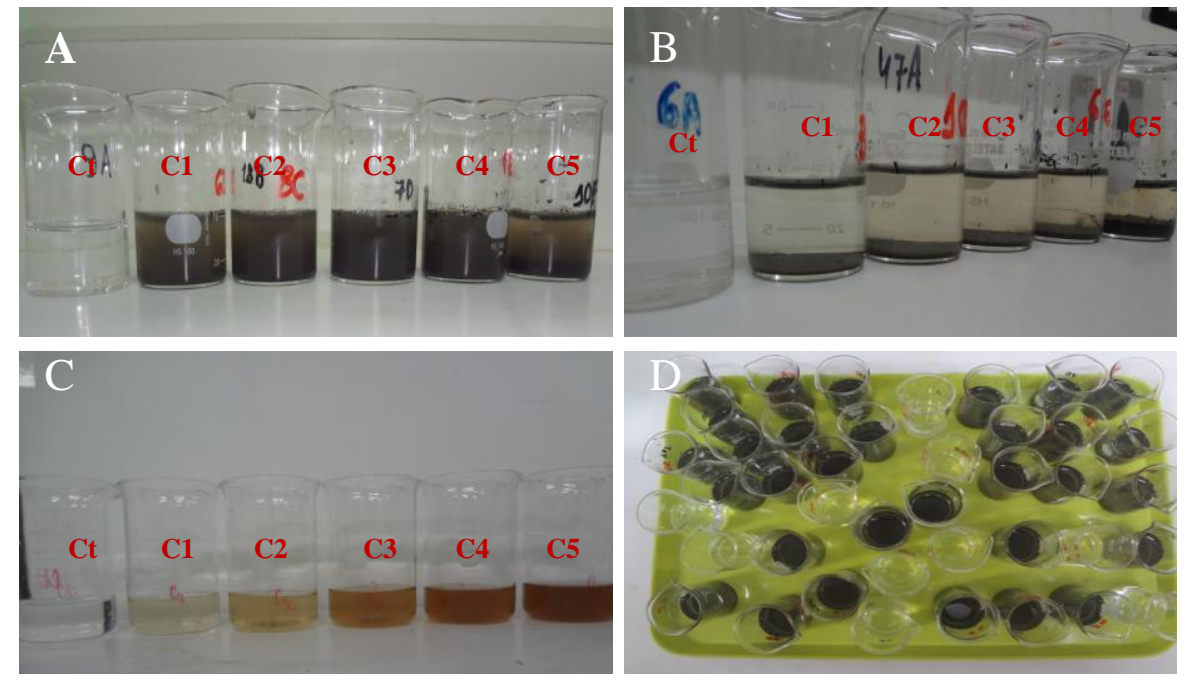

A concentração letal para imobilização de $50 \%$ da população $\left(\mathrm{CL}_{50}\right)$ e seus respectivos intervalos com 50\% de confiança, foram determinados pelo programa Trimmed Spearman Karber (HAMILTON et al., 1977). Os organismos utilizados nos ensaios foram indivíduos jovens com idade $\leq 24$ horas e provenientes de cultivos mantidos no próprio laboratório.

Com a amostra de cinzas da Lagoa Bonita, foram realizados dois ensaios com $C$. dubia nas seguintes condições:

1. Cinzas agitadas em $\mathrm{H}_{2} \mathrm{O}$ mole sintética por 96 horas e filtrada em $0,45 \mu \mathrm{m}$;

2. Cinzas agitadas em $\mathrm{H}_{2} \mathrm{O}$ mole sintética por 30 dias e filtrada em $0,45 \mu \mathrm{m}$;

Ressalta-se que inicialmente os ensaios com C. dubia foram realizados com amostras filtradas em virtude das cinzas na água manterem alto teor de sólidos suspensos, o que poderia levar a atritos físicos com o organismo. Ressalta-se também que os níveis de oxigênio embora caiam rapidamente e possam ter influência na mortalidade dos organismos, esse parâmetro foi minimizado pelas diluições realizadas. 


\subsubsection{Ensaio de mortalidade do Peixe Danio rerio}

Com o objetivo de determinar o potencial tóxico para organismos do nécton, foram realizados ensaios para avaliar a toxicidade das cinzas sobre peixes da espécie Danio rerio. Os peixes $D$. rerio foram adquiridos de fornecedor comercial.

Figura 14 - Testes de exposição do D. rerio. A- Peixe D. rerio em aquário no laboratório para ambientação; B- Condução do teste com cinzas não-filtradas com aeração. C- Detalhe do teste após algumas horas de exposição. D- Decantação das cinzas no término do teste.
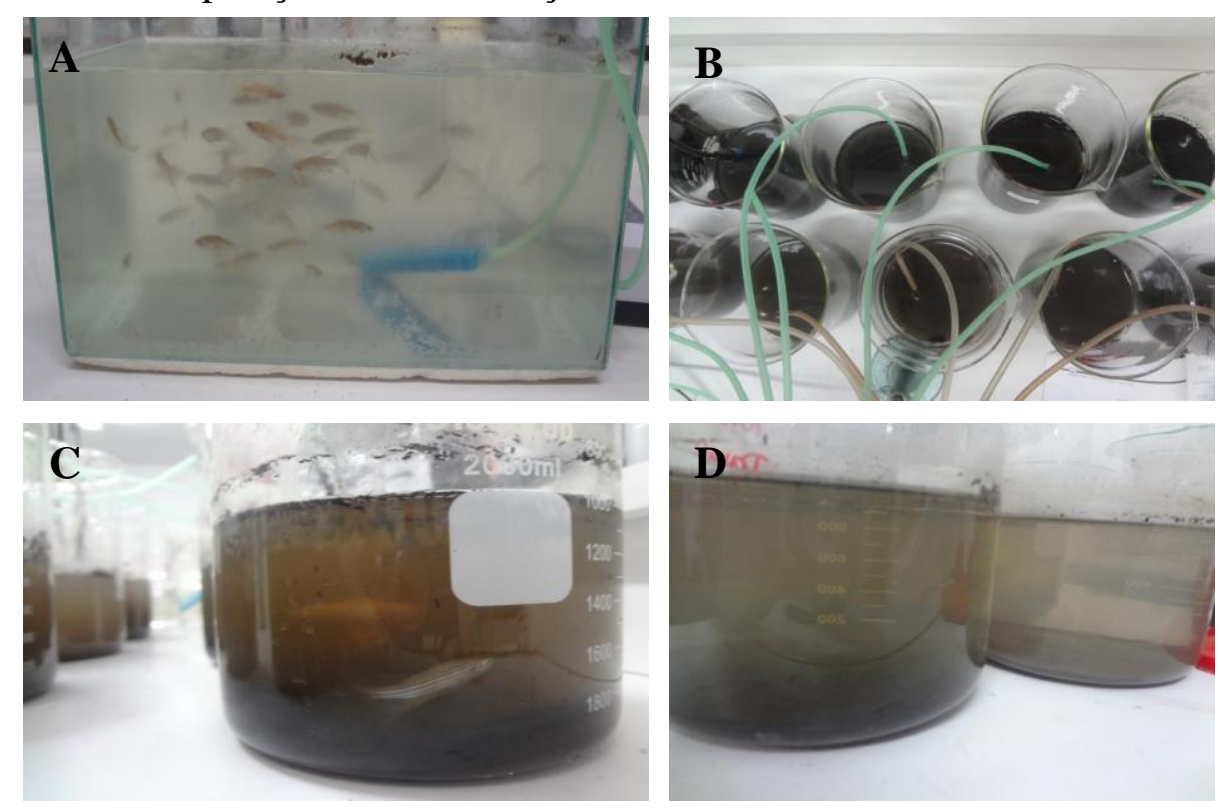

O procedimento do ensaio seguiu o previsto na norma NBR 15088 (ABNT, 2004), consistindo na exposição dos indivíduos adultos ao material testado em um periodo de até 96 horas, com quantificação diária da mortalidade. As concentrações letais de todas as cinzas testadas, para 50\% dos indivíduos, foram determinadas pelo programa Trimmed Spearman Karber (HAMILTON et al., 1977).

Os ensaios desenvolvidos com peixes foram aprovados pela Comissão de Ética em Uso de Animais do UniCEUB - CEUA/UniCEUB, sob o parecer número 013/13 de $18 / 11 / 2013$.

\subsubsection{Ensaio de mortalidade do Molusco gastrópode Biomphalaria glabrata}

Com o objetivo de determinar o potencial tóxico para organismos bentônicos, foram realizados ensaios agudos (mortalidade) para avaliar os efeitos adversos das cinzas sobre 
caramujos da espécie Biomphalaria glabrata. Esses caramujos são cultivados no Laboratório de Ecotoxicologia da Embrapa Cerrados e os procedimentos de ensaio seguiram os modelos já padronizados no laboratório (OLIVEIRA-FILHO et al., 2009b).

Figura 15 - Teste de exposição das cinzas de Lagoa Bonita ao molusco B. glabrata.
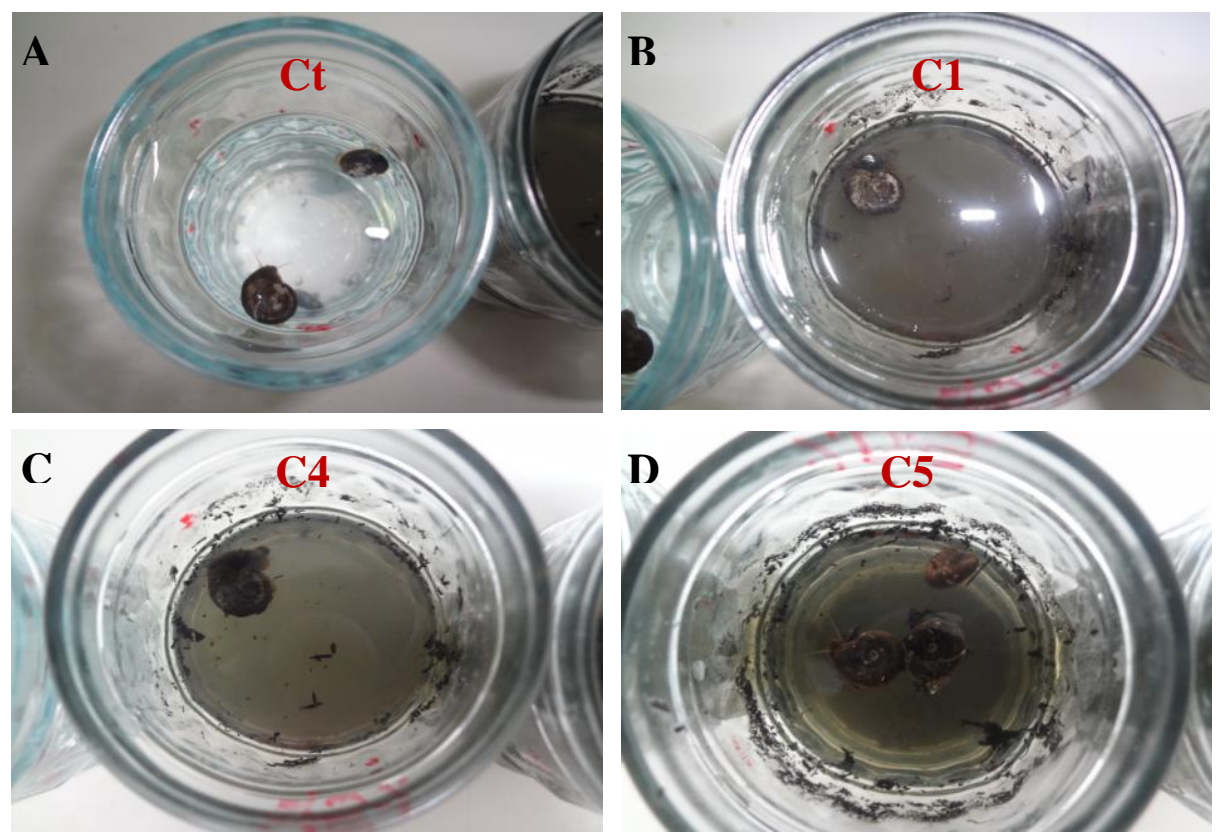

O ensaio agudo consiste na exposição dos organismos ao material testado, por período de até 96 horas, com quantificação diária da mortalidade. As concentrações letais foram determinadas pelo programa Trimmed Spearman Karber (HAMILTON et al., 1977).

\subsubsection{Análise estatística}

\subsubsection{Análise Multivariada - Análise das Componentes Principais (PCA)}

Os resultados das análises químicas foram tabulados em Excel e, a partir destes, foi organizada a matriz de dados para a análise das componentes principais (PCA). Os dados foram logaritimizados a fim de normalizar as distribuições e homogeneizar as variâncias A técnica de análise das componentes principais (PCA) tem sido bastante utilizada no monitoramento ambiental, especialmente no que se refere à qualidade da água em áreas sob uso e ocupação (BERNARDI et al., 2001; ZIBORDI et al., 2006; BERNARDI et al., 2009).

A opção pelo uso da PCA decorre, sobretudo, desse método possibilitar uma ordenação das variáveis, em um número pequeno, indicando as variáveis de maior importância em cada grupo, com a mínima perda dos dados originais (BERNARDI et al., 
2009). A PCA, utilizando-se o coeficiente $r$ de Pearson, foi aplicada para evidenciar possíveis associações entre os pontos de amostragem, com base nos parâmetros químicos das cinzas e do solo, com o pacote estatístico R versão 2.13.2 e do programa Statistica versão 10.0. Para efeitos de avaliação, foram considerados os autovalores maiores que 0,7.

Para o cálculo da $\mathrm{CL}_{50}$ nos testes de toxicidade Aguda (TA), (Concentração letal para $50 \%$ dos organismos) após $24 \mathrm{hs}$ e $48 \mathrm{hs}$ de exposição, foi utilizado o programa Trimmed Spearman Karber (HAMILTON et al., 1977). 


\section{CAPÍTULO I}

Efeitos das cinzas de Queimadas do Cerrado nas características físico-químicas do ambiente aquático 
Estudos preveem alterações nos regimes de fogo devido às mudanças no uso da terra e ao aquecimento global. Grandes extensões de áreas nativas e de pasto são queimadas anualmente no Brasil, especialmente no Bioma Cerrado. O mau uso da prática de queimadas durante os períodos de estiagem tem acarretado danos à diversidade dos ecossistemas. Com as chuvas após o período de estiagem, vários compostos químicos presentes nas cinzas entram nos sistemas aquáticos, podendo ocasionar efeitos adversos. No presente artigo, avaliam-se os atributos químicos das cinzas e do solo de quatro áreas distintas queimadas em setembro de 2010. Analisaram-se as alterações físico-químicas das cinzas na água, visando simular as escorrências em condições in-situ. Um vasto grupo de metais ( $\mathrm{Al}, \mathrm{B}, \mathrm{Ca}, \mathrm{Cd}, \mathrm{Cr}, \mathrm{Fe}, \mathrm{K}, \mathrm{Mg}$, $\mathrm{Mn}, \mathrm{Mo}, \mathrm{Ni}, \mathrm{P}, \mathrm{Pb}, \mathrm{S}, \mathrm{Si}, \mathrm{Sr}, \mathrm{V}$, Ti e $\mathrm{Zn}$ ) foram quantificados no solo, nas cinzas e na solubilização das cinzas. A comparação química das quatro áreas apresentou pouca diferença qualitativa, no entanto a quantidade dos elementos foi o aspecto de maior relevância. Apesar da composição química das cinzas possuir valores superiores à composição química do solo para alguns elementos (B, Ca, K, Mg, Mn, P, S, Si, Sr e Zn), apenas uma pequena parcela desses compostos foi solubilizada. Os íons solubilizados aumentaram sólidos solúveis totais, enquanto a condutividade elétrica e o pH diminuíram o OD na água, alterando a qualidade da água. Os resultados mostram que os ambientes lênticos são mais sensíveis aos efeitos das cinzas das queimadas em comparação aos ambientes lóticos, além de demonstrarem os efeitos do fogo nos corpos aquáticos, dada a sua elevada relevância no Bioma Cerrado.

Palavras-chave: Cerrados, Queimadas, Cinzas, recursos hídricos, atributos químicos.

Effects of ashes from tropical savanna fires on the physicochemical characteristics of the water

\section{Abstract}


Several studies predict alterations on fire regimes due the land use transformations and climate changes. Large extensions of native areas and pasture are burned in Brazil every year, especially in the Cerrado biome. The inadequate practices of burning during drought periods have caused intense fires, which bring several damages to biodiversity and ecosystem balance. With the occurrence of rains after the dry season, different chemical compounds from ashes come into contact with the aquatic systems, and cause adverse effects to these ecosystems. In this context, this paper brings an evaluation of chemical properties of ashes and soils from four distinct areas burned in September 2010. We analyzed the physical and chemical alterations promoted by ashes in the water, aiming to simulate runoff under conditions in situ. A large group of metals (Al, B, Ca, Cd, Cr, Fe, K, Mg, Mn, Mo, Ni, P, Pb, $\mathrm{S}, \mathrm{Si}, \mathrm{Sr}, \mathrm{V}, \mathrm{Ti}$ and $\mathrm{Zn}$ ) were quantified in soil, in the ashes and in the ash solubilization. Despite the chemical comparison of four areas showed little qualitative difference, the amount of chemical elements was more important. The ash composition showed higher values in relation to the soil samples ( $\mathrm{B}, \mathrm{Ca}, \mathrm{K}, \mathrm{Mg}, \mathrm{Mn}, \mathrm{P}, \mathrm{S}, \mathrm{Si}, \mathrm{Sr}, \mathrm{Zn}$ ). However, only a small quantity of these compounds was solubilized. The solubilized ions increased the total soluble solids, electrical conductivity, $\mathrm{pH}$ and decreased the oxygen dissolved concentrations in the water, altering the water quality. The results showed that lentic aquatic systems are more sensible to the effects of ashes in comparison to the lotic systems in short periods. In addition, our data demonstrate the importance of understanding the effects of fire on water bodies due to its high relevance in the Cerrado ecosystem.

Keywords: Cerrado, Fires, ash, water, chemical attributes. 


\section{Introdução}

O fogo é considerado um decompositor natural por muitos estudiosos (MEIRELLES, 1990; COUTINHO, 1990; SATO, 2003; MIRANDA et al., 2002; BOND et al., 2005). No entanto, o grande problema nesse processo de "decomposição", seria a rápida liberação de nutrientes em quantidades superiores à capacidade de assimilação pelas plantas, ocasionando perdas de nutrientes por erosão, lixiviação ou percolação.

Estudos sobre os incêndios florestais têm demonstrado que a liberação de bases durante a combustão dos resíduos vegetais promove o aumento do pH do solo (SANTOS et al., 1992; LARANJEIRA e LEITÃO, 2008; MARCOLAN et al., 2009). No momento em que a matéria orgânica é queimada, os compostos são liberados em forma de óxidos solúveis de bases que são depositados como cinzas na superfície do solo. Estas cinzas transformam-se em carbonatos capazes de neutralizar a acidez do solo (LARANJEIRA e LEITÃO, 2008). Dessa forma, o fogo acelera a mineralização da matéria orgânica do solo, viabilizando processos em curto período que demandariam meses em condições naturais (FREITAS e SANT'ANNA, 2004).

Embora as principais fontes de emissões de gases de efeito estufa (GEEs) no Brasil têm-se alterado profundamente nos últimos dez anos, devido ao combate ao desmatamento e ao uso de novas tecnologias na agropecuária (LAPOLA, 2014), contudo o uso do fogo tem sido uma característica na agropecuária no Brasil (KLINK e MACHADO, 2005; IBAMA, 2011; INPE, 2012).

As queimadas decorrem, sobretudo, do uso do fogo no meio rural como forma de manejo e do mau uso dessa prática (SAMPAIO et al., 2008; IBAMA, 2011).

No bioma Cerrado, as queimadas coincidem com o período de estiagem e se a prática não possuir procedimentos técnicos adequados, o fogo ocasiona sérios riscos ambientais, inclusive com danos à saúde da população humana (KAUFMAN et al., 1998; ARBEX et al. 2000).

O Cerrado possui uma vegetação rasteira, constituída por gramíneas, que coexiste com árvores e arbustos esparsos (KLINK e MOREIRA, 2002; MENDONÇA et al., 1998). O bioma é classificado como sendo savana tropical úmida com duas estações bem definidas 
(RIBEIRO e WALTER, 2008). Na estação seca, grande parte da biomassa aérea das gramíneas morre, favorecendo a ocorrência de incêndios (MIRANDA e SATO, 2005).

As áreas remanescentes de Cerrado desenvolveram-se sobre solos antigos, bastante intemperizados, ácidos e desprovidos de grande quantidade de nutrientes em comparação aos demais biomas tropicais. Os solos apresentam elevada concentração de alumínio e nas folhas de muitos arbustos e árvores nativas (GOODLAND, 1971; HARIDASAN, 1982; RIBEIRO e WALTER, 2008).

Após a ocorrência de uma queimada, as cinzas e os materiais particulados podem ser transportados no período das chuvas para rios e/ou águas subterrâneas e causar impactos em comunidades aquáticas (MINSHALL et al., 2001; SCRIMGEOUR et al., 2001).

Poucos estudos têm investigado os impactos decorrentes das queimadas sobre os recursos hídricos nos trópicos. Estudos realizados em regiões temperadas permitiram a obtenção dos efeitos dos incêndios florestais sobre os recursos hídricos, no entanto eles não podem ser extrapoláveis para outros ecossistemas, considerando as diferenças da vegetação e da suscetibilidade das comunidades aquáticas.

A região do Cerrado é considerado o "berço das águas", pois abriga as nascentes das três maiores bacias hidrográficas sul americanas (KLINK, 1996; SILVA e BATES, 2002; FELFILI e SILVA JÚNIOR, 2005).

O presente artigo tem como objetivo caracterizar a composição química das cinzas de áreas de queimadas de Cerrado nativo e de cinzas de uma área de pasto, além de identificar os efeitos de cinzas sobre os parâmetros físico-químicos na qualidade da água.

\section{Materiais e Métodos}

\section{1 Área de Estudo e coleta das amostras}

As três áreas amostradas estão situadas no Distrito Federal e foram queimadas no segundo semestre do ano 2010. As áreas foram selecionadas em função do tipo de fitofisionomia presente no Cerrado e identificadas como: 1-Torre, por estar localizada próxima Torre de TV Digital do Distrito Federal. Trata-se de uma área com vegetação nativa, identificada como área de Cerrado Típico (S15²42'44,0" e W 047²4'29,8");2 - Pasto, área experimental de consórcio de forrageiras da Embrapa Cerrados e de criação de pasto, foi identificada como uma área de pastagem (S 15³6'40,8" e W 047²1'52,1"); 3 - Lagoa Bonita, 
localizada no interior da Estação Ecológica de Águas Emendadas (ESECAE), é considerada uma área de transição de vereda para campo savana (S 15³5'29,9” e W 04741'48,8”).

\subsection{Amostragem}

As cinzas foram coletadas imediatamente após a ocorrência das queimadas no período de estiagem, de forma a contemplar uma maior diversidade espacial da área. Como as cinzas não se encontram distribuídas de modo homogêneo na área, foram selecionados os locais onde havia maior depósito de cinzas. As cinzas obtidas foram transportadas ao laboratório e peneiradas em malha com dimensão de $1 \mathrm{~mm}$, visando a obtenção da cinza propriamente dita e a eliminação de resíduos de carvão.

Após as coletas de cinzas, foram coletadas as amostras de solo nos primeiros $10 \mathrm{~cm}$ de profundidade.

\subsection{Análises químicas}

A composição química das cinzas coletadas foi definida por meio de extração ácida e determinação dos teores de metais e metais alcalinos terrosos por espectrometria de emissão atômica (ICP-AES). A análise química do solo foi realizada por meio de extração ácida em água régia ( $\mathrm{HCL}: \mathrm{HNO}_{3} 3: 1$ ).

Foram utilizados padrões na faixa de 0,5 a $40 \mathrm{mg} . \mathrm{L}^{-1}$ para os 19 elementos analisados, feitos a partir de soluções certificadas Merck (1000 mg/L). Os limites de detecção para cada elemento foi de $0,001 \mathrm{mg} \cdot \mathrm{L}^{-1}$.

A solubilização de elementos químicos foi avaliada nas cinzas após $24 \mathrm{hs}$ de agitação em água ultrapura. Para avaliar o potencial de solubilização em função do tempo de agitação, amostras de uma área foram mantidas em agitação por 30 dias, com leituras aos 4, 10, 15 e 30 dias para avaliação das concentrações de cátions (lítio, sódio, potássio, cálcio e magnésio) e ânions (fluoreto, cloreto, nitrito, brometo, fosfato, sulfato) por meio do cromatógrafo (modelo 761 Compact IC marca Metrohm). Nesse caso, as cinzas foram mantidas em agitação por 30 dias em água mole sintética ( $\mathrm{pH}$ 7,2 $\pm 0,2$ e dureza $43 \mathrm{mg} \cdot \mathrm{L}^{-1} \mathrm{em} \mathrm{CaCO}_{3}$, ou seja, a mesma água utilizada nos ensaios de toxicidade) (ABNT, 2004b). Para a análise das soluções na CI foram utilizados padrões na faixa de 0,02 a $50 \mathrm{mg} \cdot \mathrm{L}^{-1}$ feitos a partir de soluções certificadas Merck (1000 mg.L $\left.\mathrm{L}^{-1}\right)$. As faixas utilizadas os limites de detecção para cada ânion foi de 0,001 
mg. $L^{-1}$. Essas análises foram realizadas no Laboratório de Química de Água da Embrapa Cerrados.

\subsection{Análises físico-químicas}

Para verificar as alterações físico-químicas na água, foi conduzido um estudo das interações entre as cinzas das três áreas e a água. As cinzas coletadas foram diluídas em duas amostras com concentração de 100 g. $\mathrm{L}^{-1}$, usando água mole - dureza $40 \mathrm{mg} \cdot \mathrm{L}^{-1} \mathrm{em} \mathrm{CaCO}_{3}$ (ABNT, 2004b).

Para avaliar a solubilização das cinzas em meio aquoso, foram realizados dois experimentos com as cinzas de Lagoa Bonita: 1A - As amostras de cinzas foram agitadas por 24hs em água ultrapura e determinadas as concentrações dos elementos presentes; 1B - As amostras de cinzas foram agitadas em função do período de tempo de agitação (4, 10 ,15 e 30 dias) a fim de verificar com maior precisão o tempo máximo necessário para uma maior disponibilidade desses elementos.

Com o objetivo de simular o comportamento dos parâmetros físicos em ambientes lóticos e lênticos, foram conduzidos os seguintes testes durante 15 dias, mantidos em estufa incubadora a $20^{\circ} \mathrm{C}$ com ausência de iluminação: $2 \mathrm{~A}$ - As cinzas em meio aquoso com agitação contínua e 2B - As cinzas em meio aquoso sem agitação.

Visando analisar as diluições de cinzas na influência dos parâmetros físico-químicos, foram realizadas concentrações de 10, 25 e $50 \%$ em água mole sintética, mantidas sem agitação a uma temperatura de $20^{\circ} \mathrm{C}$.

Os parâmetros de temperatura, oxigênio dissolvido (OD), $\mathrm{pH}$, condutividade elétrica (CE) e sólidos totais dissolvidos (STD) foram aferidos na água mole sintética antes da adição das cinzas. Para a leitura do OD, foi utilizado um oxímetro de bancada Orion 3-Star Thermo, e para a medição de temperatura, $\mathrm{pH}$, condutividade e STD utilizou-se o medidor multiparâmetro SensION 156, da marca Hach.

As análises foram realizadas no Laboratório de Química de Solos, no Laboratório de Química Analítica de Plantas e no Laboratório de Química de Água da Embrapa Cerrados. 


\subsection{Análise estatística}

Os resultados analíticos foram tabulados em Excel e, a partir destes, foi organizada a matriz de dados para a análise das componentes principais (PCA). A técnica de análise das componentes principais (PCA) tem sido bastante utilizada no monitoramento ambiental, especialmente no que se refere à qualidade da água em áreas sob uso e ocupação (BERNARDI et al., 2001; ZIBORDI et al., 2006; SILVA et al., 2008; BERNARDI et al., 2009).

A PCA, utilizando-se o coeficiente $r$ de Pearson, foi aplicada para evidenciar possíveis associações entre os pontos de amostragem com base nos parâmetros químicos das cinzas e do solo com o pacote estatístico R versão 2.13 .2 e do programa Statistica versão 10.0. Para efeitos de avaliação, foram considerados os autovalores maiores que 0,7.

\section{Resultados}

\subsection{A química das cinzas e do solo}

A determinação da composição química das cinzas mostra uma grande diversidade de elementos em quantidades significativas nas quatro áreas amostradas (Figuras 1 e 2).

Figura 1 - Caracterização química das cinzas de queimadas provenientes das quatro áreas estudadas. Elementos presentes em maior quantidade. Valores expressos em ppm.

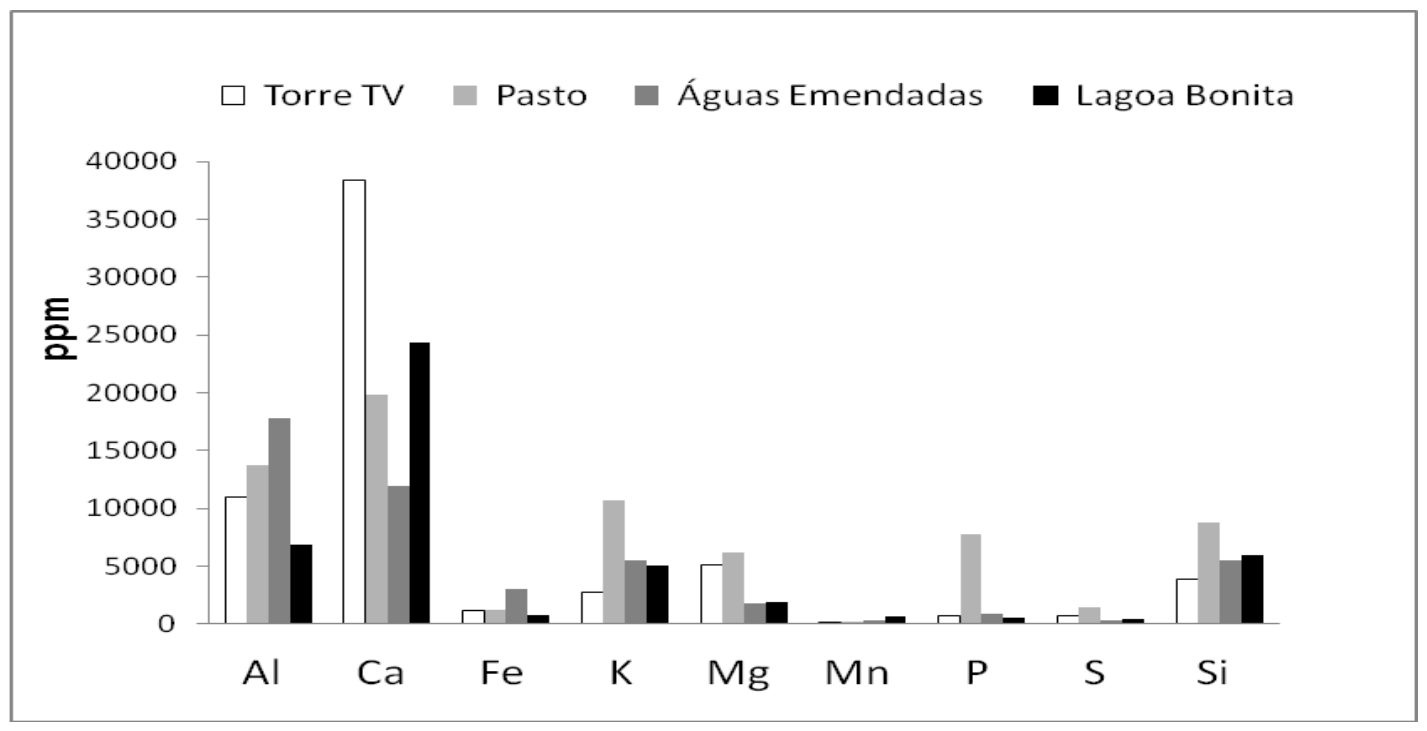


Figura 2 - Caracterização química das cinzas de queimadas provenientes das áreas estudadas. Elementos presentes em menor quantidade. Valores expressos em ppm.

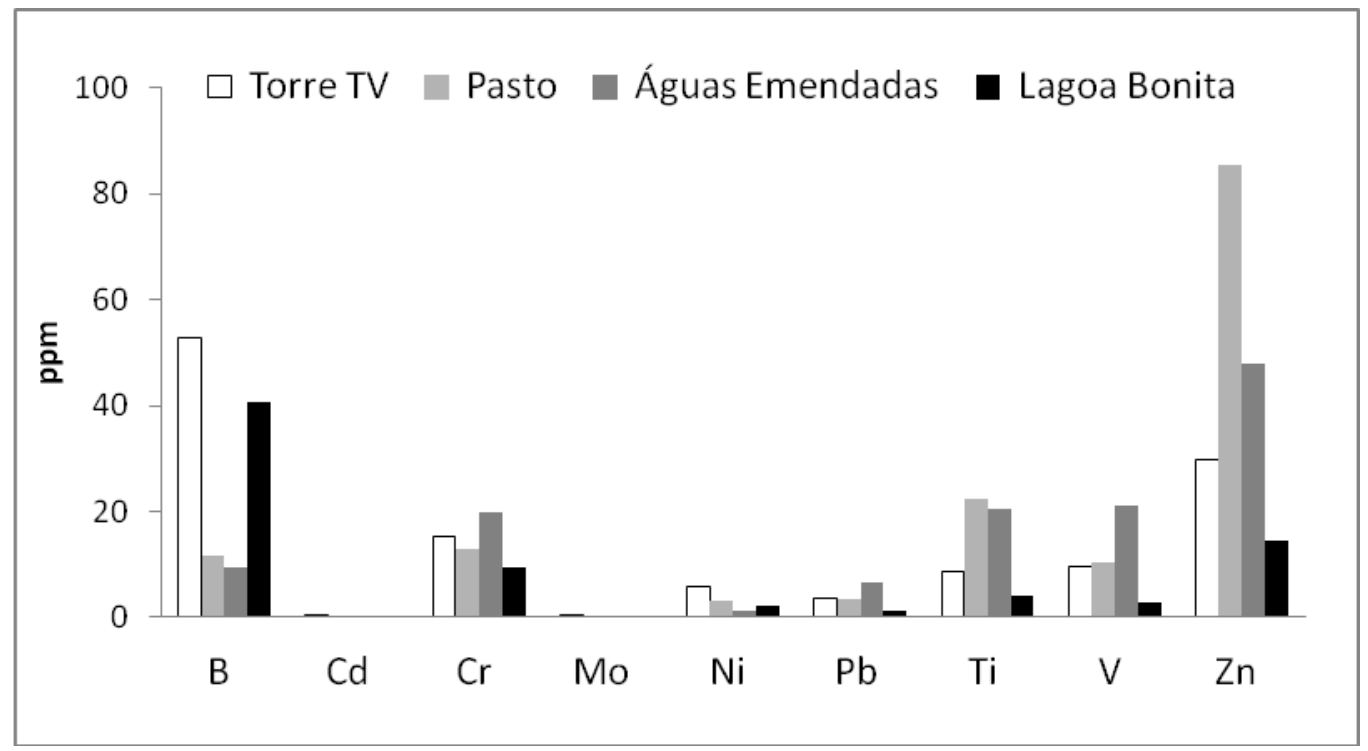

Os resultados mostram uma presença maior dos elementos mais solúveis e que, dessa forma, podem comprometer os ambientes aquáticos. As cinzas da área de Pasto apresenta os maiores teores de $\mathrm{K}, \mathrm{Mg}, \mathrm{P}, \mathrm{Si}$ e $\mathrm{Zn}$ (Figuras 1 e 2), justamente os elementos mais empregados na fertilização antrópica de solos. Por outro lado, as cinzas das áreas consideradas como naturais e nativas da região apresentaram significativa presença dos elementos presentes no solo do Cerrado, tais como Al, Ca e B.

Ao comparar-se a química das cinzas com a química dos solos, observa-se que os elementos essenciais, bem como os micronutrientes se apresentam em quantidades bem maiores nas cinzas do que no solo, como os elementos Ca, K, Mg, P, Si e Zn (Tabela 1). Por outro lado, os micronutrientes ou elementos que não fazem parte da nutrição normal das plantas (e.g., Al, $\mathrm{Cd}, \mathrm{Cr}, \mathrm{Fe}, \mathrm{Mo}, \mathrm{Pb}, \mathrm{Ti}$ e $\mathrm{V}$ ) se encontram em quantidade maior no solo do que nas cinzas. Há, ainda, o caso do $\mathrm{Ni}$, detectado nas cinzas de todas as áreas amostradas, mas não detectado nos solos das áreas (Tabela 1).

\subsection{Solubilização das Cinzas}

Os dados obtidos mostram que após $24 \mathrm{hs}$ de agitação das cinzas já estão disponibilizadas na água concentrações de vários elementos, principalmente de $\mathrm{K}$, que pode ser considerado tóxico a nível crônico para algumas espécies aquáticas. 
Os níveis mais elevados de metal em cinzas foram os de $\mathrm{Ca}, \mathrm{Al}, \mathrm{Si}, \mathrm{Mg}, \mathrm{K}$ e P (Tabela 1). Na solubilização, as maiores concentrações obtidas foram de $\mathrm{Ca}, \mathrm{S}, \mathrm{Mg}$ e $\mathrm{K}$. Ao se comparar elementos metálicos analisados nas duas matrizes, a redução para níveis baixos e não detectados na solução pode ser notado (Tabela 1).

A simples relação da concentração do metal disponivel na solução com a quantidade encontrada nas cinzas revelou que o K e o S apresentaram a recuperação mais elevada entre os metais (Tabela 2). Apesar do Mo possuir alta taxa de solubilização, constata-se que os valores absolutos desse elemento são relativamente pequenos tanto nas cinzas quanto nos solos. 
Tabela 1 - Composição química das cinzas de queimadas, do solo da solubilização em água ultra-pura após 24hs de agitação das quatro áreas amostras $\left(\mathrm{mg} . \mathrm{L}^{-1}\right)$.

\begin{tabular}{|c|c|c|c|c|c|c|c|c|c|c|c|c|}
\hline \multicolumn{4}{|c|}{ Torre } & \multicolumn{2}{|c|}{ Pasto } & \multicolumn{4}{|c|}{ Lagoa Bonita } & \multicolumn{2}{|c|}{ Águas Emendadas } & \multirow[b]{2}{*}{ Solução } \\
\hline Metais & Cinzas & Solo & Solução & Cinzas & Solo & Solução & Cinzas & Solo & Solução & Cinzas & Solo & \\
\hline Al & 10959,3 & 69602,0 & 0,266 & 13712,4 & 57506,7 & 1,636 & 17811,3 & 77180,0 & 0,272 & 6904,6 & 54750,0 & 3,382 \\
\hline B & 52,9 & 2,4 & 0,760 & 11,5 & 1,4 & 0,125 & 9,3 & 2,5 & 0,983 & 40,7 & 1,7 & 0,222 \\
\hline $\mathbf{C a}$ & 38401,0 & 2189,8 & 51,46 & 19820,0 & 929,9 & 32,60 & 11895,0 & 2592,5 & 45,61 & 24373,0 & 995,5 & 38,01 \\
\hline Cd & 0,1 & 7,3 & ** & 0,2 & 7,3 & ** & 0,3 & 4,1 & ** & 0,1 & 7,1 & ** \\
\hline $\mathrm{Cr}$ & 15,2 & 270,2 & 0,027 & 12,8 & 244,5 & 0,003 & 19,9 & 164,5 & 0,014 & 9,5 & 268,8 & 0,013 \\
\hline $\mathbf{F e}$ & 1191,5 & 61146,0 & ** & 1251,1 & 60933,3 & ** & 2996,8 & 33300,0 & ** & 732,6 & 47530,0 & 0,0811 \\
\hline $\mathbf{K}$ & 2697,8 & 410,4 & 521,5 & 10647,0 & 343,2 & 643,2 & 5538,0 & 660,0 & 292,0 & 5054,0 & 417,0 & 359,5 \\
\hline Mg & 5149,6 & 406,5 & 50,15 & 6173,7 & 409,1 & 42,23 & 1729,3 & 927,0 & 10,43 & 1880,6 & 225,1 & 21,16 \\
\hline Mn & 139,5 & 72,3 & 0,008 & 250,0 & 45,8 & 0,008 & 317,4 & 110,0 & 0,100 & 692,7 & 154,6 & 0,041 \\
\hline Mo & 0,1 & 5,9 & 0,024 & 0,3 & 3,4 & 0,061 & 0,0 & 0,5 & 0,007 & 0,0 & 2,3 & 0,034 \\
\hline $\mathbf{P}$ & 672,4 & 249,0 & 0,468 & 7722,0 & 271,1 & 2,896 & 917,3 & 380,0 & 0,602 & 501,6 & 208,5 & 2,737 \\
\hline $\mathbf{P b}$ & 3,5 & 15,8 & ** & 3,4 & 17,1 & $* *$ & 6,6 & 16,2 & ** & 1,3 & 15,1 & ** \\
\hline $\mathbf{S}$ & 714,2 & 239,2 & 186,0 & 1450,0 & 161,2 & 111,4 & 279,6 & 164,8 & 43,95 & 440,8 & 170,3 & 46,66 \\
\hline $\mathbf{S i}$ & 3820,4 & 687,7 & 2,550 & 8724,3 & 581,1 & 36,42 & 5506,8 & 451,8 & 78,28 & 5973,6 & 463,6 & 39,42 \\
\hline $\mathrm{Sr}$ & 293,4 & 2,0 & 0,276 & 127,7 & ** & 0,166 & 64,9 & 10,4 & 0,193 & 88,5 & $* *$ & 0,185 \\
\hline $\mathbf{T i}$ & 8,5 & 417,2 & 0,009 & 22,4 & 517,9 & 0,012 & 20,6 & 288,4 & 0,011 & 4,0 & 421,8 & 0,032 \\
\hline V & 9,6 & 160,4 & 0,024 & 10,3 & 126,3 & 0,107 & 21,0 & 107,2 & 0,032 & 2,7 & 156,2 & 0,038 \\
\hline $\mathrm{Zn}$ & 29,9 & 17,9 & 0,023 & 85,5 & 18,2 & 0,001 & 47,8 & 25,8 & 0,009 & 14,4 & 25,8 & 0,019 \\
\hline $\mathbf{N i}$ & 5,7 & $* *$ & 0,014 & 3,0 & ** & $* *$ & 1,3 & $* *$ & ** & 2,3 & ** & ** \\
\hline
\end{tabular}

\footnotetext{
** Abaixo do limite de detecção
} 
Tabela 2 - Taxa de solubilização obtida pela razão entre a quantidade de metais disponíveis na solução pela quantidade de elementos encontrados nas cinzas, e cargas das componentes principais indicando as percentagens de explicação da variabilidade das variáveis químicas nas áreas amostradas.

Taxa de Solubilização (\%)

\begin{tabular}{|c|c|c|c|c|c|c|}
\hline Metais & $\begin{array}{l}\text { PC } 1 \\
(80.2 \%)\end{array}$ & $\begin{array}{l}\text { PC } 2 \\
(5.9 \%)\end{array}$ & Torre & Pasto & $\begin{array}{l}\text { Lagoa } \\
\text { Bonita }\end{array}$ & $\begin{array}{c}\text { Águas } \\
\text { Emendadas }\end{array}$ \\
\hline Al & 0.98 & 0.13 & $\ldots .$. & 0.01 & $\ldots . .$. & 0.05 \\
\hline B & 0.98 & 0.11 & 1.44 & 1.09 & 10.57 & 0.55 \\
\hline $\mathrm{Ca}$ & 0.97 & 0.09 & 0.13 & 0.16 & 0.38 & 0.16 \\
\hline $\mathrm{Cd}$ & 0.96 & 0.23 & $\ldots .$. & $\ldots .$. & $\ldots .$. & $\ldots .$. \\
\hline $\mathrm{Cr}$ & 0.95 & 0.20 & 0.18 & 0.02 & 0.07 & 0.14 \\
\hline $\mathrm{Fe}$ & 0.94 & 0.23 & $\ldots .$. & $\ldots .$. & $\ldots .$. & 0.01 \\
\hline K & 0.91 & 0.22 & 19.33 & 6.04 & 5.27 & 7.11 \\
\hline $\mathrm{Mg}$ & 0.74 & 0.13 & 0.97 & 0.68 & 0.60 & 1.13 \\
\hline$M n$ & -0.53 & -0.09 & 0.01 & 0.00 & 0.03 & 0.01 \\
\hline Mo & -0.60 & 0.69 & 24.00 & 20.33 & $\ldots .$. & $\ldots .$. \\
\hline $\mathbf{P}$ & -0.83 & 0.42 & 0.07 & 0.04 & 0.07 & 0.55 \\
\hline $\mathrm{Pb}$ & -0.89 & 0.24 & $\ldots .$. & $\ldots .$. & $\ldots .$. & $\ldots .$. \\
\hline$S$ & -0.92 & 0.24 & 26.04 & 7.68 & 15.72 & 10.59 \\
\hline Si & -0.93 & -0.16 & 0.07 & 0.42 & 1.42 & 0.66 \\
\hline Sr & -0.94 & 0.10 & 0.09 & 0.13 & 0.30 & 0.21 \\
\hline $\mathrm{Ti}$ & -0.95 & 0.00 & 0.11 & 0.05 & 0.05 & 0.80 \\
\hline $\mathbf{v}$ & -0.96 & 0.11 & 0.25 & 1.04 & 0.15 & 1.41 \\
\hline $\mathrm{Zn}$ & -0.96 & 0.04 & 0.08 & 0.00 & 0.02 & 0.13 \\
\hline $\mathbf{N i}$ & 0.98 & 0.13 & 0.25 & $\ldots .$. & $\ldots .$. & $\ldots .$. \\
\hline
\end{tabular}

Esses dados mostram que o tempo de agitação influenciou na diluição dos cátions e ânions com aumento considerável em relação às $24 \mathrm{hs}$ de agitação, principalmente para $\mathrm{K}^{+}$e $\mathrm{S}$ na forma de $\mathrm{SO}_{4}{ }^{2-}$ (aumento equivalente quatro vezes para $\mathrm{K}^{+}$e cerca de três vezes para $\mathrm{S}$ ) (Tabela 1). As leituras dos quatro tempos de agitação também mostram que o período de 10 a 15 dias foi considerado ideal para atingir os maiores valores de diluição, e que o $\mathrm{Ca}$ e o $\mathrm{Mg}$ tiveram concentrações reduzidas com o passar do tempo, possivelmente com perdas para o recipiente teste. 
Tabela 3 - Solubilização de cátions e ânions das cinzas da área da Lagoa Bonita em água mole sintética após 4, 10, 15 e 30 dias de agitação (mg.L $\left.\mathrm{L}^{-1}\right)$. (Média e Desvio Padrão).

\begin{tabular}{|c|c|c|c|c|}
\hline $\begin{array}{c}\begin{array}{c}\text { Tempo } \\
\text { (dias) }\end{array} \\
\end{array}$ & 4 & 10 & 15 & 30 \\
\hline $\mathrm{Li}$ & $\ldots$ & $\ldots$ & $\ldots$. & $\ldots$ \\
\hline \multirow{2}{*}{$\mathrm{Na}^{+}$} & 48.87 & 58.16 & 55.60 & 60.18 \\
\hline & (7.73) & (3.91) & (0.98) & (12.03) \\
\hline $\mathrm{NH}_{3}-\mathrm{N}$ & $\cdots$ & $\ldots$. & $\ldots$ & $\ldots$ \\
\hline \multirow{2}{*}{$\mathrm{K}^{+}$} & 1827.53 & 2030.77 & 2063.73 & 1934.03 \\
\hline & (194.49) & $(51.94)$ & $(7.44)$ & $(390.28)$ \\
\hline \multirow{2}{*}{$\mathrm{Ca}^{2+}$} & 119.19 & 105.07 & 131.14 & 10.72 \\
\hline & (77.69) & (16.23) & (20.01) & (8.99) \\
\hline \multirow{2}{*}{$\mathrm{Mg}^{2+}$} & 14.26 & 13.99 & 6.81 & 4.02 \\
\hline & (2.03) & (3.55) & $(2.50)$ & $(5.15)$ \\
\hline$F^{-}$ & $\ldots$ & $\ldots$ & $\ldots$ & $\ldots$. \\
\hline \multirow{2}{*}{$\mathrm{Cl}^{-}$} & 24.62 & 24.37 & 23.78 & 29.56 \\
\hline & $(0.97)$ & $(0.78)$ & $(0.66)$ & $(0.16)$ \\
\hline $\mathrm{NO}_{2-}-\mathrm{N}$ & $\ldots$ & $\ldots$ & $\ldots$ & $\ldots$ \\
\hline $\mathrm{Br}^{-}$ & $\ldots$ & $\ldots$ & $\ldots$ & $\ldots$ \\
\hline $\mathrm{NO}_{3}-\mathrm{N}$ & $\ldots$ & $\ldots$. & $\ldots$. & $\ldots$ \\
\hline \multirow{2}{*}{$\mathrm{PO}_{4}{ }^{3-}$} & 50.04 & 52.44 & 51.90 & 48.62 \\
\hline & $(0.01)$ & $(0.07)$ & (2.92) & $(0.43)$ \\
\hline \multirow{2}{*}{$\mathrm{SO}_{4}{ }^{2-}$} & 316.11 & 315.03 & 312.66 & 301.83 \\
\hline & (2.57) & $(4.10)$ & (6.15) & $(0.31)$ \\
\hline
\end{tabular}

As emissões biogênicas relacionadas à decomposição de matéria orgânica, tais como atividades agrícolas, a queima de biomassa e de combustíveis fósseis são as principais fontes emissoras de $\mathrm{NH}_{3} / \mathrm{NH}_{4}{ }^{+}$para a atmosfera (KRUPA, 2003). Um estudo sobre a transferência de macronutrientes para a atmosfera em uma vegetação de campo cerrado no estado de São Paulo constatou que, em média, $95 \%$ do $\mathrm{N}, 42-59 \%$ do $\mathrm{P}, \mathrm{K}, \mathrm{Ca}, \mathrm{Mg}$ e S, contidos na biomassa, são liberados para a atmosfera (PIVELLO e COUTINHO, 1992). Devido o N ser muito volátil, ele não foi encontrado na composição das cinzas (Tabela 3).

Sistemas aquáticos localizados quilômetros de distância de uma região produtora de cana-de-açúcar ou de grandes centros urbanos recebem nitrogênio ativo carreado pela água ou transportado na forma de gás pela atmosfera. Processo similar pode ocorrer em áreas de preservação, ocasionando sérios efeitos na biodiversidade desses ecossistemas (MACHADO et al. 2008). 
Embora não tenha sido detectada amônia nas amostras, dependendo do pH da água, a amônia pode apresentar-se nas formas ionizada $\left(\mathrm{NH}_{4}{ }^{+}\right)$e não-ionizada $\left(\mathrm{NH}_{3}\right)$, que é altamente tóxica para a biota aquática (ANGELIS, 2008). Deste modo, com a elevação do pH, tem-se condições para a concentracão de amônia não-ionizada e, consequentemente, a toxicidade sobre os organismos aquáticos. Este fato permite inferir o risco da alteracão do pH em águas com altas concentrações de amônia (WIECZOREK, 2003; CETESB, 2010).

Ao observar as diferenças entre a solubilidade de cátions e ânions nas amostras de cinzas testadas, verificou-se que as cinzas de Lagoa Bonita apresentaram a maior quantidade do cátion $\mathrm{K}$ e pequenas concentrações de $\mathrm{Mg}$ (Tabela 4).

Tabela 4 - Solubilização de cátions e ânions das cinzas das três áreas em água mole sintética após 4 dias de agitação $\left(\mathrm{mg} \cdot \mathrm{L}^{-1}\right)$.

\begin{tabular}{cccccc}
\hline Área & $\mathrm{Na}^{+}$ & $\mathrm{K}^{+}$ & $\mathrm{Ca}^{2+}$ & $\mathbf{M g}^{2+}$ & $\mathbf{S O}_{4}{ }^{2-}$ \\
\hline $\begin{array}{l}\text { Lagoa } \\
\text { Bonita }\end{array}$ & 48.87 & 1827.53 & 119.19 & 14.26 & 316.11 \\
Torre & 7.58 & 344.59 & 138.52 & 128.38 & 283.65 \\
Pasto & 263.01 & 754.02 & 121.41 & 28.71 & 414.23 \\
\hline
\end{tabular}

\subsection{Alterações Físico-Químicas na água}

Com relação às alterações físico-químicas na água com cinzas das três áreas de amostragem, foi constatado o aumento do $\mathrm{pH}$ nas primeiras $24 \mathrm{hs}$. $\mathrm{O} \mathrm{pH}$ que se manteve constante até $96 \mathrm{hs}$. As cinzas das três áreas testadas tiveram perfis de alterações de pH muito semelhantes (Figura 3).

Figura 3 - Alterações do pH e do Oxigênio Dissolvido (OD) na água com cinzas durante $96 \mathrm{hs}$ em agitação contínua. 


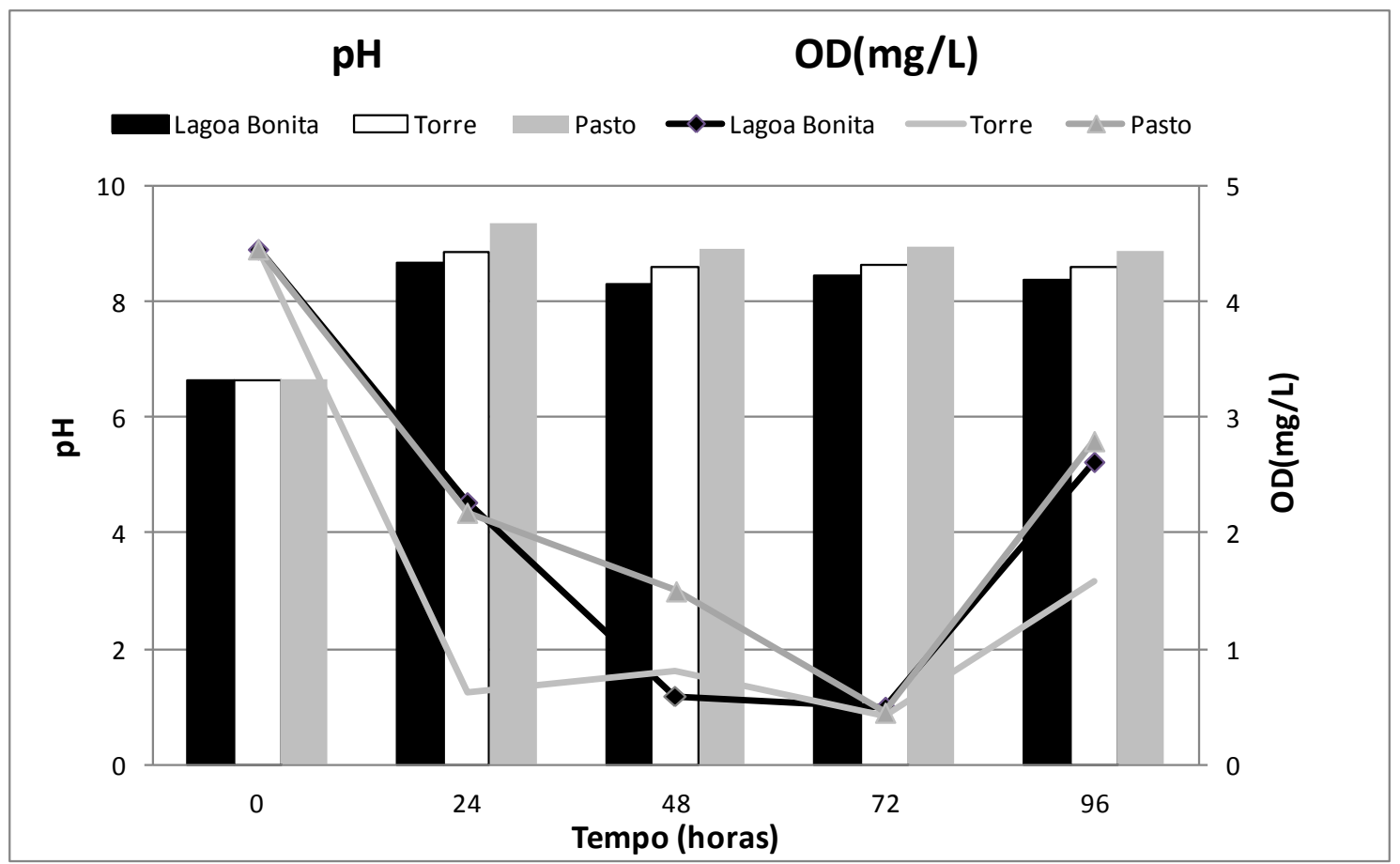

Com relação ao Oxigênio Dissolvido (OD) na água, observou-se uma redução semelhante nas primeiras $72 \mathrm{hs}$, com posterior aumento até $96 \mathrm{hs}$, não retornando ao patamar inicial.

A figura 4 apresenta simultaneamente as avaliações de sólidos totais dissolvidos (STD) e de condutividade elétrica (CE). A condutividade depende das concentracões iônicas e aumenta à medida que mais STD são adicionados. Altos valores podem indicar características corrosivas da água. Em geral, os níveis superiores a $100 \mu \mathrm{S} / \mathrm{cm}$ indicam ambientes impactados (CETESB, 2010).

Observa-se a semelhança entre as curvas dos dois parâmetros e os valores mais elevados para as diluições com cinzas das áreas Pasto e Torre, o que pode ser explicado pela maior concentração de sais dissolvidos nas cinzas dessas áreas. A amostra de Lagoa Bonita é a que apresenta menor quantidade de STD. 
Figura 4 - Comportamento dos parâmetros sólidos totais dissolvidos e condutividade elétrica durante 96hs de agitação das cinzas em água mole sintética.

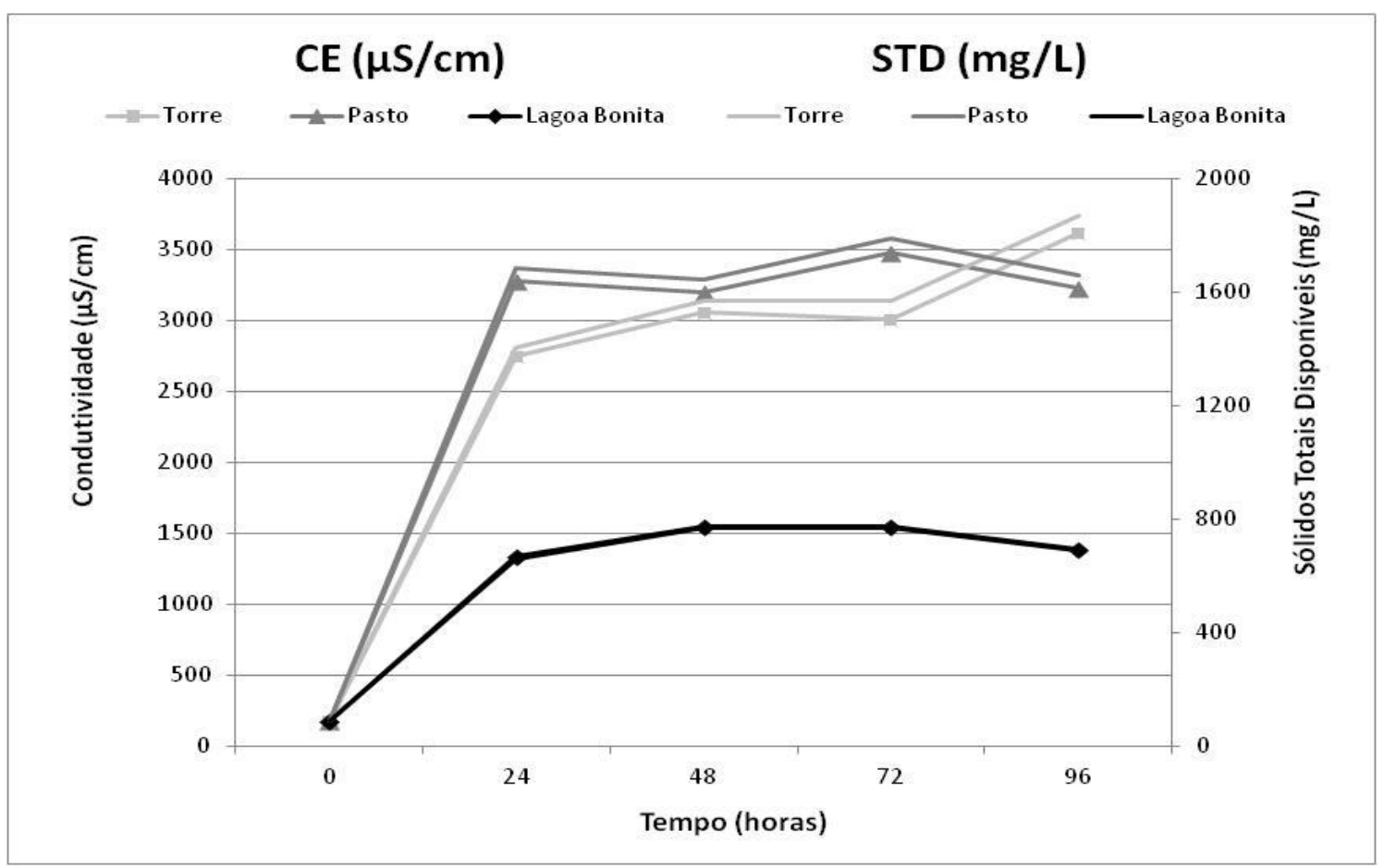

Em relação aos valores da $\mathrm{CE}$, a adição das cinzas na água indica tratar-se de águas muito mineralizadas com alto conteúdo de sais (Figura 4).

Com relação aos testes com agitação e sem agitação com as amostras de cinzas de Lagoa Bonita (Figura 5), ressalta-se que apesar dos ensaios terem ocorrido com uma amostra em agitação e outra sem agitação, o béquer contendo a solução sem agitação foi submetido a uma agitação de curto período de tempo para uniformizar a solução, ao passo que no mantido em agitação constante a mesma não foi interrompida.

Em relação ao $\mathrm{pH}$, observa-se na figura $5 \mathrm{~A}$ a tendência apresentada pela curva de $\mathrm{pH}$ observada no ensaio da primeira fase (Figura 3), mostrando apenas um aumento nos valores obtidos em ambas as situações, com e sem agitação. $\mathrm{O}$ aumento do $\mathrm{pH}$ pode ser explicado pelo alto teor de sais dissolvidos, conforme já demonstrado na tabela 1. Como observado na figura 3, é possível verificar a tendência para estabilização das curvas nas duas situações de exposição, o que nesse caso poderia representar uma situação de alcalinização da água em ambientes naturais (Figura 5A).

Com base na figura 5B, verifica-se que houve uma queda acentuada na quantidade de OD na amostra que permaneceu sem agitação. $\mathrm{Na}$ amostra com agitação. o valor inicial foi de 
6.54 para $2.42 \mathrm{mg} . \mathrm{L}^{-1}$ e na amostra sem agitação o OD foi de 6.54 para $0.02 \mathrm{mg} . \mathrm{L}^{-1}$. Após 48hs, o OD chegou a nível próximo a 0, mantendo-se constante durante os 15 dias de observação. No entanto, na amostra com agitação observa-se o decréscimo do OD em 1.5 dias e, posteriormente, um aumento próximo aos níveis iniciais em torno de 8 dias. Contudo, observa-se uma queda significativa de OD chegando a valores em torno de $2.5 \mathrm{mg} . \mathrm{L}^{-1}$, o que já deixa praticamente inviável a sobrevivência de várias espécies aquáticas.

Com relação ao monitoramento do efeito durante 15 dias, destaca-se o controle da temperatura como um parâmetro de grande influência na presença de OD na água. Os resultados mostram que após 24hs, houve um incremento no valor de $\mathrm{pH}$ (média de $28 \%$ para todas as diluições), apresentando leve decaimento no decorrer dos 15 dias (Figura 6A). Os valores máximos de $\mathrm{pH}$ foram estáveis entre as diluições, atingindo um máximo aproximado de 8.5 .

O OD exibiu um pequeno decréscimo após 24hs, contudo ao final do período de 15 dias os valores encontrados de OD na água foram de $2.17 \mathrm{mg} . \mathrm{L}^{-1}(50 \%), 2.48 \mathrm{mg} . \mathrm{L}^{-1}(25 \%) \mathrm{e}$ $3.52 \mathrm{mg} . \mathrm{L}^{-1}(10 \%)$ (Figura 6B). Observa-se que o nível de OD no Controle também foi reduzido ao final de 15 dias, no entanto no controle os valores ainda se mantiveram acima de $4.0 \mathrm{mg} . \mathrm{L}^{-1}$, valor mínimo considerado para a realização de um teste de toxicidade.

Tal como o pH, a CE (Figura 6C) e os sólidos totais dissolvidos (Figura 6D) nas diluições realizadas também tiveram um aumento considerável nas primeiras $24 \mathrm{hs}$, mesmo na concentração de $10 \%$. Verifica-se que a quantidade de STD no controle estava na ordem de $100 \mathrm{mg} / \mathrm{L}$, e as concentrações de cinzas com valores 2 a 4 vezes maior dependendo da concentração de cinzas (Figura 6D).

A partir do $10^{\circ}$ dia, houve um pequeno acréscimo nos valores desses parâmetros, permanecendo estável até o final dos 15 dias, ao contrário do Controle. 
Figura 5 - Variação do pH, do Oxigênio Dissolvido (OD), da Condutividade elétrica e dos Sólidos Totais Dissolvidos (STD) da água com cinzas da área da Lagoa Bonita nas condições com agitação contínua e sem agitação ao longo de 15 dias.
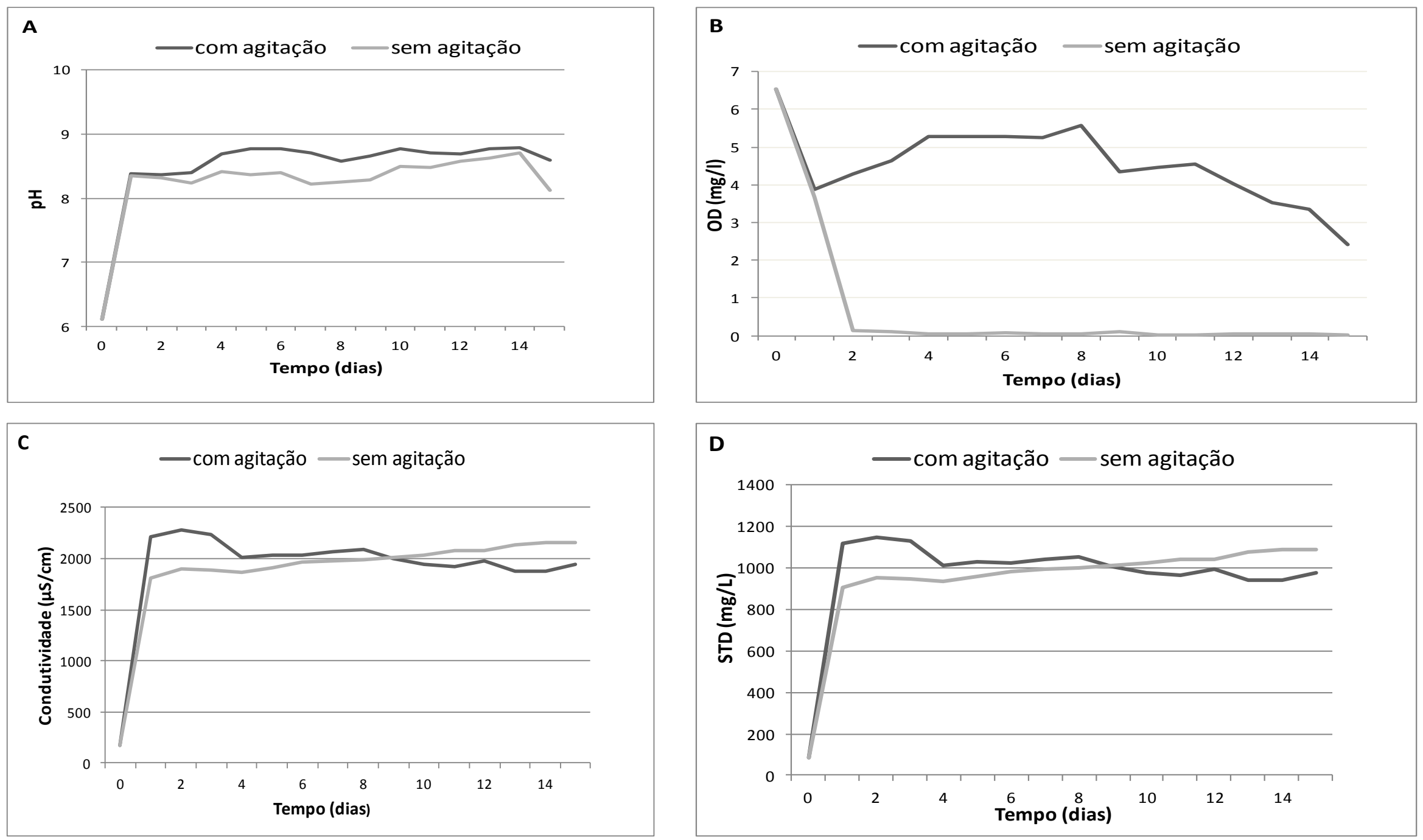
Figura 6 - Variação do pH, do Oxigênio Dissolvido (OD), da Condutividade elétrica e dos Sólidos Totais Dissolvidos (STD) nas amostras de água controle e diluições com cinzas da área da Lagoa Bonita durante 15 dias sem agitação.
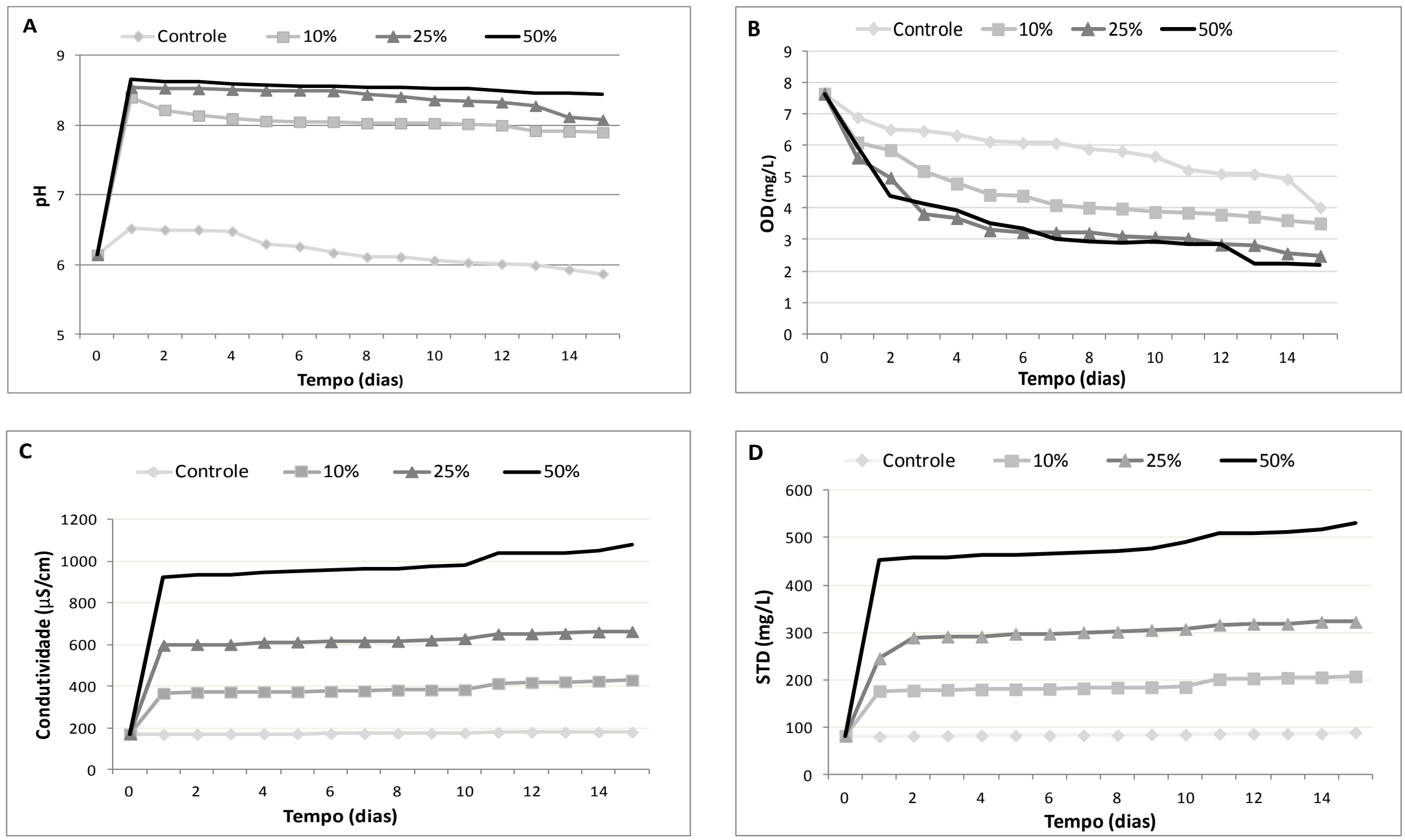


\section{Análise das Componentes Principais (PCA)}

As duas PCs juntas explicaram 85,7\% dos dados, A PC1 explica 80,2\% da variância total. Essa PC corresponde a quase totalidade dos elementos, com exceção do Mn e Mo. De acordo com a análise das duas PCs, os elementos Mn e Mo tanto nas cinzas quanto no solo não foram significantes para a variação (Tabela 2).

A projeção das cargas das variáveis associadas às duas primeiras componentes mostra a ordenação dos vetores das variáveis no espaço (Figura 3). Observa-se nitidamente a formação de dois grupos ordenados entre o primeiro e o quarto quadrante (solos), e entre o segundo e o terceiro quadrante (cinzas), indicando a diferença química entre as cinzas ( $\mathrm{Si}, \mathrm{K}$, $\mathrm{Ca}, \mathrm{S}, \mathrm{P}, \mathrm{Sr}, \mathrm{Mn}, \mathrm{Zn}$ ) e o solo (V, Ti Fe, $\mathrm{Al}, \mathrm{Cr}$ ), assim como os elementos discriminantes para cada grupo.

Nenhuma diferença evidente foi detectada entre as cinzas das diferentes áreas amostradas. No entanto, verifica-se uma similaridade nos dados de amostragem quanto aos solos, principalmente com relação ao eixo 1 que, visualmente, separou as unidades amostrais de cinzas e solos em dois grandes grupos (Figura 7).

Figura 7- Projeção espacial da ordenação dos vetores das variáveis químicas nas duas componentes principais.

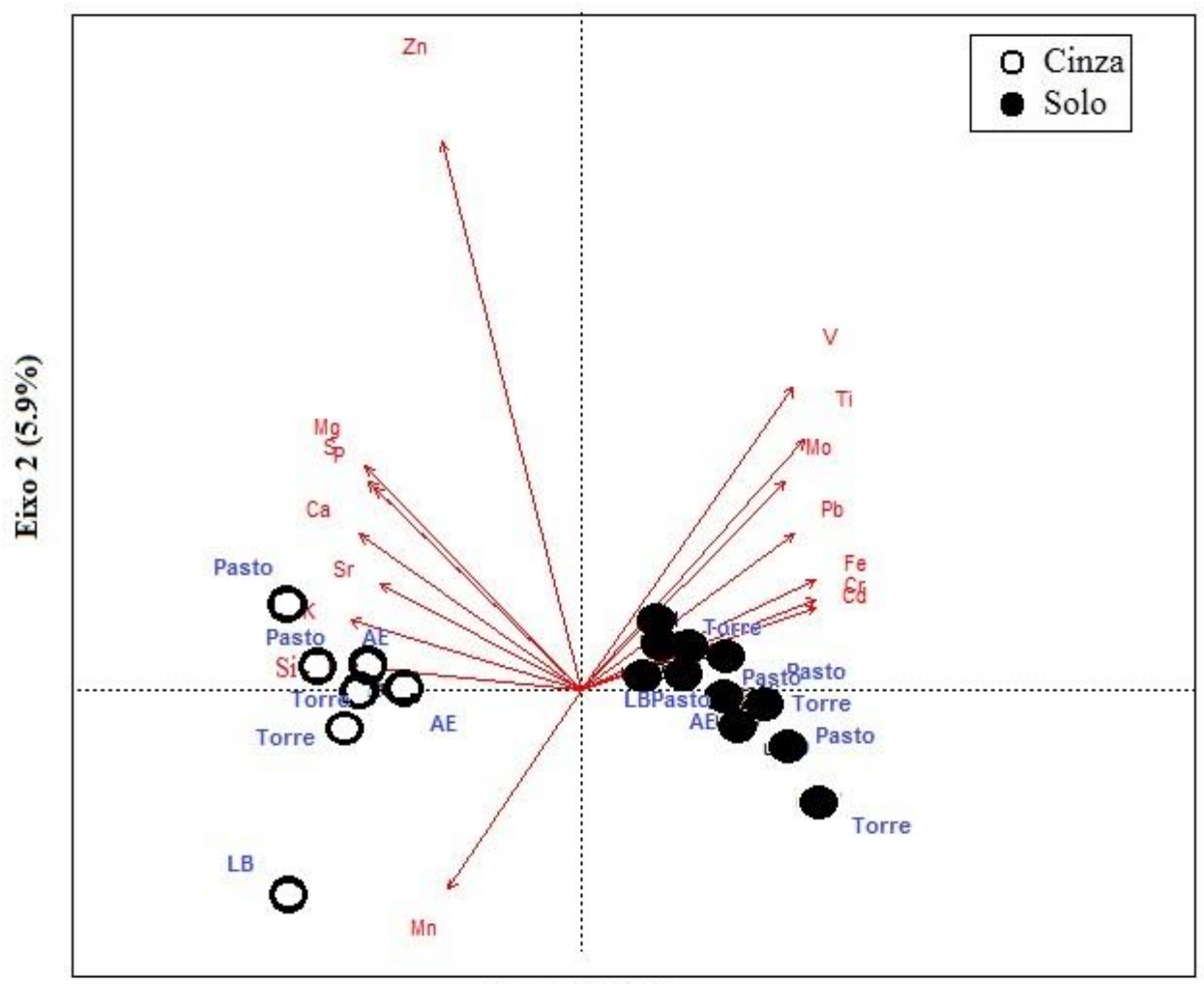

Eixo $1(80.2 \%)$ 


\section{Discussão}

As queimadas podem liberar uma vasta quantidade de metais pela combustão da biomassa ou via disponibilidade das interações entre as cinzas e o solo (DEMEYER et al., 2001; BUSTAMANTE e OLIVEIRA, 2008).

A composição das cinzas pode ser extremamente diversificada, pois além de conter metais pesados tais como: cobre, zinco, chumbo, níquel, arsênico, cobalto, cromo, cádmio e mercúrio (DEMEYER et al., 2001), ela pode conter compostos potencialmente tóxicos, tais como hidrocarbonetos policíclicos aromáticos (PAHs) (OLIVELLA et al.. 2006).

Fatores como a agropecuária, a ausência de matas ciliares e o relevo com declividade mais acentuada tendem a elevar a exposição dos ecossistemas aquáticos aos efeitos do escoamento superficial. Os metais presentes nas cinzas podem atuar como contaminantes persistentes ao se bioacumularem, causando efeitos tóxicos a diferentes organismos quando em altas concentrações (ADRIANO, 2001: IGNATAVIÈIUS et al., 2006; PEREIRA e ÚBEDA, 2010; PITMAN, 2006).

A comparação química das quatro áreas apresentou pouca diferença qualitativa. sendo a quantidade dos elementos químicos presentes em cada uma das áreas o aspecto de maior relevância, sobretudo em função do uso do solo da área queimada. As cinzas da área de pasto apresentaram os maiores teores de elementos comumente utilizados na fertilização, tais como: o K, Mg, P, Si e Zn. Por outro lado, as cinzas das áreas nativas da região apresentaram significativa presença dos elementos presentes no solo do Cerrado, tais como $\mathrm{Al}, \mathrm{Ca}$ e $\mathrm{B}$.

Ao comparar a composição química das cinzas e a composição química do solo, observaram-se valores muito superiores nas cinzas, com a presença de alguns elementos não disponíveis nas amostras de solo correspondentes. Esse dado ressalta a capacidade acumuladora das plantas, que mantêm na sua composição não só elementos necessários, mas alguns elementos que estão disponíveis em quantidades mínimas e transitórias no solo. $\mathrm{O} \mathrm{Ni}$, por exemplo, foi detectado nas cinzas de todas as áreas amostradas. mas não detectado nos solos de todas as áreas. Essa presença pode ser explicada pelo tempo de vida das plantas e pelo fato de se tratar de um concentrado dos elementos que, de alguma forma, já estiveram presentes naquele solo.

Segundo Silva et al. (1996), Mg e Ca são íons constituintes naturais da água e que seus valores toleráveis para consumo são de 4 e 2 ppm, respectivamente. Os estudos 
realizados com água e cinzas de áreas queimadas revelaram que os valores teores encontrados nas análises efetuadas foram muito superiores aos níveis permitidos (Tabela 3). O K é um composto que em altas concentrações no meio ambiente pode indicar contaminação industrial e pode ocasionar desequilíbrio em sistemas aquáticos.

Ao se comparar as matrizes de análise química das cinzas e da solubilização das cinzas, ficou evidenciado que a remobilização ou a taxa de solubilização (relação da concentração do metal disponível na solução com a quantidade encontrada nas cinzas) variou bastante entre os diferentes compostos analisados (Tabela 2). Esse fato resulta provavelmente das propriedades físico-químicas, tais como: a solubilidade e a afinidade elementos à matéria orgânica (MO). Considerando esses fatores, espera-se que os compostos com maior solubilidade e menor afinidade à MO apresentarão as maiores concentrações nas soluções. De fato, isso pode explicar a grande concentração de $\mathrm{Ca}, \mathrm{K}$ e S e a baixa disponibilidade de $\mathrm{Fe}$, $\mathrm{Al} \mathrm{e} \mathrm{Sr}$.

Estudos sobre os efeitos das drenagens ácidas em minas apontaram que as drenagens ácidas diminuem o $\mathrm{pH}$ das águas e liberam metais pesados $(\mathrm{Cd}, \mathrm{Pb}, \mathrm{Cu}, \mathrm{Fe}, \mathrm{Al}, \mathrm{Mn}, \mathrm{Zn}$, além de sulfatos) que possuem um elevado potencial de toxicidade (NIETO et al., 2007). A baixa solubilidade dos metais pesados nas soluções de cinzas pode ser em decorrência da alcalinidade da solução.

Os dados obtidos mostram que após 24 hs de agitação, quantidade considerável de vários elementos das cinzas já se encontra solubilizada na água, principalmente de alguns metais, que podem ser considerados tóxicos a nível crônico para algumas espécies aquáticas, tais como o $\mathrm{S}$ e alguns outros compostos conhecidos por seu potencial eutrofizante, tais como o Ke P (Tabela 2).

Os dados mostram que o tempo de agitação influenciou na diluição dos cátions e ânions, com aumento considerável em relação às $24 \mathrm{hs}$ de agitação para $\mathrm{K}^{+}$e $\mathrm{S}$ na forma de $\mathrm{SO}_{4}{ }^{2-}$ (Tabela 2). As leituras nos diferentes tempos de agitação mostraram que o período de 10 a 15 dias foi considerado ideal para atingir os maiores valores de diluição e que o $\mathrm{Ca}$ e o $\mathrm{Mg}$ tiveram concentrações reduzidas no decorrer do tempo.

Shakesby e Doerr (2005) afirmam que os nitratos são perdidos quando a temperatura atinge cerca de $204^{\circ} \mathrm{C}$. No entanto, para temperaturas inferiores a $371^{\circ} \mathrm{C}$, as perdas de sulfato podem ser significativas. Quando as temperaturas alcançam valores na ordem de $800^{\circ} \mathrm{C}$, todo 
o nitrato e sulfato são volatilizados. Esse dado sugere que a queimada em Lagoa Bonita não foi extremamente severa. considerando a quantidade de $\mathrm{S}$ nas cinzas.

A caracterização química gerou resultados de grande relevância para o contexto do impacto sobre os ecossistemas aquáticos. Os ensaios de solubilização permitiram constatar que no momento em que as cinzas são depositadas na água, apenas uma pequena parcela de seus elementos se dissolve (Tabela 3), contudo ocasiona transformações nos parâmetros de pH e OD. O pH aumenta chegando a patamares não suportáveis por algumas espécies (figura 3), bem como o OD que é drasticamente reduzido, passível de ocasionar a mortalidade dos organismos dependentes da sua concentração na água (Figuras 3 e 5B).

$\mathrm{O}$ aumento do $\mathrm{pH}$ pode ser explicado pelo alto teor de STP, conforme demonstrado nas tabelas 1 e 2. É possível verificar a tendência para estabilização das curvas nas duas situações de exposição, o que poderia representar uma situação de alcalinização da água em ambientes naturais (Figuras 3 e 6A).

Shakesby e Doerr (2006) afirmam que após a passagem do fogo, o pH dos rios pode ser afetado pela deposição direta das cinzas nos cursos de água. No primeiro ano após o fogo, o aumento do $\mathrm{pH}$ dos solos pode também contribuir para a elevação do $\mathrm{pH}$ da água dos rios. Assim sendo, os valores de $\mathrm{pH}$ observados no presente estudo refletem a influência das cinzas e corroboram os dados de outros estudos (LARANJEIRA e LEITÃO, 2008; PEREIRA e ÚBEDA, 2010).

Observou-se a semelhança nas curvas de STD e de CE. Nos dois parâmetros, os valores mais elevados foram nas diluições com cinzas das áreas Pasto e Torre, que pode ser explicado pela maior concentração de sais dissolvidos nas cinzas dessas áreas. A amostra de Lagoa Bonita é a que apresenta menor quantidade de STD. Apesar de uma maior semelhança fitofisionômica com a área da Torre, os dados mostram que essa diferença tenha sido ao menor grau de severidade do fogo na área de Lagoa Bonita.

Em relação aos valores CE, as amotras com cinzas indicam tratar-se de águas muito mineralizadas com alto conteúdo de sais (Figura 6C). Laranjeira e Leitão (2008) verificaram a existência de variações na condutividade em uma área queimada que apresentava um valor de $46 \mu \mathrm{s} / \mathrm{cm}$ antes do incêndio e de $66 \mu \mathrm{s} / \mathrm{cm}$ após o mesmo atribuindo esse aumento à presença de cinzas na água. 
Os valores de OD revelaram que todas as amostras mostraram-se pouco oxigenadas, visto que os valores oscilaram entre 5 a $0.8 \mathrm{mg} . \mathrm{L}^{-1}$ no período estudado. Earl e Blinn (2003) mostraram que a $\mathrm{CE}$ e o $\mathrm{pH}$ nos rios aumentam imediatamente após as cinzas alcançarem as águas e que o OD destas águas, consequentemente, diminui. No entanto, após um período de quatro meses, os valores destes parâmetros tenderam a voltar às condições originais antes do incêndio.

Houve um significativo decréscimo no OD na amostra que permaneceu sem agitação (Figura 6). Após 48hs, o OD chegou a nível próximo a 0, mantendo-se constante durante os 15 dias de observação. No entanto, na amostra com agitação observou-se um pequeno decréscimo do OD em 1.5 dias e, em seguida, um aumento próximo aos níveis iniciais em aproximadamente 6 dias. Posteriormente, a queda foi significativa chegando a valores em torno de $2.5 \mathrm{mg} . \mathrm{L}^{-1}$, o que já deixa praticamente inviável a sobrevivência de várias espécies aquáticas.

Com relação às diferentes concentrações de cinzas, verificou-se que o OD exibiu um pequeno decréscimo após 24hs. Contudo, ao final do período de 15 dias, os valores encontrados de OD na água foram de $2.17 \mathrm{mg} . \mathrm{L}^{-1}(50 \%) .2 .48 \mathrm{mg} . \mathrm{L}^{-1}(25 \%)$ e $3.52 \mathrm{mg} . \mathrm{L}^{-1}$ (10\%) (Figura 11). Observou-se que o nível de OD do controle também foi reduzido ao final de 15 dias. Entretanto no controle os valores de OD ainda se mantiveram acima de 4.0 mg.L $\mathrm{L}^{-1}$, valor mínimo considerado para a realização de um teste de toxicidade.

A partir desses resultados, também é possível inferir que ambientes com baixa vazão ou circulação de água, como os ambientes lênticos, por exemplo, poderão sentir de forma bem mais acentuada a entrada de cinzas de queimadas no seu meio (Figura 5). Acredita-se também que as poças de água situadas nas extremidades dos rios, onde o fluxo de água é pequeno, possa sofrer mais acentuadamente os efeitos das cinzas após uma queimada. 


\section{Conclusões}

Com base nos achados do presente estudo e baseado nos objetivos propostos foi possível concluir que:

- A comparação química das quatro áreas apresentou pouca diferença qualitativa. sendo o quantitativo dos elementos químicos presentes o aspecto de maior relevância.

- As cinzas das diferentes áreas apresentarem altas concentrações de Ca, P, K, Mg, Si e S.

- A composição química das cinzas em relação à composição química do solo apresentou valores muito superiores para a grande maioria dos elementos ( $\mathrm{B}, \mathrm{Ca}, \mathrm{K}, \mathrm{Mg}$, $\mathrm{Mn}, \mathrm{P}, \mathrm{S}, \mathrm{Si}$, Sr e Zn). com a presença de alguns elementos não disponíveis nas amostras de solo correspondentes ( $\mathrm{Ni}$ ). Por outro lado, verificaram-se elementos presentes nos solos em maior quantidade que nas cinzas da biomassa ( $\mathrm{Al}, \mathrm{Fe}, \mathrm{Cd}, \mathrm{Cr}, \mathrm{Mo}, \mathrm{Pb}, \mathrm{Ti}$ e $\mathrm{V}$ ). No entanto, apenas uma pequena parcela desses compostos são solubilizados.

- Quanto à taxa de solubilidade, observou-se que o $\mathrm{K}$ e o $\mathrm{S}$ apresentaram a recuperação mais elevada entre os metais. Apesar de o Ca, $\mathrm{Mg}$ e $\mathrm{P}$ estarem em grandes quantidades na cinzas, esses elementos apresentaram um percentual pequeno de solubilidade em relação aos demais elementos.

- A presença das cinzas na água elevam os STD e a condutividade elétrica, devido à solubilização dos sais. Os íons solubilizados elevam o pH e diminuem o OD na água, ocasionando sérios efeitos aos organismos aquáticos.

- Apesar dos testes de solubilização das cinzas com agitação ter apresentado um queda menos acentuada de OD, após 15 dias de observação os níveis de OD ficaram em torno de $2.5 \mathrm{mg} . \mathrm{L}^{-1}$, quantidade praticamente inviável à sobrevivência de muitos organismos aquáticos.

- Diante dos resultados, os ambientes lênticos e os poços de água nas extremidades dos rios poderão sentir os efeitos das cinzas das queimadas de forma bem mais acentuada que ambientes lóticos. 


\section{Referências bibliográficas}

ADRIANO, DC. 2001. Trace metals in terrestrial environments: biogeochemistry, bioavailability, and risks of metals. 2nd edition: Springer Verlag.

ANGELIS, D.F. Estudo das condições físicas, químicas e biológicas do efluente da refinaria de Paulínia - REPLAN e do Rio Atibaia, à montante e jusante, considerandose a prevenção de danos ambientais. Relatório Final - Processo 817/2007. Contrato REPLAN-FUNDUNESP. 2008-2009.

ARBEX, M. A.; BOHM, G. M.; SALDIVA, P.H.N.; CONCEIÇÃO, G.; POPEIII, A.G.; BRGA, A. L. F. 2000. Assessment of the effects of sugar cane plantation burning on daily counts of inhalation therapy. Journal of the Air \& Waste Management Association 50: 1745-1749.

BOND, W.J., F.I. WOODWARD; G.F. MIDGLEY. 2005. The Global Distribution of Ecosystems in a World without Fire. New Phytologist 165: 525-537.

BUSTAMANTE, M.M.C, AND E.L. OLIVEIRA. 2008. Impacto das atividades agrícolas, florestais e pecuárias nos recursos naturais. In FALEIRO, F.G., AND A.L. FARIAS NETO (Eds.). Savanas: desafios e estratégias para o equilíbrio entre sociedade, agronegócio e recursos naturais. Planaltina, DF: EMBRAPA Cerrados. p. 303-33.

CETESB - Companhia Ambiental do Estado de São Paulo. Variáveis de Qualidade das Águas. 2010. Disponivel em:< http://www.cetesb.sp.gov.br/Agua/rios/variaveis.asp> Acesso em: 28/06/2011.

COUTINHO, L. M. 1990. Fire in the ecology of Brazilian Cerrado. In: GOLDAMMER, J. G. Fire in the tropical biota. New York: Springer-Verlag, p. 82-105.

DEMEYER, A.; VOUNDI NKANA, J.C.; VERLOO, M.G. 2001. Characteristics of wood ash and influence on soil properties and nutrient uptake: an overview. Bioresources Technology 77(3): 287-295.

FELFILI, J.M., AND M.C. SILVA JÚNIOR. 1993. A comparative study of cerrado (sensu stricto) vegetation in Central Brazil. Journal of Tropical Ecology 9(3): 277-289. 
FREITAS, L. C. de; SANT'ANNA, G. L. Efeitos do fogo nos ecossistemas florestais. Revista da Madeira 79, 2004. Disponível em: 〈http://www.remade.com.br> Acesso: 05 nov. 2013.

GOODLAND, R. A. 1972. Physiognomic analysis of the cerrado vegetation of Central Brazil. Journal of Ecology 59(1880): 411-419.

HARIDASAN, M. 1982. Aluminum accumulation by some Cerrado native species in Central Brazil. Plant and Soil 65: 265-273.

IBAMA. 2011. INSTITUTO BRASILEIRO DO MEIO AMBIENTE E DOS RECURSOS NATURAIS RENOVÁVEIS. Relatório de Combate a Incêndios. Disponível em < http:www.ibama.gov.br> Acesso em fev. 2013.

IGNATAVIÈIUS G, SAKALAUSKIENE G, OSKINIS V. 2006. Influence of land fires on increase of heavy metal concentrations in river waters of Lithuania. Journal of Environmental Engineering and Landscape Management XIV(1): 46-51.

INPE. 2013. INSTITUTO NACIONAL DE PESQUISAS ESPACIAIS. Monitoramento de queimadas e incêndios em tempo quase real. 2012. Disponível em <http://www.inpe.br/queimadas>. Acesso em: 15 fev. 2013.

KAUFMAN, Y. J; HOBBS, P.V., KIRCHOFF, V.W.J.H; ARTAXO, P.; REMER, L.A., HOLBEN, B.N. 1998. Smoke clouths and radiation-Brazil (SCAR-B) experiment. $J$. Geophys Res 103(31): 783-808.

KLINK, C. A. e MACHADO, R. B. 2005. A conservação do Cerrado brasileiro. Disponível em:

http://www.agencia.cnptia.embrapa.br/recursos/Texto_Adicional_ConservacaoIDxNOKMLsupY.pdf Acesso em: 02 de Nov. de 2010. Malacologia 34: 33-40.

KLINK, C.A. 1996. Relação entre o desenvolvimento agrícola e a biodiversidade. Pp. 25-27. In: R.C. Pereira, L. C. B. Nasser (Eds.). Anais VIII Simpósio sobre o Cerrado, $1^{\text {st }}$ International Symposium on Tropical Savanas - Biodiversidade e Produção Sustentável de Alimentos e fibras nos Cerrados. Embrapa CPAC. Brasília. 
KLINK, C.A.; MOREIRA, A.G. 2002. Past and Current Human Occupation, and Land Use. In OLIVEIRA, O.S., AND R.J. MARQUIS (eds.). The cerrados of Brazil: ecology and natural history of a neotropical savanna. Columbia University Press, New York, pp. 69-88.

KRUPA, S.V. 2003. Effects of atmospheric ammonia $\left(\mathrm{NH}_{3}\right)$ on terrestrial vegetation: a review. Environ. Pollut., n.124, p. 179-221.

LARANJEIRA, I. e LEITÃO, T. E. 2008. Avaliação do Impacte de Fogos Florestais nos Recursos Hídricos Subterrâneos. Análise do Impacte dos Fogos Florestais na Qualidade Química das Águas Superficiais e Subterrâneas das Áreas de Estudo da Região Centro. Disponível em: http://www.Inec.pt/organizacao/dha/nas/estudos_id/Ficha_POCI_Fogos $>. \quad$ Acesso em: Ago. 2012.

MACHADO, C.M.D.; CARDOSO, A.A. e ALEN, A.G. 2008. Atmospheric emission of reactive nitrogen during biofuel ethanol production. Environmental Science \& Technology 42: 381-385.

MARCOLAN, A. L.; LOCATELLI, M.; FERNANDES, S. R. 2009. Atributos químicos e físicos de um Latossolo e rendimento de milho em diferentes sistemas de manejo da capoeira. EMBRAPA, Comunicado Técnico 352.

MEIRELLES, M.L. 1990. Efeito do fogo sobre a umidade do solo em área de campo sujo de cerrado. Ciência e Cultura 42(7). São Paulo, Brasil, p. 359-360.

MENDONÇA, R.; J. FELFILI, B; WALTER, J.C.; SILVA Jr., A.; REZENDE, T. FILGUEIRAS \& NOGUEIRA, P. 1998. Flora vascular do Cerrado. In: S. Sano \& S. Almeida (eds.). Cerrado. Ambiente e flora. Empresa Brasileira de Pesquisa Agropecuária- Embrapa - Cerrados, Planaltina, Brasil, p. 288-556.

MINSHALL, G.W.; ROBINSON, C.T.; LAWRENCE, D.E.; ANDREWS, D.A.; BROCK, J.T. 2001. Benthic macroinvertebrate assemblages in five central Idaho (USA) streams over a 10-year period following disturbance by wildfire. International Journal of Wildland Fire 10: 201-213. 
MIRANDA, H. S.; SATO, M. N. 2005. Efeitos do fogo na vegetação lenhosa do Cerrado. In: SCARIOT, A.; SOUSA-SILVA, J.C.; FELFILI, J.M. Cerrado: ecologia, biodiversidade e conservação. Brasília: Ministério do Meio Ambiente, p. 93-105.

MIRANDA, H.S.; BUSTAMANTE, M.M.C.; MIRANDA, A.C. 2002. The fire factor. In: Oliveira, P.S. \& Marquis, R.J. (Eds.) The Cerrados of Brazil: Ecology and natural history of a neotropical savanna. Columbia University Press.New York. p.51-68.

OLIVELLA, M.A.; RIBALTA, T.G; DE-FEBRER, A.R.; MOLLET, J.M.; DE LAS HERAS, F.X.C. 2006. Distribution of polycyclic aromatic hydrocarbons in riverine waters after Mediterranean forest fires. Science of the Total Environment 355: 156-166.

PEREIRA, P; ÚBEDA, X. 2010. Spatial distribution of heavy metals released from ashes after a wildfire. Journal of Environmental Engineering and Landscape Management 18: $13-22$.

PITMAN, RM. 2006. Wood ash use in forestry - a review of the environmental impacts. Forestry 79(5): 563-588.

RIBEIRO, J.F.; WALTER, B.M.T. 2008. As principais fitofisionomias do bioma Cerrado. In: SANO, S.M.; ALMEIDA, S.P.; RIBEIRO, J.F. Cerrado: Ecologia e Flora. Embrapa Cerrados - Brasília, DF: Embrapa Informação Tecnológica. p. 151-212.

SANTOS, D.; BAHIA, V.G.; TEIXEIRA, W.G. 1992. Queimadas e erosão do solo. Informe Agropecuário, Belo Horizonte 16(176): 62-68.

SATO, M. N. 2003. Efeito a longo prazo de queimadas prescritas na estrutura da comunidade de lenhosas da vegetação do Cerrado sensu stricto. Dissertação (mestrado) - Universidade de Brasília, Brasília.

SCRIMGEOUR, G. J.; TONN, W. M.;PASZKOWSKI, C. A.;GOATER, C. 2001. Benthic macroinvertebrate biomass and wildfires: evidence for enrichment of boreal subartic lakes. Freshwater Biology 46: 367-378.

SILVA, J.M.C.; BATES, J.M. 2002. Biogeographic patterns and conservation in the south american cerrado: a tropical savanna hotspot. Bioscience, 52: 225-233. 
WIECZOREK, A. 2003. Efeito do Efluente da Refinaria de Petróleo REPLAN/PETROBRÁS sobre a Dinâmica populacional de Daphnia similis. Trabalho de conclusão de curso (Especialização em ecotoxicologia aquática) 81p. - Instituto de Biociências - IB UNESP, Rio Claro. 


\section{CAPÍTULO II}

Avaliação da ecotoxicidade aquática das cinzas de queimadas do Cerrado 


\section{Resumo}

No cenário mundial das mudanças climáticas, vários estudos prevêem o aumento das queimadas em diferentes partes do mundo. Com o advento das chuvas após o período de estiagem no bioma Cerrado, os compostos presentes nas cinzas entram nos sistemas aquáticos, podendo ocasionar efeitos adversos a esses ecossistemas. Nesse contexto, o presente artigo propôs-se a avaliar o potencial de toxicidade das cinzas provenientes de duas áreas nativas do bioma Cerrado, e de uma área de pasto por meio de testes ecotoxicológicos com organismos aquáticos de diferentes níveis tróficos: o microcrustáceo Ceriodaphnia dubia, o peixe Danio rerio e o molusco Biomphalaria glabrata. Os resultados demonstraram que houve diferença na toxicidade das cinzas. Todas as cinzas apresentaram toxicidade aguda no ensaio com $C$. dubia. Com relação aos ensaios com o $D$. rerio e com B. glabrata, não foi constatada toxicidade para as cinzas de Pasto e de Torre. As cinzas de Lagoa Bonita apresentaram toxicidade ao D. rerio $\left(\mathrm{CL}_{50}-24 \mathrm{hs}\right.$ : $31.50 \%$; $\mathrm{CL}_{50}-48 \mathrm{hs}$ : 25 . 0\%. Com relação aos ensaios com o D. rerio e com B. glabrata, não foi constatada toxicidade para as cinzas de Pasto e de Torre. A cinza de Lagoa Bonita apresentou toxicidade ao peixe D. rerio $\left(\mathrm{CL}_{50^{-}}\right.$ 24hs:31.50\%; $\left.\mathrm{CL}_{50}-48 \mathrm{hs}: 25.0 \%\right)$. Somente as amostras sob agitação de 30 dias apresentou toxicidade ao B. glabrata ( $\mathrm{CL}_{50}-24 \mathrm{hs}: 50.0 \%$ (37.7-66.4); $\mathrm{CL}_{50}-48 \mathrm{hs:} 35.4 \%$ ). Estes resultados demonstram que as queimadas influenciam a toxicidade das águas superficiais, tornando este ambiente tóxico à sobrevida de comunidades aquáticas, especialmente as zooplanctônicas, e enfatizam a necessidade de estudos para a compreensão da complexidade dos efeitos ecológicos do fogo em comunidades aquáticas.

Palavras-chave: Cerrados, Queimadas, ecossistemas aquáticos e ensaios ecotoxicológicos. 


\section{Assessment of aquatic ecotoxicity of ashes from fires in a tropical savanna (Cerrado)}

\section{Abstract}

In a global scenario of climate change, several studies have predicted an increase of fires in different parts of the world. With the occurrence of rains following the drought period in the Cerrado biome, the compounds present in ashes may come into the aquatic systems and cause adverse effects to these ecosystems. In this context, this paper proposes to evaluate the potential toxicity of the ashes from two areas of Cerrado, and an area of pasture through ecotoxicological biossays using three aquatic species from distinct trophic levels, which were exposed to different dilutions of ash: microcrustacean Ceriodaphnia dubia, fish Danio rerio and the mollusc Biomphalaria glabrata. The results showed that there was difference in acute toxicity among different ashes. All ashes showed toxicity to C. dubia. In relation to $D$. rerio and $B$. glabrata tests, no acute toxicity was observed when they were exposed to ashes from pasture and Torre (native vegetation from Cerrado biome). Lagoa Bonita ashes showed toxicity for D. rerio (LC50 (24hs): $31.50 \%$; LC50 (48hs): 25.0\%). Only the ashes mixed for 30 days caused acute toxicity to B. glabrata (LC50 (24hs): 50.0\% (37.766.4); LC50 (48hs): $35.4 \%$ ). These results demonstrate that the fires influence the toxicity of surface waters not only in short periods of time, making it toxic to the survival of aquatic organisms, specially zooplankton communities, and emphasize the need for more studies in order to understand the complexity of the ecological effects of fire on aquatic communities.

Key-words: Cerrado, Fire, aquatic ecosystems and ecotoxicological biossays. 


\section{Introdução}

As queimadas e os incêndios florestais destacam-se como os principais elementos da matriz de emissões de gases do efeito estufa (GEEs) nos países em desenvolvimento (IPCC, 2007). No entanto, as principais fontes de emissões de GEEs no Brasil têm-se alterado profundamente nos últimos anos, devido às ações de combate ao desmatamento e ao uso de novas tecnologias na agropecuária (LAPOLA, 2014).

Devido às mudanças ocorridas no uso do solo no Brasil, o padrão brasileiro de emissão de GEEs tem-se modificado bastante (LAPOLA, 2014). O desmatamento, que correspondia a $57 \%$ das emissões totais do país em 2005 , passou a corresponder a $22 \%$ em 2010. O setor agropecuário lidera com $37 \%$ das emissões nacionais em 2010, oriundas da digestão de ruminantes, da decomposição de dejetos animais e do uso de fertilizantes.

O uso indiscriminado do fogo decorre, sobretudo, da fraca atuação de órgãos públicos, da vulnerabilidade socioeconômica e dos aspectos culturais das populações, pois parcela considerável das emissões de GEEs provém do uso do fogo no meio rural como forma de manejo e de incêndios quando provocados pelo mau uso dessa prática (SAMPAIO et al., 2008; IBAMA, 2011).

Considerando que a prática das queimadas tem sido uma das principais causas de incêndios florestais no país e que a contribuição do Brasil na emissão mundial de GEEs é relativamente elevada, a redução do uso do fogo na agricultura por meio de alternativas viáveis economicamente tem sido fortemente incentivada nas práticas agrícolas (IBAMA, 2011).

O bioma Cerrado é classificado como sendo savana tropical úmida e possui duas estações bem definidas: seca e chuvosa (RIBEIRO e WALTER, 2008). Durante a estação seca, grande parte das gramíneas fica inativa e parte considerável de sua biomassa aérea morre, favorecendo a ocorrência de incêndios (MIRANDA e SATO, 2005).

As queimadas acarretam sérios efeitos ambientais tanto aos ecossistemas terrestres quanto aos ecossistemas aquáticos (SPENCER et al., 2003; PIVELLO, 2006; SHAKESBY e DOERR, 2006). Esses efeitos podem ser imediatos ou de longa duração após a ocorrência das queimadas, dependendo da fitofisionomia vegetal, do relevo, da geologia, das condições 
meteorológicas, da intensidade e da duração do fogo (PIVELLO e COUTINHO, 1992; EMMERICH, 1998; SPENCER et al., 2003, SHAKESBY e DOERR, 2006).

O fogo altera a cobertura vegetal (MIRANDA et al., 2002; PEREIRA et al., 2007) e a camada superior do solo (e.g., alterações do $\mathrm{pH}$ do solo), passando a ter um impacto no movimento da água entre os vários compartimentos do ciclo hidrológico (SPENCER et al., 2003). Na medida em que o fogo altera a qualidade da água, ele pode afetar a comunidade aquática, tais como: o fitoplâncton, os micro e macroinvertebrados, além de peixes (MINSHALL et al., 2001).

O Distrito Federal, apesar de ser uma região relativamente pequena, tem registrado um grande número de queimadas anualmente, sendo que em 2010 mais de 120 dias de estiagem carbonizaram 35 mil hectares de vegetação preservada e quase 3 mil ocorrências de focos de incêndios foram registradas de janeiro a setembro (INPE, 2012).

O uso do fogo para o manejo, o combate às queimadas descontroladas e a necessidade de compreensão dos efeitos do fogo em longo prazo incentivam estudos sobre os efeitos de queimadas em diferentes compartimentos ambientais. Nesse sentido, torna-se perceptível a necessidade de estudos que avaliem as respostas da biota aquática a fim de gerar informações para ações de manejo que visam minimizar as perturbações de queimadas em ambientes aquáticos.

O uso de ensaios ecotoxicológicos para verificar o risco representado pelas queimadas no ecossistema aquático permite uma avaliação mais integrativa que a análise química os efeitos interativos entre os contaminantes, estabelecendo o efeito tóxico real (CHAPMAN, 2000; MOWAT e BUNDY, 2001; SMOLDERS et al., 2003, ARIAS et al., 2007).

Os bioensaios usam metodologias que consistem testar a sobrevida de organismosteste. Nesse sentido, tem-se adotado vários organismos testes, dentre os quais: o microcrustáceo Ceriodaphnia dubia, pertencente ao zooplâncton (RUPPERT et al. 2005; EPS, 2007); o molusco gastrópode Biomphalaria glabrata, aos bentos (OLIVEIRA-FILHO et al., 1999) e o peixe Danio rerio, ao nécton (EPA, 1996; NAGEL, 2002; ABNT, 2004; OECD 236, 2013).

Os ensaios de toxicidade envolvendo os microcrustáceos zooplanctônicos são amplamente utilizados no monitoramento da qualidade das águas e na avaliação da toxicidade 
de efluentes (ROSA, 2008; OLIVEIRA-FILHO et al., 2009a), pois esses organismos figuram-se como elos importantes nas cadeias alimentares aquáticas e são facilmente cultivados em condições laboratoriais (KNIE e LOPES, 2004).

Este trabalho tem como objetivo realizar uma avaliação ecotoxicológica das cinzas provenientes de diferentes áreas queimadas do Cerrado sobre os organismos aquáticos (Ceriodaphnia dubia, Danio rerio e o Biomphalaria glabrata) e comparar a toxicidade de cinzas obtidas em áreas com diferentes fitofisionomias e usos.

\section{Materiais e Métodos}

\section{1 Área de Estudo e Coleta das amostras}

As três áreas amostradas estão situadas no Distrito Federal e foram queimadas no segundo semestre do ano 2010. As áreas foram selecionadas em função do tipo de fitofisionomia presente no Cerrado e identificadas como: 1-Torre, por estar localizada próxima Torre de TV Digital do Distrito Federal. Trata-se de uma área com vegetação nativa, identificada como área de Cerrado Típico (S15²4'44,0" e W 04748'29,8"); 2 - Pasto, área experimental de consórcio de forrageiras da Embrapa Cerrados e de criação de pasto, foi identificada como uma área de pastagem (S 15³6'40,8" e W 04741'52,1"); 3 - Lagoa Bonita, localizada no interior da Estação Ecológica de Águas Emendadas (ESECAE), é considerada uma área de transição de vereda para campo savana (S 15³5'29,9” e W $\left.047^{\circ} 41^{\prime} 48,8^{\prime \prime}\right)$.

\subsection{Amostragem}

As cinzas foram coletadas imediatamente após a ocorrência das queimadas no período de estiagem, de forma a contemplar uma maior diversidade espacial da área. Como as cinzas não se encontram distribuídas de modo homogêneo na área, foram selecionados os locais com maior depósito delas. As cinzas obtidas foram transportadas ao laboratório e peneiradas em malha com dimensão de $1 \mathrm{~mm}$, visando a eliminação de resíduos de carvão.

\subsection{Ensaio de Toxicidade Aguda com Ceriodaphnia dubia}

Para avaliar os efeitos das cinzas sobre o microcrustáceo Ceriodaphnia dubia, foram realizados ensaios de toxicidade aguda, de acordo com a norma NBR 13373 (ABNT, 2005). Os ensaios consistiram na exposição de 10 jovens de 0 a $24 \mathrm{hs}$ de idade durante $48 \mathrm{hs}$ e 
avaliada a mortalidade dos indivíduos. Os organismos utilizados foram indivíduos jovens com idade $\leq 24 \mathrm{hs}$ e provenientes de cultivos mantidos no Laboratório de Ecotoxicologia da Embrapa Cerrados. Os indivíduos foram expostos individualmente a $10 \mathrm{~mL}$ de solução de cinzas em béqueres de $25 \mathrm{~mL}$ em sistemas estáticos. As amostras brutas (100\%) e diluições de $75 \%, 50 \%, 25 \%, 12,5 \%$ e $6,25 \%$ foram preparadas com água de cultivo de acordo com a NBR 13373 (ABNT, 2005). O pH e o OD das soluções foram medidos no início e no término dos ensaios. Os ensaios foram considerados válidos quando não foi observado mortalidade de até $10 \%$ de efeito no grupo controle.

Para a condução dos ensaios com C. dubia, ressalta-se uma diferença metodológica: ensaio 1A- amostra filtrada antes das diluições e ensaio 2A - amostras filtradas após as diluições.

Com as cinzas da área de Lagoa Bonita, foram realizados ensaios com C. dubia nas seguintes condições: 1B - Cinzas (100 g.. $\left.\mathrm{L}^{-1}\right)$ agitadas por $96 \mathrm{hs} \mathrm{em} \mathrm{água} \mathrm{mole} \mathrm{sintética} \mathrm{e}$ filtradas em $0,45 \mu \mathrm{m}$ e $2 \mathrm{~B}$ - Cinzas (100 g.. $\left.\mathrm{L}^{-1}\right)$ agitadas por 30 dias em água mole sintética e filtradas em $0,45 \mu \mathrm{m}$.

Com as cinzas da área do Pasto foram realizados 02 ensaios nas condições: 1C Cinzas $\left(100\right.$ g. $\left.\mathrm{L}^{-1}\right)$ agitadas em $\mathrm{H}_{2} \mathrm{O}$ mole sintética por 96hs e filtradas em $0,45 \mu \mathrm{m} ; 2 \mathrm{C}$ Cinzas (100 g. $\mathrm{L}^{-1}$ ) agitadas em $\mathrm{H}_{2} \mathrm{O}$ mole sintética por 96hs sem filtração.

\subsection{Ensaio de Toxicidade Aguda com peixe Danio rerio}

Para determinar o potencial tóxico para organismos do nécton, foram realizados ensaios para avaliar a toxicidade das cinzas sobre peixes da espécie Danio rerio. Os peixes $D$. rerio foram adquiridos de fornecedor comercial. $\mathrm{O}$ procedimento do ensaio de sistema estático seguiu a norma NBR 15088 (ABNT, 2004), consistindo na exposição dos indivíduos adultos ao material testado durante 48hs, com quantificação diária da mortalidade (Aprovação pela Comissão de Ética em Uso de Animais do UniCEUB - CEUA/UniCEUB, sob parecer número: 013/13 de 18/11/2013).

\subsection{Ensaio de Toxicidade Aguda com Biomphalaria glabrata}

Foram realizados ensaios agudos para avaliar os efeitos adversos das cinzas sobre o molusco gastrópode da espécie Biomphalaria glabrata. Esses caramujos são cultivados no Laboratório de Ecotoxicologia da Embrapa Cerrados e os procedimentos de ensaio seguiram 
os modelos padronizados em laboratório (OLIVEIRA-FILHO et al., 2009b). O ensaio agudo consiste na exposição dos organismos ao material testado, por período de até $96 \mathrm{hs}$, com quantificação diária da mortalidade.

Após a exposição, foi realizada a contagem dos indivíduos mortos e calculada a concentração efetiva para imobilização de $50 \%$ da população (CE 50) através do método matemático Trimmed Spearman-Karber (HAMILTON et al., 1977), sendo esta definida como a concentração na qual ocorre a mortalidade em $50 \%$ dos organismos quando expostos às diferentes concentrações do teste.

\section{Resultados}

\subsection{Ensaio de mortalidade com Ceriodaphnia dúbia}

Inicialmente os ensaios com C. dubia foram realizados com amostras filtradas, devido às cinzas na água apresentarem alto teor de sólidos totais disponíveis (STD), o que poderia levar a atritos físicos com o organismo. Os níveis de oxigênio dissolvido (OD), embora caiam rapidamente e possam ter influência na mortalidade dos organismos, foram minimizados pelas diluições realizadas.

No ensaio 1A, foi determinada a $\mathrm{CL}_{50}-24 \mathrm{hs}$ de 50.06\% (35.9-69.9). Observa-se que a $\mathrm{CL}_{50}$ do ensaio $2 \mathrm{~A}$ possui uma toxicidade significativamente maior que a do ensaio $1 \mathrm{~A}$ ( $\mathrm{p}<$ 0.05) (Tabela 1). A diferença metodológica ocorreu devido ao fato da amostra ter sido filtrada antes das diluições no ensaio 1A. Para os ensaios nesse estudo, a filtração ocorreu depois das diluições das cinzas para as concentrações esperadas, conforme o ensaio $2 \mathrm{~A}$.

Tabela 1 - Comparação dos resultados dos ensaios realizados com as amostras filtradas para o microcrustáceo C. dubia.

\begin{tabular}{|c|c|c|}
\hline & & Toxicidade Aguda para $C$. dubia \\
\hline Amostras & Preparação & $\mathrm{CL}_{50}-24$ horas $(\%) \quad \mathrm{IC}=95 \%$ \\
\hline \multirow[t]{2}{*}{$\begin{array}{c}\text { Lagoa Bonita } \\
\text { Agitação } \\
96 \text { hs }\end{array}$} & $\begin{array}{c}\text { Ensaio 1A } \\
\text { Soluçãao } \\
\text { estoque } \\
\text { Filtrada }\end{array}$ & $50.06(35.9-69.9)$ \\
\hline & $\begin{array}{c}\text { Ensaio 2A } \\
\text { Concentrações } \\
\text { filtradas }\end{array}$ & $12.4(9.04-15.65)$ \\
\hline
\end{tabular}


Com relação aos ensaios de exposição das cinzas de Lagoa Bonita, observa-se que o valor da $\mathrm{CL}_{50}-24 \mathrm{hs}$ do ensaio $2 \mathrm{~B}$ caiu drasticamente para 3.13 (2.32- 4.21) \% e 1.41 (0.842.36) \%após 48hs em comparação ao ensaio 1B (agitação por 96hs), evidenciando que provavelmente algum dos elementos mais dissolvidos no período de 30 dias pode ter sido responsável pela toxicidade observada.

Tabela 2 - Comparação entre os resultados dos ensaios realizados com as amostras filtradas (F) e não-filtradas (NF) de cinzas para o microcrustáceo C. dubia.

\begin{tabular}{|c|c|c|c|}
\hline \multirow[b]{2}{*}{ Amostras } & \multirow[b]{2}{*}{ Preparação } & \multicolumn{2}{|c|}{ Toxicidade Aguda para $C$. dubia } \\
\hline & & $\begin{array}{c}\mathrm{CL}_{50}-24 \text { hs }(\%) \\
\text { IC }=95 \%\end{array}$ & $\begin{array}{c}\mathrm{CL}_{50}-48 \text { hs }(\%) \\
\text { IC }=95 \%\end{array}$ \\
\hline \multirow[t]{2}{*}{ Lagoa Bonita } & $\mathrm{F}$ & $\begin{array}{c}8.4 \\
(7.08-15.65)\end{array}$ & $\begin{array}{c}6.73 \\
(4.81-9.46)\end{array}$ \\
\hline & NF & $\begin{array}{c}17.68 \\
(12.52-24.97)\end{array}$ & $\begin{array}{c}13.4 \\
(9.95-18.4)\end{array}$ \\
\hline \multirow[t]{2}{*}{$\begin{array}{l}\text { Agitação } \\
30 \text { dias }\end{array}$} & $\mathrm{F}$ & $\begin{array}{c}3.13 \\
(2.32-4.21)\end{array}$ & $\begin{array}{c}1.41 \\
(0.84-2.36)\end{array}$ \\
\hline & NF & ND & ND \\
\hline \multirow[t]{2}{*}{ Pasto } & $\mathrm{F}$ & 5.10 & $\begin{array}{c}4.86 \\
(3.77-6.26)\end{array}$ \\
\hline & NF & $\begin{array}{c}7.18 \\
(5.35-9.63)\end{array}$ & $\begin{array}{c}6.33 \\
(4.83-8.28)\end{array}$ \\
\hline \multirow[t]{2}{*}{ Torre } & $\mathrm{F}$ & $\begin{array}{c}4.96 \\
(2.93-8.40)\end{array}$ & $\begin{array}{c}4.05 \\
(2.70-6.08)\end{array}$ \\
\hline & NF & $\begin{array}{c}10.15 \\
(7.04-14.65) \\
\end{array}$ & $\begin{array}{c}9.73 \\
(6.82-13.87) \\
\end{array}$ \\
\hline
\end{tabular}

ND: Não determinado

Com relação às cinzas da área do Pasto, nota-se uma $\mathrm{CL}_{50}-24 \mathrm{hs}$ de $5.10 \%$ e de $4.86 \%$ (3.77-6.26) após 48hs de exposição no ensaio 1C. Quanto ao ensaio com as amostras sem filtração (2C), obteve-se uma $\mathrm{CL}_{50}-24 \mathrm{hs}$ de $7.18 \%$ (5.35 - 9.63) e de 6.33\% (4.83- 8.28) após 48hs.

Com as cinzas da área da Torre, observou-se no ensaio com filtração, a $\mathrm{CL}_{50}-24 \mathrm{hs}$ de $4.96 \%$ (2.93-8.40) e 4.05\% (2.70-6.08) após 48hs. Já no ensaio sem filtração, foram obtidas as CL50-24hs de $10.15 \%$ (7.04-14.65) e 9.73\% (6.82-13.87) após 48hs (Tabela 2).

Todas as amostras filtradas apresentaram os $\mathrm{CL}_{50}$ menores que as amostras não filtradas. Todavia, ao se comparar a resposta de $C$. dubia exposta às várias amostras, por meio dos intervalos de confiança, não foi possível verificar diferenças de toxicidade para as 
amostras não filtradas e filtradas, e nem entre os diferentes tipos de cinzas sob agitação de 4 dias (Figura 1).

Figura 1 - Comparação das $\mathrm{CL}_{50}$ e seus respectivos intervalos de confiança (IC=95\%) da exposição das amostras filtradas e não filtradas de cinzas ao microcrustáceo C. dubia.

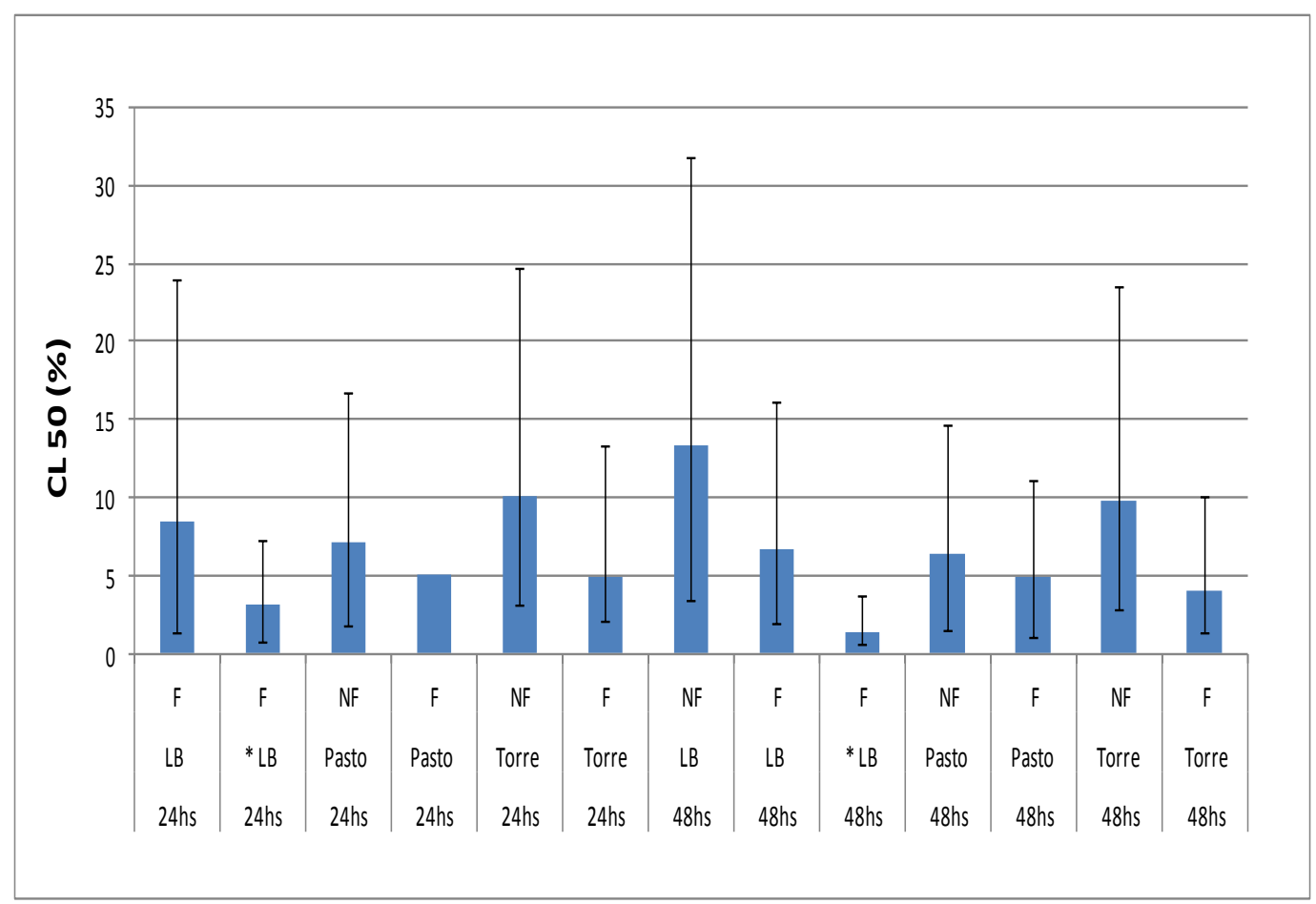

*LB (Lagoa Bonita): Agitação por 30 dias. F: Amostras filtradas e NF: Amostras não filtradas.

\subsection{Ensaios de toxicidade aguda $\operatorname{com} D$. rerio}

Os testes com peixes foram executados sem a filtração previamente realizada para os microcrustáceos e, desse modo, os peixes foram expostos à cinza dissolvida na água após agitação de 96hs.

Inicialmente, foi testada a amostra das cinzas de Lagoa Bonita diluída em água mole sintética. Esse ensaio foi realizado sem a aeração e a $\mathrm{CL}_{50}-24 \mathrm{hs}$ foi de $41.05 \%$ (27.01 - 62.39) e após 48hs de exposição a $\mathrm{CL}_{50}$ foi de $32.06 \%$ (21.03-52.94) (tabela 3). 
Tabela 3 - Comparação dos resultados dos ensaios de exposição das amostras de cinzas de Lagoa Bonita ao D. rerio com aeração e sem aeração.



\subsection{Ensaios de toxicidade aguda com o caramujo B. glabrata}

Ao comparar as $\mathrm{CL}_{50}$ das amostras sob agitação durante 4 e 30 dias não se verificam diferenças para o peixe, no entanto a amostra sob agitação de 30 dias passa a apresentar letalidade aos caramujos.

A partir da tabela 4, constata-se também que a toxicidade das cinzas de Lagoa Bonita Tabela 4 - $\mathrm{CL}_{50}(\%)$ das amostras de cinzas ao molusco B. glabrata e ao peixe D.rerio

Toxicidade Aguda para B. glabrata Toxicidade Aguda para D. rerio

\begin{tabular}{|c|c|c|c|c|}
\hline $\begin{array}{l}\text { Amostras } \\
\text { (Agitação) }\end{array}$ & $\mathrm{CL}_{50}-24 \mathrm{hs}$ & $\mathrm{CL}_{50}-48 \mathrm{hs}$ & $\mathrm{CL}_{50}-24 \mathrm{hs}$ & $\underset{5 \%)}{C L_{50}-48 ~ h s}$ \\
\hline $\begin{array}{l}\text { Lagoa Bonita } \\
\text { (4 dias) }\end{array}$ & NT & NT & 31.50 & 25.0 \\
\hline $\begin{array}{l}\text { Lagoa Bonita } \\
\quad \text { (30 dias) }\end{array}$ & $\begin{array}{c}50.0 \\
(37.7-66.4)\end{array}$ & 35.4 & $\begin{array}{c}28.91 \\
(20.4-40.97)\end{array}$ & $\begin{array}{c}23.76 \\
(19.36-38.23)\end{array}$ \\
\hline $\begin{array}{l}\text { Pasto } \\
\text { (4 dias) }\end{array}$ & NT & NT & NT & NT \\
\hline $\begin{array}{l}\text { Torre } \\
\text { (4 dias) }\end{array}$ & NT & NT & NT & NT \\
\hline
\end{tabular}


ocorre independentemente do tempo de agitação da amostra ao D. rerio. Os ensaios com $B$. glabrata foram realizados em paralelo com os ensaios de peixes.

Nesse contexto, os organismos foram expostos às soluções com todas as cinzas nas concentrações de 12.5, 25,50, 75 e 100\% após 96hs de agitação em água mole sintética, e não houve mortalidade após $48 \mathrm{hs}$ de exposição em todas as amostras de cinzas testadas.

\section{Discussão}

Para a preparação da solução-estoque $\left(100 \mathrm{~g} . \mathrm{L}^{-1}\right)$, deve-se reconhecer, sobretudo, que a quantidade de cinzas para a condução dos testes pode ser resultado de uma concentração de cinza maior do que o esperado em escoamentos em condições $e x$-situ.

A variabilidade na concentração de cinzas no meio ambiente é dependente de vários fatores (relevo, fitofisionomia, biomassa e severidade do fogo) tornando, assim, difícil identificar exatamente as proporções de cinzas e de solvente (água ou meio de cultivo) que devem ser usados na preparação das concentrações dos testes. Contudo, apesar dessas limitações, ressalta-se que o presente estudo realizou uma série de diluições para a condução dos bioensaios, tornando muito provável que a concentração aproximada de escoamento seja contemplada no presente estudo (1,5\% a $100 \%)$.

Diversos estudos sobre as transformações químicas das cinzas na água, constataram que parte desses elementos se dissolve, ocasionando diretamente transformações no $\mathrm{pH}$ e no oxigênio dissolvido (OD) (PEREIRA e ÚBEDA, 2010). O pH pode aumentar e chegar a patamares não suportáveis por algumas espécies, bem como o OD é drasticamente reduzido, causando a mortalidade dos organismos dependentes da sua concentração na água. De fato, as alterações no $\mathrm{pH}$, proveniente da mineralização da matéria orgânica libera metais no solo e as cinzas resultantes da combustão (constituídas basicamente por óxidos e cátions, tais como:

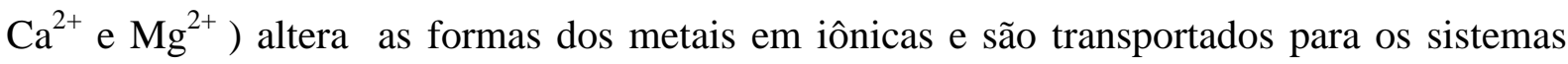
aquáticos (PITMAN 2006; PEREIRA e ÚBEDA 2010). O aumento do pH pode alterar a solubilidade, a polaridade, a volatilidade, a estabilidade, assim como a especiação de compostos em uma dada solução (RAND, 1995).

$\mathrm{O}$ pH é importante na solubilizacão de íons metálicos e especialmente na dissociação da amônia (CETESB, 2010). Em pH ácido, a toxicidade da amônia é insignificante quando comparada ao $\mathrm{pH}$ superior a 8,0. A maioria dos organismos é muito sensivel à amônia, pois 
esse composto causa impactos ecológicos nas comunidades de peixes e invertebrados bentônicos, sobretudo nas formas larvais e juvenis (ANGELIS, 2008).

O efeito tóxico das amostras de cinzas não foi devido ao efeito direto do $\mathrm{pH}$, pois foi realizada a correção de $\mathrm{pH}$ antes do início dos ensaios, caso o pH não se encontrasse dentro da faixa de aceitação do organismo-teste (ABNT 13373, 2005).

Os testes de exposição com as soluções filtradas foram usados inicialmente para excluir o efeito de particulados de cinzas na imobilização dos cladóceros, assim como verificar se a solução filtrada de contaminantes possuíria uma toxicidade maior em relação às amostras de particulados, que podem entrar no organismo dos dafinídeos pela de ingestão de compostos adsorvidos em partículas orgânicas suspensas. Richardson (1993), por exemplo, demonstrou que os contaminantes ambientais podem diminuir a sua toxicidade, devido eles se complexarem, precipitarem ou adsorverem em material orgânico. Ao testar os efeitos da matéria orgânica (MO) na toxicidade do $\mathrm{Cu}, \mathrm{Pb}$ e $\mathrm{Zn}$ à bacteria $V$. fischeri, Tsiridis et al. (2006) verificaram que o aumento das concentrações da $\mathrm{MO}$, diminuiu a toxicidade do $\mathrm{Cu}$ via complexação do metal com a $\mathrm{MO}$, aumentou a toxicidade do $\mathrm{Pb}$, (aumentando a biodisponibilidade do $\mathrm{Pb}$ ), contudo a MO não influenciou a toxicidade do $\mathrm{Zn}$.

Diversos estudos constatam que o uso intensivo de agroquímicos pela agricultura tem facilitado a complexação de íons recohecidamente tóxicos em MO. O uso dos fertilizantes e o reuso de resíduos na pecuária, por exemplo, aumentam as concentrações de nitrato $\left(\mathrm{NO}_{3}\right)$ e de nitrito $\left(\mathrm{NO}_{2}\right)$ nas águas subterrâneas e superficiais (RESENDE, 2002), promovendo a eutrofização de corpos hídricos com o aumento da quantidade de MO e a diminuição de OD, ocasionando efeitos danosos à comunidade aquática (CETESB, 2001).

O trabalho de Campos et al. (2012) conduzido em Portugal, mostra que a água lixiviada coletada imediatamente de uma área queimada de eucalipto resultou em efeitos inibitórios na taxa de crescimento da bactéria $V$. fischeri (5min $\mathrm{EC}_{50}$ : 10\% (1-83); 15min EC $_{50}$ : 7\% (2-25)), da alga P. subcapitata (EC50: 90.3\% (87.1-93.5)) e da macrófita $L$. minor (EC50: > 100\%). No entanto, a exposição do lixiviado da área queimada após um ano apresentou uma $\mathrm{EC}_{50}$ de 41.8 (35.8-47.8) à macrófita L. minor. A exposição dos lixiviados ao crustáceo D. magna não apresentou efeitos de inibição significativos. O estudo constatou também que as escorrências (run-offs) coletadas de áreas queimadas após um ano foram mais tóxicas aos organismos quando comparadas às escorrências recém-coletadas, demonstrando 
que os efeitos do fogo nos ecossistemas não se limitam aos efeitos imediatos de áreas queimadas, além de uma menor importância dos compostos poliaromáticos (PAHs) na toxicidade das cinzas.

Uma avaliação ecotoxicológica com extratos aquosos de cinzas (1:4 v/v) de uma área queimada de eucaliptos e pinheiros em Portugal ocasionou efeitos na inibição de biomassa de produtores primários, como: $P$. subcapitata (EC50: 35 $\pm 8.6 \%$ ), L. minor (EC50: $96.41 \pm 14.96 \%)$ e inibiu a luminescência de $V$. fischeri na maior concentração testada $(81.9 \%)$ em 33.98\% após 15 minutos de exposição. Nesse estudo, não foi observada imobilização significativa em D. magna (EC50: >100\%) e a autora sugere que não se espera toxicidade, em curto prazo, aos níveis tróficos superiores (SILVA, 2012).

Testes de exposição com lixiviados de áreas queimadas mostraram-se tóxicos aos produtores primários e aos decompositores de ecossistemas aquáticos (CAMPOS et al., 2012; SILVA, 2012). Devido às funções ecológicas que os organismos testados representam no ecossistema, a mortalidade e diminuição de crescimento induzidas pelas cinzas são esperadas em níveis funcionais correspondentes, resultando em efeitos no ecossistema. Em ambos estudos, não foi constatada uma toxicidade direta aos dafinídeos, o que não se verifica com os dados observados no presente estudo.

Ao avaliar a toxicidade dos percolados de colunas de cinza de carvão de termelétricas e de solo com cinza de carvão, observaram-se efeitos tóxicos à mobilidade e/ou sobrevivência D. similis expostos aos percolados da coluna de cinza de carvão (CE50 (48h): 25,6 - 84,1\%). Verificou-se também efeitos tóxicos à germinação das sementes de L. sativa nos percolados da coluna de cinza de carvão (CI 50 (120h): 27,6 a 90,6\% e o IG (índice de germinação): 6,7 40,8\%). No entanto, os percolados das colunas de solo com cinza de carvão não apresentaram toxicidade tanto às $D$. Similis, quanto à L. sativa, indicando a capacidade do solo das colunas reter as substâncias tóxicas lixiviadas da cinza de carvão (CASTRO, 2013).

As amostras de cinzas das três áreas queimadas na região dos Cerrados se mostraram tóxicas para C. dubia em pequenas concentrações ( $\mathrm{CL}_{50}$-48hs: 6.33\% (4.83 - 8.28) (Tabela 2), o que releva ainda mais a toxicidade das cinzas para o zooplâncton. Concentrações elevadas de STD podem comprometer o sistema filtrante de $C$. dúbia e levá-la à morte, dada a dificuldade de ingestão de alimentos e incapacidade de locomoção. 
Todas as amostras filtradas tenderam a ser mais tóxicas quando comparada às nãofiltradas. A filtração tendeu a aumentar levemente a toxicidade em níveis consideráveis para as áreas nativas, ao contrário da área de pasto. $\mathrm{Na}$ área de pasto, verificou-se que a $\mathrm{CL}_{50}$ das soluções filtradas e não-filtradas foi muito semelhante quando comparada às das demais áreas. Com relação ao tempo de agitação, contatou-se uma diferença significativa entre as amostras de Lagoa Bonita sob agitação de 4 e 30 dias.

Comparando a resposta de $C$. dubia exposta às várias amostras, não se verificou um ordem decrescente de toxicidade paras as amostras não-filtradas e filtradas nas diferentes áreas. As amostras das cinzas de duas áreas (Pasto e Torre) não provocaram toxicidade aguda ao D. rerio e ao B. glabrata, no entanto a área de Lagoa Bonita, cujas cinzas agitadas por 4 dias e 30 dias apresentaram toxicidade ao peixe D. rerio e apenas as amostras agitadas de 30 dias foram tóxicas ao caramujo B. glabrata (Tabela 4).

Uma avaliação da genotoxicidade do rejeito do carvão mineral por meio de testes de toxicidade aguda com o molusco Helix aspersa constatou efeito genotóxico ao molusco quando comparado ao grupo controle (LEFFA, 2008).

\section{Conclusões}

O uso de ensaios ecotoxicológicos com organismos aquáticos para avaliar a toxicidade de amostras de cinzas de áreas com diferentes características indicaram que:

- O efeito tóxico das amostras de cinzas de todas as áreas queimadas foi confirmado nos ensaios de efeito agudo em C. dubia.

- Apesar das diferenças de fitofisionomias (Torre e Lagoa Bonita) e de uso (pastagem), o que confere uma diferença de composição química de cinzas de biomassa, as CLs 50 das cinzas amostras de todas as áreas foram muito semelhantes para C. dubia.

- As amostras filtradas de cinzas tenderam a ser mais tóxicas que as não-filtradas para C. dubia. As amostras de Lagoa Bonita sob agitação de 30 dias apresentaram maior toxicidade significativa em relação às amostras agitadas por 4 dias.

- Observou-se que as cinzas das áreas da Torre e do Pasto não apresentaram toxicidade aos peixes e aos caramujos. Apenas as amostras de Lagoa Bonita causaram 
mortalidade no peixe $D$. rerio e no caramujo $B$. glabrata (somente as amostras agitadas durante 30 dias).

Os resultados apresentados sugerem que as cinzas de queimadas do Cerrado podem comprometer a qualidade de águas superficiais e causar efeitos tóxicos aos organismos pertencentes ao zooplâncton. Os dados mostram que os efeitos das cinzas não se limitam ao curto prazo, considerando que houve a toxicidade aos organismos bentônicos nas cinzas sob agitação de 30 dias. Nesse trabalho, foram conduzidos testes agudos (TA) ao invés de testes crônicos (TC) devido às cinzas, em condições ambientais, causarem efeitos imediatos nos corpos aquáticos, sobretudo nos ambientes lóticos e em pequenos corpos d'água.

Como a avaliação ecotoxicológica foi conduzida em condições controladas e padronizadas, as previsões sobre os efeitos ambientais em áreas queimadas próximos aos ecossistemas aquáticos devem ser realizadas criteriosamente, considerando que, em condições naturais, os fatores bióticos e abióticos podem alterar a resposta do organismo na presença das cinzas. Informações sobre os efeitos tóxicos das queimadas sobre a biota aquática são muito escassas, especialmente em regiões tropicais. Estudos, como esse, contribui para uma melhor compreensão dos efeitos do fogo sobre a biota aquática. A partir dos resultados obtidos e diante da complexidade dos efeitos ecológicos das queimadas em organismos aquáticos, a realização de bioensaios em ambientes naturais contribuirá na compreensão dos efeitos potencialmente deletérios causados às comunidades aquáticas. 


\section{Referências bibliográficas}

ABNT (ASSOCIAÇÃO BRASILEIRA DE NORMAS TÉCNICAS). 2004. Ecotoxicologia aquática - Toxicidade aguda - Método de ensaio com peixes. NBR 15088. Rio de Janeiro: ABNT.

ABNT (ASSOCIAÇÃO BRASILEIRA DE NORMAS TÉCNICAS). 2005. Ecotoxicologia aquática - Toxicidade Crônica - Método de ensaio com Ceriodaphnia spp (Cladocera, Crustácea). NBR 13373. Rio de Janeiro: ABNT.

ARIAS, A. R. L. et al. 2007.Utilização de bioindicadores na avaliação de impacto e no monitoramento da contaminação de rios e córregos por agrotóxicos. Ciência \& Saúde Coletiva 12 (1): 61-72.

CAMPOS, I.; ABRANTES, N.; VIDAL, T.; BASTOS, A. C.; GONÇALVES, F.; KEIZER, J. J. 2012. Assessment of the toxicity of ash-loaded runnoff from a recently burnt eucalypt plantation. European Journal of Forest Research 131: 1889-1903.

CASTRO, F. J. Avaliação ecotoxicológica dos percolados das colunas de cinzas de carvão e de solos com cinza de carvão utilizando Lactuca sativa e Daphnia similis como organismo teste. 2013. Dissertação (Mestrado em Ciências na Área de Tecnologia Nuclear) - Instituto de Pesquisas Energéticas e Nucleares / Comissão Nacional de Energia Nuclear - São Paulo (IPEN/CNEN-SP), São Paulo, p. 119.

CETESB. 2001. COMPANHIA DE TECNOLOGIA E SANEAMENTO AMBIENTAL DE SÃO PAULO. Relatório de Qualidade das Águas Interiores do Estado de São Paulo 2000: São Paulo, Brasil.

CHAPMAN, PM. 2000. Whole effluent toxicity testing - Usefulness, level of protection, and risk assessment. Environmental Toxicology and Chemistry 19: 3-13.

EMMERICH, W.E. 1998. Estimating prescribed burn impacts on surface runoff and water quality in southeastern Arizona, in Proc., Rangeland Management and Water Resources, Potts, D.F., Ed., AWRA, pp, 149-158.

EPA (ENVIRONMENTAL PROTECTION AGENCY, U.S.). 1996. Fish Acute Toxicity. 
EPS (ENVIRONMENTAL PROTECTION SERIES). - 1/RM/21 2007- Biological test method: Test of Reproduction and Survival Using the Cladoceran Ceriodaphnia dubia/ Method Development and Applications Section, Environmental Science and Technology Centre, Environment Canada. ( $2^{\text {nd }}$ edition).

HAMILTON, M. A.; RUSSO, R. C.; THURSTON, R. V. 1977. Trimmed Spearman-Karber method for estimating median lethal concentrations in toxicity bioassays. Environ Sci Technol. 11: 714-719.

INSTITUTO BRASILEIRO DO MEIO AMBIENTE E DOS RECURSOS NATURAIS RENOVÁVEIS (IBAMA). PREVFOGO. Disponível em: <http://www.ibama.gov.br/prevfogo>. Acesso em: 12 fev. 2013.

INSTITUTO NACIONAL DE PESQUISAS ESPACIAIS (INPE). Monitoramento de queimadas e incêndios em tempo quase real. 2012. Disponível em <http://www.inpe.br/queimadas>. Acesso em: 15 fev. 2013.

KNIE, J. L. W.; LOPES, E. W. B. 2004. Testes ecotoxicológicos: métodos, técnicas e aplicações. Florianópolis: FATMA/GTZ, p. 289.

LAPOLA, D. M, et al. 2014. Pervasive transition of the Brazilian land-use system. Nature Climate Change 4: 27-35.

LEFFA, D.D. 2008. Avaliação do potencial genotóxico do rejeito de carvão mineral através do molusco Helix aspersa (Müller 1774). Trabalho de conclusão de curso (Bacharelado em Ciências Biológicas) Universidade do Extremo Sul Catarinense, Santa Catarina, SC, Brasil.

MINSHALL, G.W.; ROBINSON, C.T.; LAWRENCE, D.E.; ANDREWS, D.A.; BROCK, J.T. 2001. Benthic macroinvertebrate assemblages in five central Idaho (USA) streams over a 10-year period following disturbance by wildfire. International Journal of Wildland Fire 10: 201-213.

MIRANDA, H. S.; SATO, M. N. 2005. Efeitos do fogo na vegetação lenhosa do Cerrado. In: SCARIOT, A.; SOUSA-SILVA, J.C.; FELFILI, J.M. Cerrado: ecologia, biodiversidade e conservação. Brasília: Ministério do Meio Ambiente, p. 93-105. 
MIRANDA, H.S.; BUSTAMANTE, M.M.C.; MIRANDA, A.C. 2002. The fire factor. In: Oliveira, P.S. \& Marquis, R.J. (Eds.) The Cerrados of Brazil: Ecology and natural history of a neotropical savanna. Columbia University Press.New York.pp.51-68.

MOWAT FS, BUNDY KJ. 2001. Correlation of field-measured toxicity with chemical concentration and pollutant availability. Environment International 27: 479-489.

NAGEL, R., 2002. Darl: The EmbryoTest with the Zebrafish Danio rerio - a General Model in Ecotoxicology and Toxicology. ALTEX 19. Suppl. 1: 38-48.

OECD. 2013. OECD guidelines for the testing of chemicals: fish embryo acute toxicity (FET) test: test n. 236: acute toxicity for fish. Organization for Economic Cooperation and Development, Paris.

OLIVEIRA-FILHO, E.C., DE-CARVALHO, R.R. \& PAUMGARTTEN, F.J.R., 1999. Effects ofEuphorbia milii latex on the development of Biomphalaria glabrata embryos. In: VII International Symposium on Schistosomiasis, Anais, p. 159, Rio de Janeiro: RJ.

OLIVEIRA-FILHO, E.C.; GRISOLIA, C.K.; PAUMGARTTEN, F.J.R. 2009a. Transgeneration study of the effects of nonylphenol ethoxylate on the reproduction of the snail Biomphalaria tenagophila. Chemosphere, v. 72, p. 458-465.

OLIVEIRA-FILHO, E.C.; GRISOLIA, C.K.; PAUMGARTTEN, F.J.R. 2009b. Effects of endosulfan and ethanol on the reproduction of the snail Biomphalaria tenagophila: A multigeneration study. Chemosphere 75: 398-404.

PEREIRA, P; ÚBEDA, X. 2010. Spatial distribution of heavy metals released from ashes after a wildfire. Journal of Environmental Engineering and Landscape Management 18: 13-22.

PEREIRA, R. S.; NAPPO, M. E.; REZENDE, A. V. 2007. Prevenção de incêndios florestais e uso do fogo como prática silvicultural. Brasília: Universidade de Brasília, Departamento de Engenharia Florestal, Comunicações técnicas florestais 9 (2). 60 p. 
PITMAN, RM. 2006. Wood ash use in forestry - a review of the environmental impacts. Forestry 79(5): 563-588.

PIVELLO, V.R. 2006. "Fire management for biological conservation in the Brazilian Cerrado". In: Mistry, J. \& Berardi, A. (eds.) Savanas and d ry forests - linking $\mathrm{p}$ eople with nature. Ashgate, Hants. pp. 129-154.

PIVELlO, V.R.; COUTINHO, L. 1992. Transfer of Macro-Nutrients to the Atmosphere during Experimental Burnings in an Open Cerrado (Brazilian Savanna). Journal of Tropical Ecology 8: 487-497.

RAND, G.M. 1995. Fundamentals of Aquatic Toxicology. 2 ed. 1125 p.

RESENDE, A.V. 2002. Agricultura e qualidade da água: contaminação da água por nitrato. Planaltina, EMBRAPA Cerrados. 29p.

RIBEIRO, J.F.; WALTER, B.M.T. 2001. As matas de galeria no contexto do bioma Cerrado. Pp. 29-47. In Ribeiro, J.F.; Fonseca, C.E.L. \& Sousa- Silva, J.C. Cerrado: caracterização e recuperação de Matas de Galeria, Planaltina, Embrapa Cerrados.

ROSA, G.A.B. 2008. Estudo dos efeitos do fármaco Propanolol para Ceriodaphnia silvestrii (Cladocera, Crustácea) com ênfase em efeitos na populações. Tese (Mestrado em Ciências da área de Tecnologia Nuclear - Materiais) - Instituto de Pesquisas Energéticas e Nucleares - Autarquia associada à Universidade de São Paulo, 161 p.

RUPPERT, E.E; FOX, R.F.; BARNES, R.D. 2005. Zoologia dos invertebrados: uma abordagem funcional-evolutiva. 7a. Ed., São Paulo, Roca.

SAMPAIO, C. A. et al. 2008. Sistema de corte e trituração da capoeira sem queima como alternativa de uso da terra, rumo à sustentabilidade florestal no nordeste paraense. Revista de Gestão Social e Ambiental 2(1):41-53.

SHAKESBY, R.A. \& DOERR, S.H. 2006. Wildfire as a hydrological and geomorphological agent. Earth Science Reviews 74 (3-4): 269-307.

SILVA, V. 2012. Contaminação por escorrências de incêndios: efeitos da biofiltração. 2012. 86 p. Tese (Mestrado em Biologia Aplicada, ramo Ecologia, Biodiversidade e Gestão 
de Ecossistemas) Departamento de Biologia - Universidade de Aveiro. Aveiro, Portugal.

SMOLDERS R, BERVOETS L, WEPENER V, BLUST R. 2003. A Conceptual Framework for Using Mussels as Biomonitors in Whole Effluent Toxicity. Human and Ecological Risk Assessment: An International Journal 9: 741-760.

SPENCER C.N., GABEL K.O., HAUER F.R. 2003. Wildfire effects on stream food webs and nutrient dynamics in Glacier National Park, USA. Forest Ecology and Management 178 (2003) 141-153.

TSIDIRIS V, PETALA M, SAMARAS P, HADJISPYROU S, SAKELLAROPOULOS G, KUNGOLOS A. 2006. Interactive toxic effects of heavy metals and humic acids on Vibrio fischeri. Ecotoxicology and Environmental Safety 63: 158-167. 


\section{CONSIDERAÇÕES FINAIS}

O principal objetivo desta dissertação foi avaliar os efeitos das queimadas nos parâmetros físicos e químicos da água e avaliar os potenciais efeitos nocivos das queimadas na biota aquática devido à entrada das cinzas por escoamento superficial em ambientes aquáticos. Desse modo, foram conduzidos simulações e testes para identificar efeitos das cinzas na qualidade da água e na biota aquática a partir da coleta de cinzas de diferentes áreas do Bioma cerrado. Em seguida, foram preparadas soluções que simulavam as condições naturais, isto é, o escoamento superficial cinzas resultantes da chuva nas áreas queimadas.

A avaliação química das cinzas, dos solos e das soluções $\left(100 \mathrm{~g} . \mathrm{L}^{-1}\right)$ possibilitou verificar que a comparação química das quatro áreas estudadas apresentou pouca diferença qualitativa, sendo o quantitativo dos elementos químicos presentes o aspecto de maior relevância.

Na comparação da composição química das cinzas com à composição química do solo, observaram-se valores muito superiores nas cinzas para a grande maioria dos elementos ( $\mathrm{B}, \mathrm{Ca}, \mathrm{K}, \mathrm{Mg}, \mathrm{Mn}, \mathrm{P}, \mathrm{S}, \mathrm{Si}, \mathrm{Sr}, \mathrm{Zn}$ ), com a presença de alguns elementos não disponíveis nas amostras de solo correspondentes (Ni). Por outro lado, verificaram-se elementos presentes nos solos em maior quantidade que nas cinzas da biomassa (Al, Fe, Cd, Cr, Mo, Pb, Ti e V). No entanto, apenas uma pequena parcela desses compostos foram solubilizados.

A análise química das cinzas das diferentes áreas apresentarem altas concentrações de $\mathrm{Ca}, \mathrm{P}, \mathrm{K}, \mathrm{Mg}$, Si e S. Na solubilização, as maiores concentrações obtidas foram de $\mathrm{Ca}, \mathrm{S}$, Mg e K . Estes resultados estão em concordância estudos sobre a composição química de amostras de escoamento superficial após incêndios (OLIVELLA et al., 2006; VILA-ESCALÉ et al., 2007).

Uma relação simples entre a concentração dos compostos na solução e nas cinzas, o qual corresponde à recuperação de elementos químicos entre as matrizes, mostraram que as concentrações dos compostos na fração dissolvida é quimicamente dependente da sua concentração em cinzas. A maior recuperação observada foi para K e para o S.

A presença das cinzas na água elevam os sólidos solúveis totais e a condutividade elétrica, devido à solubilização dos sais. Os íons solubilizados elevam o pH e diminuem o OD na água, ocasionando sérios efeitos aos organismos aquáticos. Apesar dos testes de solubilização das cinzas com agitação terem apresentado uma queda menos acentuada de OD, após 15 dias de observação os níveis de OD ficaram em torno de 2,5 mg. $\mathrm{L}^{-1}$, quantidade praticamente inviável à sobrevivência de muitos organismos aquáticos. A partir dos testes 
dos efeitos das cinzas na água, os ambientes lênticos e os poços de água nas extremidades dos rios poderão sentir os efeitos das cinzas das queimadas de forma bem mais acentuada que ambientes lóticos.

A avaliação da composiçao química permite identificar e quantificar a presença de determinado composto químico em diferentes compartimentos ambientais, desconsiderando a biodisponibilidade desses elementos e a sua toxicidade ambiental, tais como a ocorrência de interações entre as substâncias. Dessa forma, ensaios ecotoxicológicos são realizados para verificar os potenciais efeitos na biota aquática após input das cinzas. Para tanto, foram utilizadas três espécies aquáticas, de diferentes grupos funcionais e níveis tróficos.

Bionesaios com exposição de lixiviados de áreas queimadas apresentaram toxicidade aos produtores primários e aos decompositores de ecossistemas aquáticos (CAMPOS et al., 2012; SILVA, 2012), contudo não se observou uma toxicidade direta aos dafinídeos, o que não se verifica com os resultados do presente estudo.

Constatou-se efeito tóxico das amostras de cinzas de todas as áreas queimadas nos ensaios de efeito agudo em C. dubia. Apesar das diferenças de fitofisionomias (Torre e Lagoa Bonita) e de uso (pastagem), o que confere uma diferença de composição química de cinzas de biomassa, a CL 50 das cinzas amostras de todas para C. dubia mostrou-se muito semelhante. As amostras filtradas de cinzas tenderam a ser mais tóxicas que as não filtradas para C. dubia. Estudo sobre a toxicidade dos percolados de colunas de cinza de carvão de termelétricas com cinza de carvão, observaram-se efeitos tóxicos à mobilidade e/ou sobrevivência $D$. similis expostas aos percolados da coluna de cinza de carvão (CE50 (48h): $25.6-84.1 \%)$.

As amostras das cinzas de duas áreas (Pasto e Torre) não provocaram toxicidade aguda, com exceção da área de Lagoa Bonita, cujas cinzas após agitação de 30 dias apresentaram $\mathrm{CL}_{50}-24 \mathrm{hs}$ : 50,0\% (37,7- 66,4); $\mathrm{CL}_{50}-48 \mathrm{hs}: 35,4 \%$ ao caramujo B. glabrata, $\mathrm{CL}_{50}$-24hs: $31,50 \% \mathrm{CL}_{50}-48 \mathrm{hs}: 25,0 \%$ ao peixe $D$. rerio.

Desta forma, a partir da química e resultados obtidos ecotoxicológicos, é possível constatar que as cinzas da biomassa, independentemente das áreas, podem desencadear efeitos nocivos em ecossistemas aquáticos. No entanto, outros estudos são necessários para compreender a complexidade das cinzas nos efeitos ecotoxicológicos, tais como os efeitos nos produtores primários (microalgas e macrófitas).

Considerando que todos os resultados foram obtidos em condições altamente controladas e utilizando espécies-padrão que não representam, necessariamente, os 
ecossistemas de água doce que são freqüentemente afetados por queimadas no Bioma Cerrado (sistemas lóticos), extrapolações impulsionadas por este estudo para estimar os efeitos em condições naturais devem ser realizadas com bastante cautela, pois em condições naturais vários fatores bióticos e abióticos, não abordados neste estudo, podem afetar a resposta do organismo na presença das cinzas. Diante disso, estudos em ambientes naturais são necessários para entender a complexidade dos efeitos ecológicos potencialmente deletérios das queimadas em comunidades aquáticas.

Os resultados obtidos no presente estudo sobre o efeito das queimadas em ambientes aquáticos suscitam várias questões que se constituem desafios para futuros estudos que possam agregar à compreensão dos efeitos do fogo no equilíbrio dos ecossistemas naturais e na melhoria de gestão da qualidade da água em um bioma que tem passado, ao longo das últimas décadas, por rápido processo de degradação ambiental, dentre as quais as mudanças nos regimes de fogo. 


\section{APÊNDICES}

\section{APÊNDICE A - Produção da água mole}

A água mole tem muitas aplicações na área de ecotoxicologia para a manutenção de meios de cultivo, a lavagem das vidrarias que serão utilizadas para os bioensaios.

Como padronizado pela ABNT (2005), a água mole utilizada para ensaios ecotoxicológicos deve ter o $\mathrm{pH}$ entre 7,2 a 7,6 e dureza entre 40 a 48 mg. $\mathrm{L}^{-1}$ de CaCO3.

Tabela 1 - Composição da água mole sintética.

\begin{tabular}{ll}
\hline REAGENTE & QUANTIDADE \\
\hline $\begin{array}{l}\text { Sulfato de Cálcio } \\
\text { (CaSO4.2H2O) }\end{array}$ & $0,015 \mathrm{~g}$ \\
\hline Cloreto de Potássio $(\mathrm{KCl})$ & $0,0002 \mathrm{~g}$ \\
\hline Bicarbonato de Sódio & $0,048 \mathrm{~g}$ \\
(NaHCO3) & \\
\hline Sulfato de Magnésio & $0,061 \mathrm{~g}$ \\
(MgSO4.7H2O) & \\
\hline Água Destilada & $1000 \mathrm{~mL}$
\end{tabular}

(Fonte: ABNT, 2005). 


\section{APÊNDICE B}

Tabela 2 - Comportamento dos parâmetros físicos durante 96hs de agitação das cinzas em água mole sintética.

\begin{tabular}{|c|c|c|c|c|c|c|}
\hline Area & $\begin{array}{l}\text { Tempo } \\
\text { (hs) }\end{array}$ & $\begin{array}{l}\text { OD } \\
\mathrm{mg} / \mathrm{L}\end{array}$ & $\begin{array}{l}\text { OD } \\
\%\end{array}$ & $\begin{array}{l}\mathbf{p H} \\
-\end{array}$ & $\begin{array}{l}\text { Condutividade } \\
\mu \mathrm{S} / \mathrm{cm}\end{array}$ & $\begin{array}{l}\text { STD } \\
\mathrm{mg} / \mathrm{L}\end{array}$ \\
\hline \multirow[t]{5}{*}{ Lagoa Bonita } & 0 & 4.46 & 61.60 & 6.66 & 180.10 & 86.10 \\
\hline & 24 & 2.27 & 31.20 & 8.69 & 1332.50 & 660.00 \\
\hline & 48 & 0.59 & 7.70 & 8.30 & 1549.33 & 770.67 \\
\hline & 72 & 0.50 & 7.00 & 8.47 & 1543.00 & 767.00 \\
\hline & 96 & 2.62 & 34.56 & 8.39 & 1390.00 & 689.00 \\
\hline \multirow[t]{5}{*}{ Torre TV } & 0 & 4.46 & 61.60 & 6.66 & 180.10 & 86.10 \\
\hline & 24 & 0.63 & 9.00 & 8.85 & 2750.00 & 1402.00 \\
\hline & 48 & 0.80 & 11.40 & 8.59 & 3060.00 & 1567.33 \\
\hline & 72 & 0.41 & 5.03 & 8.65 & 3006.67 & 1570.67 \\
\hline & 96 & 1.58 & 20.84 & 8.60 & 3616.67 & 1867.00 \\
\hline Pasto & 0 & 4.46 & 61.60 & 6.66 & 180.10 & 86.10 \\
\hline \multirow[t]{4}{*}{ Embrapa } & 24 & 2.18 & 30.00 & 9.35 & 3280.00 & 1685.30 \\
\hline & 48 & 1.50 & 20.00 & 8.92 & 3200.00 & 1642.70 \\
\hline & 72 & 0.45 & 6.00 & 8.96 & 3480.00 & 1790.00 \\
\hline & 96 & 2.80 & 37.40 & 8.88 & 3226.67 & 1657.33 \\
\hline
\end{tabular}




\section{APÊNDICE C}

Tabela 3 - Medição do pH, do Oxigênio Dissolvido (OD), da Condutividade elétrica e dos Sólidos Totais Dissolvidos (STD) da água com cinzas da área da Lagoa Bonita nas condições com agitação contínua ao longo de 15 dias.

\begin{tabular}{|c|c|c|c|c|c|c|}
\hline Dia & $\begin{array}{c}\text { OD } \\
(\mathrm{mg} / \mathrm{L})\end{array}$ & OD & pH & Condutividade & STD & $\begin{array}{c}\text { Temperatura } \\
{ }^{\circ} \mathrm{C} \\
-\end{array}$ \\
\hline 0 & 6.54 & 82.7 & 6.12 & 177 & 84 & 21.0 \\
\hline 1 & 3.87 & 51.4 & 8.38 & 2210 & 1116 & 23.3 \\
\hline 2 & 4.30 & 57.4 & 8.37 & 2280 & 1150 & 23.7 \\
\hline 3 & 4.65 & 61.6 & 8.40 & 2240 & 1131 & 23.1 \\
\hline 4 & 5.29 & 70.0 & 8.69 & 2010 & 1010 & 22.7 \\
\hline 5 & 5.28 & 67.9 & 8.78 & 2040 & 1028 & 21.5 \\
\hline 6 & 5.27 & 85.0 & 8.77 & 2030 & 1021 & 22.3 \\
\hline 7 & 5.26 & 69.0 & 8.71 & 2070 & 1041 & 22.8 \\
\hline 8 & 5.58 & 74.1 & 8.58 & 2090 & 1053 & 23.1 \\
\hline 9 & 4.35 & 58.4 & 8.66 & 2000 & 1005 & 23.7 \\
\hline 10 & 4.46 & 59.3 & 8.78 & 1950 & 979 & 23.4 \\
\hline 11 & 4.54 & 60.6 & 8.71 & 1928 & 967 & 23.3 \\
\hline 12 & 4.02 & 48.2 & 8.69 & 1983 & 996 & 23.2 \\
\hline 13 & 3.54 & 47.4 & 8.77 & 1874 & 939 & 23.6 \\
\hline 14 & 3.36 & 44.0 & 8.79 & 1883 & 943 & 22.9 \\
\hline 15 & 2.42 & 32.1 & 8.60 & 1945 & 976 & 23.3 \\
\hline
\end{tabular}




\section{APÊNDICE D}

Tabela 4 - Medição do pH, do Oxigênio Dissolvido (OD), da Condutividade elétrica e dos Sólidos Totais Dissolvidos (STD) da água com cinzas da área da Lagoa Bonita nas condições sem agitação ao longo de 15 dias.

\begin{tabular}{|c|c|c|c|c|c|c|}
\hline Dia & (mg/L) & OD & $\mathrm{pH}$ & Condutividade & $\mathrm{mg} / \mathrm{L}$ & $\begin{array}{c}\text { Temperatura } \\
{ }^{\circ} \mathrm{C} \\
-\end{array}$ \\
\hline 0 & 6.54 & 82.7 & 6.12 & 177 & 84 & 21.0 \\
\hline 1 & 3.66 & 48.4 & 8.35 & 1807 & 904 & 22.8 \\
\hline 2 & 0.15 & 1.5 & 8.32 & 1897 & 951 & 22.9 \\
\hline 3 & 0.12 & 1.4 & 8.24 & 1894 & 949 & 22.2 \\
\hline 4 & 0.05 & 0.7 & 8.41 & 1870 & 937 & 22.3 \\
\hline 5 & 0.05 & 0.7 & 8.37 & 1911 & 958 & 22.4 \\
\hline 6 & 0.07 & 0.9 & 8.40 & 1962 & 984 & 22.7 \\
\hline 7 & 0.05 & 0.7 & 8.22 & 1984 & 996 & 23.2 \\
\hline 8 & 0.04 & 0.6 & 8.26 & 1995 & 1002 & 22.5 \\
\hline 9 & 0.12 & 1.1 & 8.29 & 2010 & 1011 & 22.7 \\
\hline 10 & 0.03 & 0.4 & 8.50 & 2030 & 1022 & 22.3 \\
\hline 11 & 0.02 & 0.2 & 8.48 & 2080 & 1044 & 22.5 \\
\hline 12 & 0.05 & 0.6 & 8.58 & 2080 & 1044 & 22.9 \\
\hline 13 & 0.04 & 0.5 & 8.63 & 2140 & 1077 & 23.1 \\
\hline 14 & 0.04 & 0.5 & 8.71 & 2160 & 1087 & 23.0 \\
\hline 15 & 0.02 & 0.3 & 8.13 & 2160 & 1087 & 22.5 \\
\hline
\end{tabular}




\section{APÊNDICE E}

Tabela 5 -Medição do $\mathrm{pH}$, do Oxigênio Dissolvido (OD), da Condutividade elétrica e dos Sólidos Totais Dissolvidos (STD) nas amostras de água controle e diluições com cinzas da área da Lagoa Bonita durante 15 dias sem agitação.

\begin{tabular}{|c|c|c|c|c|c|}
\hline $\begin{array}{c}\text { Amostra } \\
-\end{array}$ & $\begin{array}{c}\text { Temperatura } \\
{ }^{\circ} \mathrm{C}\end{array}$ & $\begin{array}{c}\text { OD } \\
\mathrm{mg} / \mathrm{L} \\
\text { de } \mathrm{O}_{2}\end{array}$ & $\begin{array}{c}\mathrm{pH} \\
-\end{array}$ & $\begin{array}{c}\text { Condutividade } \\
\mu S / \mathrm{cm}\end{array}$ & $\begin{array}{l}\text { STD } \\
\mathrm{mg} / \mathrm{L}\end{array}$ \\
\hline \multirow{23}{*}{ Controle } & 21,3 & 7,66 & 6,14 & 171,1 & 81,7 \\
\hline & 22,9 & 6,90 & 6,52 & 169,0 & 80,0 \\
\hline & 22,3 & 6,51 & 6,50 & 169,6 & 81,0 \\
\hline & 23,5 & 6,47 & 6,50 & 171,2 & 81,7 \\
\hline & 21,2 & 6,33 & 6,48 & 171,8 & 82,0 \\
\hline & 22,1 & 6,13 & 6,30 & 172,0 & 82,1 \\
\hline & 21,8 & 6,08 & 6,26 & 172,3 & 82,1 \\
\hline & 21,4 & 6,08 & 6,17 & 172,9 & 82,6 \\
\hline & 21,3 & 5,89 & 6,11 & 173,6 & 83,0 \\
\hline & 21,1 & 5,82 & 6,11 & 174,7 & 84,1 \\
\hline & 21,3 & 5,66 & 6,06 & 175,5 & 84,1 \\
\hline & 21,1 & 5,21 & 6,03 & 179,0 & 85,5 \\
\hline & 21,2 & 5,10 & 6,01 & 179,7 & 85,8 \\
\hline & 21,6 & 5,09 & 5,99 & 179,8 & 85,9 \\
\hline & 21,4 & 4,93 & 5,93 & 180,0 & 86,0 \\
\hline & 22,9 & 4,03 & 5,87 & 180,6 & 88,8 \\
\hline & 21,3 & 7,66 & 6,14 & 171,1 & 81,7 \\
\hline & 22,5 & 6,10 & 8,40 & 366,0 & 176,1 \\
\hline & 22,3 & 5,86 & 8,22 & 370,0 & 177,3 \\
\hline & 21,8 & 5,19 & 8,14 & 372,0 & 178,8 \\
\hline & 20,9 & 4,79 & 8,10 & 373,0 & 179,4 \\
\hline & 21,6 & 4,43 & 8,06 & 373,0 & 179,7 \\
\hline & 21,3 & 4,40 & 8,05 & 375,0 & 180,4 \\
\hline
\end{tabular}




\begin{tabular}{|c|c|c|c|c|c|}
\hline & 21,5 & 4,10 & 8,05 & 377,0 & 181,8 \\
\hline & 21,5 & 4,02 & 8,03 & 381,0 & 183,3 \\
\hline & 21,2 & 3,99 & 8,03 & 382,0 & 184,2 \\
\hline \multirow[t]{12}{*}{$10 \%$} & 21,0 & 3,88 & 8,03 & 383,0 & 184,4 \\
\hline & 21,0 & 3,86 & 8,02 & 413,0 & 201,0 \\
\hline & 22,0 & 3,80 & 8,00 & 418,0 & 202,8 \\
\hline & 21,1 & 3,73 & 7,92 & 421,0 & 204,0 \\
\hline & 22,0 & 3,62 & 7,91 & 424,0 & 205,0 \\
\hline & 21,7 & 3,52 & 7,90 & 429,0 & 207,0 \\
\hline & 21,3 & 7,66 & 6,14 & 171,1 & 81,7 \\
\hline & 22,1 & 5,62 & 8,54 & 596,0 & 245,0 \\
\hline & 23,4 & 4,98 & 8,53 & 600,0 & 289,0 \\
\hline & 21,6 & 3,82 & 8,52 & 600,0 & 291,0 \\
\hline & 21,4 & 3,69 & 8,51 & 610,0 & 291,0 \\
\hline & 21,7 & 3,30 & 8,50 & 612,0 & 297,0 \\
\hline \multirow[t]{14}{*}{$25 \%$} & 21,3 & 3,24 & 8,50 & 613,0 & 297,0 \\
\hline & 20,8 & 3,23 & 8,49 & 613,0 & 300,0 \\
\hline & 21,2 & 3,21 & 8,44 & 615,0 & 301,0 \\
\hline & 21,3 & 3,12 & 8,41 & 621,0 & 305,0 \\
\hline & 20,8 & 3,08 & 8,36 & 628,0 & 307,0 \\
\hline & 21,6 & 3,04 & 8,35 & 650,0 & 316,0 \\
\hline & 22,3 & 2,84 & 8,33 & 651,0 & 318,0 \\
\hline & 21,7 & 2,83 & 8,28 & 653,0 & 318,0 \\
\hline & 21,4 & 2,56 & 8,12 & 660,0 & 322,0 \\
\hline & 22,1 & 2,48 & 8,08 & 662,0 & 322,0 \\
\hline & 21,3 & 7,66 & 6,14 & 171,1 & 81,7 \\
\hline & 22,3 & 5,96 & 8,66 & 924 & 453 \\
\hline & 23,4 & 4,38 & 8,62 & 933 & 457 \\
\hline & 22,1 & 4,13 & 8,62 & 935 & 458 \\
\hline \multirow[t]{4}{*}{$50 \%$} & 21,0 & 3,93 & 8,59 & 946 & 463 \\
\hline & 22,1 & 3,52 & 8,57 & 952 & 463 \\
\hline & 21,4 & 3,36 & 8,56 & 956 & 467 \\
\hline & 20,9 & 3,03 & 8,56 & 960 & 469 \\
\hline
\end{tabular}




\begin{tabular}{lllll}
\hline 21,4 & 2,93 & 8,55 & 961 & 472 \\
21,3 & 2,91 & 8,55 & 972 & 477 \\
20,7 & 2,92 & 8,53 & 981 & 491 \\
21,2 & 2,86 & 8,53 & 1036 & 509 \\
20,9 & 2,86 & 8,50 & 1038 & 510 \\
21,3 & 2,23 & 8,46 & 1039 & 511 \\
21,5 & 2,21 & 8,46 & 1052 & 517 \\
22,6 & 2,17 & 8,44 & 1078 & 531 \\
& & & & \\
\hline
\end{tabular}




\section{REFERÊNCIAS BIBLIOGRÁFICAS}

ABNT (ASSOCIAÇÃO BRASILEIRA DE NORMAS TÉCNICAS). 2004. Ecotoxicologia aquática - Toxicidade aguda - Método de ensaio com peixes. NBR 15088. Rio de Janeiro: ABNT.

ABNT (ASSOCIAÇÃO BRASILEIRA DE NORMAS TÉCNICAS). 2005. Ecotoxicologia aquática - Toxicidade Crônica - Método de ensaio com Ceriodaphnia spp (Cladocera, Crustácea). NBR 13373. Rio de Janeiro: ABNT.

ALHO, C.J.R.; MARTINS, E.S. 1995. De grão em grão o Cerrado perde espaço. Impactos do processo de ocupação. Brasília: WWF. 65 p (Documento para discussão).

ALVIM, P. T.; ARAÚJO, W. A. El suelo como factor ecológico en el desarrolo de la vegetación en el centro oeste del Brasil. Turrialba, 2:153-160, 1952.

ANDRADE, S. J. 2004. Investigação sobre a composição química e avaliação da mutagenicidade do material particulado atmosférico sob a influência da fuligem da queima de cana-de-açúcar. 120 p. Tese (Doutorado em Química) - Instituto de Química, Universidade Estadual Paulista, Araraquara. São Paulo, Brasil.

AQUiNO, F. G.; AGUIAR, L. M. S.; CAMARGO, A. J. A.; DUBOC, E.; OLIVEIRAFILHO, E. C.; PARRON, L. M. 2008. Sustentabilidade no Bioma Cerrado: visão geral e desafios. In: PARRON, L. M.; AGUIAR, L. M. S.; DUBOC, E.; OLIVEIRA-FILHO, E. C.; CAMARgo, A. J. A.; AQUINO, F. G.. (Org.). Cerrado Desafios e Oportunidades para o Desenvolvimento Sustentável. 1 ed. Planaltina - DF: Embrapa Cerrados, v. 1, p. 23-32.

ARAÚJO, E. A. de ; RIBEIRO, G. A. 2005. Impactos do fogo sobre a entomofauna do solo em ecossistemas florestais. Revista Natureza \& Desenvolvimento, v. 1 (1): 75-85.

ARBEX, M. A.; BOHM, G. M.; SALDIVA, P.H.N.; CONCEIÇÃO, G.; POPEIII, A.G.; BRGA, A. L. F. 2000. Assessment of the effects of sugar cane plantation burning on daily counts of inhalation therapy. Journal of the Air \& Waste Management Association 50: $1745-1749$. 
ARENS, K. O cerrado como vegetação oligotrófico. 1958. Boletim da Faculdade de Filosofia, Ciências e Letras, Universidade de São Paulo, 224. Bot. (15): 59-77.

ARONSSON, K.A.; EKELUND, N.G. 2004. Biological effects of wood ash application to forest and aquatic ecosystems. Journal of Environmental Quality 33 (5): 1595-1605.

BERNARDI, J. V. E. et al. 2001. Um estudo de impacto ambiental utilizando análises estatísticas espacial e multivariada. Holos Environment, 1(2): 162-172.

BERNARDI, J. V. E. et al. 2009.Aplicação da Análise das componentes principais na ordenação dos parâmetros físico-químicos no alto rio madeira e afluentes, Amazônia ocidental. Geochimica Brasiliensis, 23 (1): 079-090.

BOND, W.J., F.I. WOODWARD; G.F. MIDGLEY. 2005. The Global Distribution of Ecosystems in a World without Fire. New Phytologist 165: 525-537.

BRASIL. Decreto nº 2.661, de 8 de julho de 1998.

BUIKEMA JR, A. L.; NIEDERLEHNER, B. R.; CAIRNS JR. 1982. J. Biological monitoring part IV-toxicity testing. Water Research 16 (3): 239-262,

BUSTAMANTE, M.M.C, AND E.L. OLIVEIRA. 2008. Impacto das atividades agrícolas, florestais e pecuárias nos recursos naturais. In FALEIRO, F.G., AND A.L. FARIAS NETO (Eds.). Savanas: desafios e estratégias para o equilíbrio entre sociedade, agronegócio e recursos naturais. Planaltina, DF: EMBRAPA Cerrados. p. 303-33.

CANO, P.D. \& LEYNAUD, G.C. 2010. Effects of fire and cattle grazing on amphibians and lizards in northeastern Argentina (Humid Chaco). Eur. J. Wildlife. Res. 56: 411-420.

CARSON, R. Silent Spring. Boston: Houghton Mifflin, 1962.

CASTRO, E., AND J. KAUFFMAN, 1998. Ecosystem structure in the Brazilian Cerrado: a vegetation gradient of aboveground biomass, root mass and consumption by fire. Journal of Tropical Ecology 14: 263-283. 
COSTA, C. R., OLIVI, P., BOTTA, C. M., \& ESPINDOLA, E. L. 2008. A toxicidade em ambientes aquáticos: discussão e métodos de avaliação. Química Nova, 31(7): 18201830.

COUTINHO, L. M. 1990. Fire in the ecology of Brazilian Cerrado. In: GOLDAMMER, J. G. Fire in the tropical biota. New York: Springer-Verlag, p. 82-105.

DURIGAN, G. 2004. Estimativas de estoque de carbono na vegetação natural do estado de São Paulo. In G. DURIGAN (Ed.) Oportunidades de negócios em segmentos produtivos nacionais. pp. 1-6. São Paulo: Secretaria do Meio Ambiente do Estado de São Paulo.

EARL, S.R.; BLINN, D.W. 2003. Effects of wildfire ash on water chemistry and biota in South-Western USA streams. Freshwater Biol. 48: 1015-1030.

EMMERICH, W.E. 1998. Estimating prescribed burn impacts on surface runoff and water quality in southeastern Arizona, in Proc., Rangeland Management and Water Resources, Potts, D.F., Ed., AWRA, pp, 149-158.

EPA (ENVIRONMENTAL PROTECTION AGENCY, U.S.). 1996. Fish Acute Toxicity.

EPA (ENVIRONMENTAL PROTECTION AGENCY, U.S.). 2002. Short-term Methods for Estimating the Chronic Toxicity of Effluents and Receiving Waters to Freshwater Organisms. (4th edition), U.S. Environmental Protection Agency.

EPS (ENVIRONMENTAL PROTECTION SERIES). - 1/RM/21 2007- Biological test method: Test of Reproduction and Survival Using the Cladoceran Ceriodaphnia dubia/ Method Development and Applications Section, Environmental Science and Technology Centre, Environment Canada. ( $2^{\text {nd }}$ edition).

FELFILI, J.M., AND M.C. SILVA JÚNIOR. 1993. A comparative study of cerrado (sensu stricto) vegetation in Central Brazil. Journal of Tropical Ecology 9(3): 277-289.

FERREIRA, J. P. L., OLIVEIRA M. M., LARANJEIRA I., LEITÃO T. E., QUINTA-NOVA L,.FERNANDEZ P., LOPES M. H., PARALTA, E. A. 2004. Avaliação do impacte de fogos florestais em recursos Hídricos subterrâneos. 
FORZZA, R.C., J.F. BAUMGRATZ, C.E.M. BICUDO, D.A.L CANHOS, A.A. CARVALHO-JÚNIOR, A. COSTA, D. COSTA, M. HOPKINS, P.M. LEITMAN, L.G. LOHMANN, E. NIC-LUGHADHA, L.C. MAIA, G. MARTINELLI, M. MENEZES, M.P. MORIM, M.A.N. COELHO, A.L. PEIXOTO, J.R. PIRANI, J. PRADO, L.P. QUEIROZ, S. SOUZA, V.C. SOUZA, J.R. STEHMANN, L.S. SYLVESTRE, B.M.T. WALTER, AND D. ZAPPI, 2010. Síntese da diversidade brasileira. In: FORZZA, R.C. et al. (Eds.). Catálogo de Plantas e Fungos do Brasil. Rio de Janeiro vol. 1, p. 21-39.

FREITAS, L. C. de; SANT'ANNA, G. L. Efeitos do fogo nos ecossistemas florestais. Revista da Madeira, n. 79, 2004. Disponível em: <http://www.remade.com.br > Acesso: 05 nov. 2010 .

GOODLAND, R. A. Physiognomic analysis of the cerrado vegetation of Central Brazil. Journal of Ecology, v. 59, n. 1880, p. 411-419, 1972.

GOODLAND, R. Oligotrofismo e alumínio no cerrado. In: FERRI, M. G. (Ed.) III Simpósio sobre o cerrado. São Paulo: EDUSP, 1971. p. 44-60.

HAMILTON, M. A.; RUSSO, R. C.; THURSTON, R. V. 1977. Trimmed Spearman-Karber method for estimating median lethal concentrations in toxicity bioassays. Environ Sci Technol., 11, 714-719.

HILL, A.J., TERAOKA, H., HEIDEMAN, W., PETERSON, R.E., 2005. Zebrafish as a model vertebrate for investigating chemical toxicity. Toxicological Sciences 86, 6-19.

HOFFMAN D. J., RATTNER B. A., BURTON G. A. JR., CAIRNS J. JR. 2003. Handbook of Ecotoxicology. Lewis Publishers.

HOFFMANN, W.A. 1999. Fire and Population Dynamics of Woody Plants in a Neotropical Savanna: Matrix Model Projections. Ecology 80: 1354-1369.

IBAMA 2011. INSTITUTO BRASILEIRO DO MEIO AMBIENTE E DOS RECURSOS NATURAIS RENOVÁVEIS. Relatório de Combate a Incêndios (PREVFOGO). Disponível em < http:www.ibama.gov.br> Acesso em fev. 2013.

IBAMA. INSTITUTO BRASILEIRO DO MEIO AMBIENTE E DOS RECURSOS NATURAIS. In: Seminário o Fogo no Meio Rural e a Proteção dos Sítios do Patrimônio 
Mundial Natural no Brasil: alternativas, implicações socioeconômicas, preservação da biodiversidade e mudanças climáticas. - Brasília: Ibama, UNESCO, 2008. 112 p.

INPE. INSTITUTO NACIONAL DE PESQUISAS ESPACIAIS. Disponível em: <http://sigma.cptec.inpe.br/queimadas/\# >Acesso: 09 out. 2010.

Instituto APLYSIA. Disponível em: http:<//aplysia.com.br/blog/15-01-2010/entenda-o-usodo-peixe-danio-rerio-em-ensaios-ecotoxicologicos-2/>Acesso em: 05 de out. 2012.

INSTITUTO NACIONAL DE PESQUISAS ESPACIAIS (INPE). Monitoramento de queimadas e incêndios em tempo quase real. 2012. Disponível em <http://www.inpe.br/queimadas>. Acesso em: 15 fev. 2013.

IPCC - INTERGOVERNAMENTAL PANEL ON CLIMATE CHANGE. 2007. Climate Change: The IPCC Scientific Assessment. Cambridge University Press.

KAUFMAN, Y. J; HOBBS, P.V., KIRCHOFF, V.W.J.H; ARTAXO, P.; REMER, L.A., HOLBEN, B.N. Smoke clouths and radiation-Brazil (SCAR-B) experiment. J. Geophys Res. 1998; 103: 31. 783-808.

KAWANO, T., OKAZAKI, K. \& RÉ, L., 1992. The principal stages of the embryonic development of Biomphalaria glabrata (Mollusca, Planorbidae): Pratical guide. Malacologia, 34: 33-40.

KIMMEL, C, BALLARD, W., KIMMEL, S., 1995. Stages of embryonic development of the zebrafish. Development Dynamics. 203: 253-310.

KLINK, C. A. e MACHADO, R. B. 2005. A conservação do Cerrado brasileiro. Disponível em: http://www.agencia.cnptia.embrapa.br/recursos/Texto_Adicional_ConservacaoIDxNOKMLsupY.pdf Acesso em: 02 de Nov. de 2010. Malacologia, 34: 33-40.

KLINK, C.A. 1996. Relação entre o desenvolvimento agrícola e a biodiversidade. Pp. 25-27. In: R.C. Pereira, L. C. B. Nasser (Eds.). Anais VIII Simpósio sobre o Cerrado, $1^{\text {st }}$ International Symposium on Tropical Savanas - Biodiversidade e Produção Sustentável de Alimentos e fibras nos Cerrados. Embrapa CPAC. Brasília. 
KLINK, C.A.; MOREIRA, A.G. 2002. Past and Current Human Occupation, and Land Use. In OLIVEIRA, O.S., AND R.J. MARQUIS (eds.). The cerrados of Brazil: ecology and natural history of a neotropical savanna. Columbia University Press, New York, pp. 6988.

KOPROSKI, L. de P. 2005. O fogo e seus efeitos sobre a herpeto e a mastofauna terrestre no Parque Nacional de Ilha Grande (PR/MS), Brasil. Dissertação (Mestrado em Ciências Florestais), Universidade Federal do Paraná, Curitiba, 143p.

LAGARES, R. de Oliveira. 2006. Análise da efetividade e eficácia do plano de prevenção e combate a incêndios florestais no Distrito Federal. Brasília. Dissertação de mestrado. Centro de Desenvolvimento Sustentável (CDS), Universidade de Brasília, Brasília,181p.

LAL, R. 2008. Savannas and global climate change: source or sink of atmospheric CO2. In FALEIRO, F.G., AND A.L. FARIAS NETO, (Eds.). Savanas: desafios e estratégias para o equilíbrio entre sociedade, agronegócio e recursos naturais. Planaltina, DF: EMBRAPA Cerrados. p. 81-102.

LAPOLA, D. M, et al. 2014. Pervasive transition of the Brazilian land-use system Nature Climate Change 4, 27-35.

LARANJEIRA, I. e LEITÃO, T. E. 2008. Avaliação do Impacte de Fogos Florestais nos Recursos Hídricos Subterrâneos. Análise do Impacte dos Fogos Florestais na Qualidade Química das Águas Superficiais e Subterrâneas das Áreas de Estudo da Região Centro. Disponível em: http://www.Inec.pt/organizacao/dha/nas/estudos_id/Ficha_POCI_Fogos $>$. Acesso em: Ago. 2012.

LELE, Z. \& KRONE, P. H., 1996. The zebrafish as a model system in developmental, toxicological and transgenic research. Biotechnology Advances. 14 (1): 57-72.

LIMA, L.C., 1995. Família Planorbidae. In: Tópicos em Malacologia Médica (F. S. Barbosa), pp. 90-112, Rio de Janeiro: Fiocruz. 
LOMBARDI, R. J. R. 2003. Estudo da recorrência de queimadas e Permanências de Cicatrizes do Fogo em Áreas Selecionadas do Cerrado Brasileiro, utilizando Imagens TM/LANDSAT. Dissertação de Mestrado do Curso de Pós-Graduação em Sensoriamento Remoto, São José dos Campos, INPE.

MALEKNIA, S. D.; BELL, T. L.; ADAMS, M. A. 2009. Eucalypt smoke and wildfires: Temperature dependent emissions of biogenic volatile organic compounds. International Journal of Mass Spectrometry 279: 126-133.

MARCOLAN, A. L.;LOCATELLI, M.; FERNANDES, S. R. Atributos químicos e físicos de um Latossolo e rendimento de milho em diferentes sistemas de manejo da capoeira. Embrapa, Comunicado Técnico 352, 2009.

MARINHO-FILHO, J; REIS, M. L.; OLIVEIRA, PS; OLIVEIRA, E.M.; PAES, M.N. Diversity standards and small mamal numbers: conservation of the cerrado biodiversity. Anais da Academia Brasileira de Ciencias, Rio de Janeiro, v. 66, p. 149-157, 1994.

MATTHEWS, C.E.; MOORNMAN, C.E.; GREENBERG, C.H.. 2010. Response of reptiles and amphibians to repeated fuel reduction treatments. J. Wildlife Manage. 74: 13011310.

MCGINLEY, M.A.; TILMAN, D. 1993. The University of Notre Dame Short-term Response of Old-field Plant Communities to Fire and Disturbance. American Midland Naturalist 129: 409-413.

MEIRELLES, M.L. 1990. Efeito do fogo sobre a umidade do solo em área de campo sujo de cerrado. Ciência e Cultura 42(7). São Paulo, Brasil, p. 359-360.

MENDONÇA, R.; J. FELFILI, B; WALTER, J.C.; SILVA Jr., A.; REZENDE, T. FILGUEIRAS \& NOGUEIRA, P. 1998. Flora vascular do Cerrado. In: S. Sano \& S. Almeida (eds.). Cerrado. Ambiente e flora. Empresa Brasileira de Pesquisa Agropecuária-Embrapa - Cerrados, Planaltina, Brasil, p. 288-556.

MENDONÇA, R.C., J.M. FELFILI, B.M.T. WALTER, M.C. SILVA JÚNIOR, A.V. REZENDE, T.S. FILGUEIRA, AND P.E. NOGUEIRA, 2008. Flora vascular do Cerrado. In: SANO, S.M., S.P. ALMEIDA, AND J.F. RIBEIRO (eds.). Cerrado: 
ecologia e flora. Embrapa Cerrados. Brasília-DF.

MINSHALL, G.W.; ROBINSON, C.T.; LAWRENCE, D.E.; ANDREWS, D.A.; BROCK, J.T. 2001. Benthic macroinvertebrate assemblages in five central Idaho (USA) streams over a 10-year period following disturbance by wildfire. International Journal of Wildland Fire, 10: 201-213.

MIRANDA, H. S.; SATO, M. N. 2005. Efeitos do fogo na vegetação lenhosa do Cerrado. In: SCARIOT, A.; SOUSA-SILVA, J.C.; FELFILI, J.M. Cerrado: ecologia, biodiversidade e conservação. Brasília: Ministério do Meio Ambiente, p. 93-105.

MIRANDA, H.S.; BUSTAMANTE, M.M.C.; MIRANDA, A.C. 2002. The fire factor. In: Oliveira, P.S. \& Marquis, R.J. (Eds.) The Cerrados of Brazil: Ecology and natural history of a neotropical savanna. Columbia University Press.New York.pp.51-68.

MISTRY, J. 1998. Decision-making for fire use among farmers in savannas: an exploratory study in the Distrito Federal, central Brazil. Journal of environmental Management, 54:321-334.

MISTRY, J.; BIZERRIL, M. 2011. Por que é importante entender as inter-relações entre pessoas, fogo e áreas protegidas? Why it is important to understand the relationship between people, fire and protected areas? Biodiversidade Brasileira Ano I, 2: 40-49.

MITTERMEIER, R.A.; P. ROBLES, M. HOFFMAN, J. PILGRIM, T. BROOKS, C.G. MITTERMEIER, J. LAMOREUX, AND G.B. FONSECA, 2005. Hotspots revisited. Conservação Internacional/CI, Agrupación Sierra Madre. Pp. 15-96.

MMA. 2007. MINISTÉRIO DO MEIO AMBIENTE. MAPAS DE COBERTURA VEGETAL DOS BIOMAS BRASILEIROS. BRASÍLIA, DF. Disponível em: < http://www.mma.gov.br> Acesso: 01 nov. 2011.

MMA. 2010. MINISTÉRIO DO MEIO AMBIENTE. Disponível em: <http://www.mma.gov.br> Acesso: 01 nov. 2010. 
MORAIS, A.R.; CORTES, L. G.; BASTOS R, P. 2011. Queimadas podem alterar as assembléias de anuros? O caso das veredas na Estação ecológica Serra Geral do Tocantins. Revista de Biologia Neotropical, v. 8, p. 32-39.

MOREIRA, A.G., 2000. Effects of Fire Protection on Savanna Structure in Central Brazil. Journal of Biogeography 27: 1021-1029.

MYERS, N.; MITTERMEIER, R. A.; MITTERMEIER, C. G.; FONSECA, G. A. B. \& KENT, J. 2000 Biodiversity hotspots for conservation priorities. Nature 403: 853-858.

NAGEL, R., 2002. Darl: The EmbryoTest with the Zebrafish Danio rerio - a General Model in Ecotoxicology and Toxicology. ALTEX 19. Suppl. 1: 38-48.

NEPSTAD, D. C.; MOREIRA, A. G.; ALENCAR, A. A. 1999. A floresta em chamas: origens, impactos e prevenção de fogo na Amazônia. Brasília, DF: Programa Piloto para a Proteção das Florestas Tropicais do Brasil (Conservação e Desenvolvimento das Florestas Tropicais do Brasil).

NOBRE, C. A. Amazônia e o carbono atmosférico. Revista Scientific América, ano 1, n. 6, nov. 2002.

OECD. 2013. OECD guidelines for the testing of chemicals: fish embryo acute toxicity (FET) test: test no. 236: acute toxicity for fish. Organization for Economic Cooperation and Development, Paris.

OLIVEIRA-FILHO, A. T.; RATTER, J.A. 2002. Vegetation phisiognomies and Woody flora of the Cerrado Biome. In: OLIVEIRA, P.S.; MARQUIS, R.J. (ed). Cerrados of Brazil. Columbia University Press. p. 91-120.

OLIVEIRA-FILHO, E.C., DE-CARVALHO, R.R. \& PAUMGARTTEN, F.J.R., 1999. Effects of Euphorbia milii latex on the development of Biomphalaria glabrata embryos. In: VII International Symposium on Schistosomiasis, Anais, p. 159, Rio de Janeiro: RJ.

OLIVEIRA-FILHO, E.C.; GRISOLIA, C.K.; PAUMGARTTEN, F.J.R. 2009a. Transgeneration study of the effects of nonylphenol ethoxylate on the reproduction of the snail Biomphalaria tenagophila. Chemosphere, v. 72, p. 458-465. 
OLIVEIRA-FILHO, E.C.; GRISOLIA, C.K.; PAUMGARTTEN, F.J.R. 2009b. Effects of endosulfan and ethanol on the reproduction of the snail Biomphalaria tenagophila: A multigeneration study. Chemosphere, v. 75, p. 398-404.

OLIVELLA, M.A.; RIBALTA, T.G; DE-FEBRER, A.R.; MOLLET, J.M.; DE LAS HERAS, F.X.C. 2006. Distribution of polycyclic aromatic hydrocarbons in riverine waters after Mediterranean forest fires. Science of the Total Environment 355: 156-166.

PARAENSE, W.L., 1972. Fauna planorbídica do Brasil. In: Introdução à geografia médica do Brasil (C. S. Lacaz, R. G. Baruzzi \& J. W. Siqueira), pp. 213-239, São Paulo: Edgar Blucher.

PEREIRA, R. S.; NAPPO, M. E.; REZENDE, A. V. Prevenção de incêndios florestais e uso do fogo como prática silvicultural. Brasília: Universidade de Brasília, Departamento de Engenharia Florestal, 2007 (Comunicações técnicas florestais, v.9, n.2, 60p.)

PIVELLO, V.R. 2006. "Fire management for biological conservation in the Brazilian Cerrado”. In: Mistry, J. \& Berardi, A. (eds.) Savanas and dry forests - linking people with nature. Ashgate, Hants. pp. 129-154.

PIVELlO, V.R.; COUTINHO, L.. 1992. Transfer of Macro-Nutrients to the Atmosphere during Experimental Burnings in an Open Cerrado (Brazilian Savanna). Journal of Tropical Ecology 8: 487-497.

PRADA, M. 2001. Effects of fire on the abundance of large mammalian herbivores in Mato Grosso, Brazil. Mammalia 65: 55-62.

PROBIO. 1999. Projeto de Conservação e Utilização Sustentável da Diversidade Biológica Brasileira do Ministério do Meio Ambiente. Ações Prioritárias para a Conservação da Biodiversidade do Cerrado e Pantanal.

PROGRAMA R v. 2.13.2. The $R$ Project for Statistical Computing. Disponível em: http://www.r-project.org/. 
RIBEIRO, J.F.; WALTER, B.M.T. 2001. As matas de galeria no contexto do bioma Cerrado. Pp. 29-47. In Ribeiro, J.F.; Fonseca, C.E.L. \& Sousa- Silva, J.C. Cerrado: caracterização e recuperação de Matas de Galeria, Planaltina, Embrapa Cerrados.

RIBEIRO, J.F.; WALTER, B.M.T. 2008. As principais fitofisionomias do bioma Cerrado. In: SANO, S.M.; ALMEIDA, S.P.; RIBEIRO, J.F. Cerrado: Ecologia e Flora. Embrapa Cerrados - Brasília, DF: Embrapa Informação Tecnológica. p. 151-212.

ROBINSON, C.T.; RUSHFORTH, S.R.; MINSHALL, G.W. 1994. Diatom assemblages of streams influenced by wildfire. Journal of Phycology, v. 30, p. 30: 209-216.

ROSA, G.A.B. Estudo dos efeitos do fármaco Propanolol para Ceriodaphnia silvestrii (Cladocera, Crustácea) com ênfase em efeitos na populações. 2008. 161 p. Tese (Mestrado em Ciências da área de Tecnologia Nuclear - Materiais) - Instituto de Pesquisas Energéticas e Nucleares - Autarquia associada à Universidade de São Paulo, 2008.

ROSEIRO, M. N. V.; TAKAYANAGUI, A. M. M.; Meio ambiente e poluição atmosférica: o caso da cana-de-açúcar. Revista Saúde, v. 30 n. 1-2, p. 76-83, 2004.

RUPPERT, E.E; FOX, R.F.; BARNES, R.D. 2005. Zoologia dos invertebrados: uma abordagem funcional-evolutiva. $7^{\mathrm{a}}$. Ed.,São Paulo, Roca.

SAMPAIO, C. A. et al. 2008. Sistema de corte e trituração da capoeira sem queima como alternativa de uso da terra, rumo à sustentabilidade florestal no nordeste paraense. Revista de Gestão Social e Ambiental. 2 (1): 41-53.

SANO, E.E., R. ROSA, J.L.S. BRITO, AND L.G. FERREIRA, 2010. Land cover mapping of the tropical savanna region in Brazil. Environmental Monitoring and Assessment 166: p.113-124.

SATO, M. N. 2003. Efeito a longo prazo de queimadas prescritas na estrutura da comunidade de lenhosas da vegetação do Cerrado sensu stricto.Dissertação (mestrado) Universidade de Brasília, Brasília. 
SCRIMGEOUR, G. J.; TONN, W. M.;PASZKOWSKI, C. A.; GOATER, C. 2001. Benthic macroinvertebrate biomass and wildfires: evidence for enrichment of boreal subartic lakes. Freshwater Biology 46: 367-378.

SEMARH-DF. SECRETARIA DE MEIO AMBIENTE E RECURSOS HÍDRICOS DO DISTRITO FEDERAL. Caderno técnico: prevenção e combate aos incêndios florestais em Unidades de Conservação / GDF. Secretaria de Meio Ambiente e Recursos Hídricos do Distrito Federal. - Brasília: Athalaia Gráfica e Editora, 2004. 96 p.

SHAKESBY, R.A. \& DOERR, S.H. 2006. Wildfire as a hydrological and geomorphological agent. Earth Science Reviews, 74 (3-4), 269-307.

SILVA FILHO, E. B. da; TELES, L. de J. S.; NETO, L. A. dos S. 2009. Ocorrências de focos de calor no Estado de Rondônia em 2007. Sociedade \& Natureza 21(2): 123-140.

SILVA, J.M.C. \& BATES, J.M. 2002. Biogeographic patterns and conservation in the south american cerrado: a tropical savanna hotspot. Bioscience, 52: 225-233.

SILVA, S. A. da; CABRAL, J. B. P.; SCOPEL, I. 2004. Incêndios em vegetação entre 2002 e 2002, nas propriedades rurais limítrofes às rodovias pavimentadas do município de Jataí - GO. Revista Eletrônica do curso de Geografia do Campus avançado de Jataí-GO. n. 02 20p. Disponível em:<http://jatai.ufg.br/geo/geoambiente.htm>. Acesso: 04 ago. 2010.

SOARES, R. V. 2000. Novas tendências no controle de incêndios florestais. Revista Floresta 30: 11-21.

SOARES, R. V.; BATISTA, A. C. 2007. Incêndios florestais: controle, efeitos e uso do fogo. Curitiba: FUPEF. 264p.

SOUZA, C.P; LIMA, L.C. 1990. Moluscos de interesse parasitológico no Brasil. Belo Horizonte: Fiocruz, 76p.

SPENCER C.N., GABEL K.O., HAUER F.R. 2003. Wildfire effects on stream food webs and nutrient dynamics in Glacier National Park, USA. Forest Ecology and Management 178 (2003) 141-153. 
The Genome Institute. Washington University School of Medicine. Disponível em:http:/genome.wustl.edu/genomes/detail/biomphalaria-glabrata/ Acesso em: 05 de dez. 2014.

TRUHAUT, R. 1977. Ecotoxicology: Objectives, Principles and Perspectives. Ecotoxicology and Environmental Safety. New York, V.1, p. 151-173,

VASCONCELlOS, P. C.; MAGAlHAES, D.; BRUNS, R. E. 2007. Hidrocarbonetos policíclicos aromáticos como traçadores de cana-de-açúcar: uma abordagem estatística. Química Nova, v. 3, p. 577-581.

VILA-ESCALÉ M, VEGAS-VILARRÚBIA T, PRAT N. 2007. Release of polycyclic aromatic compounds into a Mediterranean creek (Catalonia, NE Spain) after a forest fire. Water Research 41: 2171-2179.

WESTERFIELD, M. 2000. The zebrafish book. A guide for the laboratory use of zebrafish (Danio rerio). 4th ed., University of Oregon Press, Eugene.

YUNKER, M. B.; MacDONALD, R. W.; VINGARZAN, R.; REGINALD, H. M.; GOYETTE, D.; SYLVESTRE, S. 2002. PAHs in the Fraser River basin: a critical appraisal of $\mathrm{PAH}$ ratios as indicators of $\mathrm{PAH}$ source and composition. Organic Geochemistry 33: 489-515.

ZAGATTO, P. A. 2006. Ecotoxicologia. Cap. 1, p: 1-13. In: ZAGATO, P.A. e BERTOLETTI, E. 2006. Ecotoxicologia aquática - princípios e aplicações. ZAGATTO e BERTOLETTI (org.) São Carlos: Rima; 2006.

ZIBORDI, M. S.; CARDOSO, J. L.; FILHO, L. R. V. Análise de aspecto socioeconômicos e tecnológicos da agropecuária na Bacia Hidrográfica do Rio Mogi Guaçu. Engenharia Agrícola 26 (2): 644-653, 2006. 